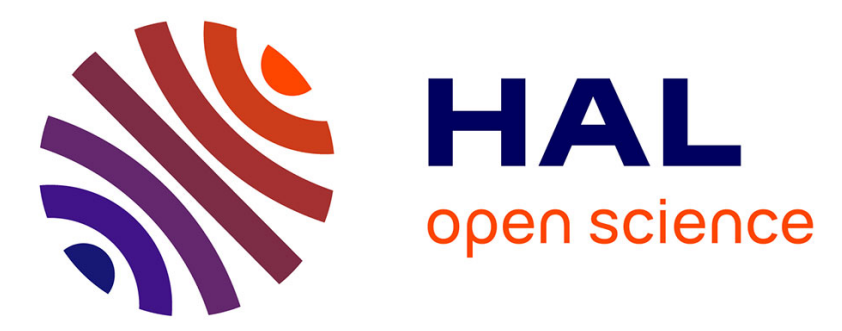

\title{
Des armatures variées et des modes de productions variables: réflexions à partir de quelques exemples issus du Gravettien d'Europe occidentale (France, Portugal, Allemagne) \\ Laurent Klaric, Patricia Guillermin, Thierry Aubry
}

\section{To cite this version:}

Laurent Klaric, Patricia Guillermin, Thierry Aubry. Des armatures variées et des modes de productions variables: réflexions à partir de quelques exemples issus du Gravettien d'Europe occidentale (France, Portugal, Allemagne). Gallia Préhistoire - Préhistoire de la France dans son contexte européen, 2009, 51, pp.113-154. 10.3406/galip.2009.2476 . hal-02343294

\author{
HAL Id: hal-02343294 \\ https://hal.science/hal-02343294
}

Submitted on 19 Dec 2019

HAL is a multi-disciplinary open access archive for the deposit and dissemination of scientific research documents, whether they are published or not. The documents may come from teaching and research institutions in France or abroad, or from public or private research centers.
L'archive ouverte pluridisciplinaire HAL, est destinée au dépôt et à la diffusion de documents scientifiques de niveau recherche, publiés ou non, émanant des établissements d'enseignement et de recherche français ou étrangers, des laboratoires publics ou privés.

\section{(ㅇ)(1) $\$$}

Distributed under a Creative Commons Attribution - NonCommercial - NoDerivatives 44.0 


\title{
DES ARMATURES VARIÉES ET DES MODES DE PRODUCTIONS VARIABLES
}

\author{
Réflexions à partir de quelques exemples issus du Gravettien \\ d'Europe occidentale (France, Portugal, Allemagne)
}

\author{
Laurent KLARIC*, Patricia GUILLERMIN** et Thierry AUBRY***
}

\begin{abstract}
Mots-clés. France, Allemagne, Portugal, Paléolithique supérieur, Gravettien, technologie lithique, production lamellaire, armature. Résumé. Ces dernières années, de nombreux travaux ont été consacrés aux modalités de production des supports d'armatures retouchées du Gravettien. Si les résultats obtenus contribuent à améliorer notre connaissance des systèmes techniques de ce techno-complexe, les tentatives de synthèse élargies sont encore rares. Certes, l'état des connaissances s'avère encore disparate d'une région et/ou d'une phase à l'autre, mais cela ne saurait justifier la seule poursuite d'un objectif documentaire visant à caractériser les modes de production lamellaires. Pour dépasser le simple constat de variabilité/analogies/différences, nous proposons quelques pistes de réflexion fondées sur l'étude de sites du Gravettien (moyen, récent et final) de France, du Portugal et d'Allemagne. La comparaison des modalités de production d'armatures de ces sites (la Picardie, à Preuilly-sur-Claise, en Indre-et-Loire; la Grotte-du-Renne à Arcy-sur-Cure, dans l'Yonne; Brassempouy dans les Landes; le Cirque de la Patrie, à Nemours, en Seine-et-Marne; le Blot, à Cerzat dans le Massif central, en Haute-Loire; Mainz-Linsenberg en Rhénanie, en Allemagne; Olga Grande 4, Cardina 1 dans la vallée du Côa, au Portugal, Vale dos Covões à Soure, au Portugal; Terra do Manual en Estremadura au Portugal) issus de phases chronologiques distinctes et de milieux écologiques différents permet d'alimenter la réflexion sur les contraintes et les choix techniques et économiques, mais aussi culturels, de ces groupes gravettiens. Il s'agit de mettre en «lueur» comment ces différents facteurs ont pu peser sur les choix techniques des hommes, conditionnant de manière variable l'ensemble du système technique lithique.
\end{abstract}

Key-words. France, Germany, Portugal, Upper Palaeolithic, Gravettian, lithic technology, bladelet production, weapon armatures. Abstract. In recent years, much research has been devoted to understanding the production strategies associated with retouched weapon armatures during the Gravettian. While the results have contributed to our knowledge of the technical systems of this techno-complex, attempts to formulate broad syntheses are still rare. Though it is true that the available data is still disparate from one region and/or one phase to another, this does not justify a purely documentary approach with the limited aim of characterising bladelet production methods. To move beyond simple observations of variability/analogies/differences, we propose a few research orientations based on the study of Gravettian (Middle, Late and Final) sites in France, Portugal and Germany. The comparison of the weapon armature production strategies at these sites (La Picardie in Preuilly-sur-Claise, Indre-et-Loire; Grotte-du-Renne in Arcy-sur-Cure, Yonne; Brassempouy in the Landes; Cirque de la Patrie in Nemours, Seine-et-Marne; and le Blot in Cerzat, Massif Central, Haute-Loire for the French sites; Mainz-Linsenberg in Rhineland, Germany; Olga Grande 4, Cardina 1 Côa Valley, Portugal, Vale dos Covões at Soure, Portugal; Terra do Manual in Estremadura, Portugal), associated with distinct chronological phases and different ecological environments, contributes to our understanding of the constraints faced by these Gravettian groups and the technical, economic and cultural choices

\footnotetext{
* UMR 7055 du CNRS, «Préhistoire et Technologie», Université de Paris Ouest Nanterre-La Défense, MAE, 21, allée de l’Université, F-92023 Nanterre Cedex. Courriel: laurent.klaric@mae.u-paris10.fr

** Université de Toulouse-Le Mirail, UMR 5608 du CNRS «Traces», Maison de la recherche, 5, allée Antonio-Machado, F-31058 Toulouse Cedex 9. Courriel: patriciaguillermin@yahoo.fr

*** Instituto de Gestão do Património arquitectónico e arqueológico, Parque arqueológico do Vale do Côa, Vila Nova de Foz Côa, Portugal. Courriel: taubry.pavc@ipa.min-cultura.pt
} 
that they made. Our goal is to shed light on the different factors that could have influenced the technical choices made by humans and the variable consequences that they had on the whole lithic technical system.

Translation: Magen O'FARRELL

Schlüsselwörter. Frankreich, Deutschland, Portugal, Jungpaläolithikum, Gravettien, Steinbearbeitung, Lamellenproduktion, Pfeilspitze.

Zusammenfassung. In den letzten Jahren wurden den Herstellungstechniken der Grundformen der retuschierten Pfeilspitzen des Gravettien zahlreiche Studien gewidmet. Deren Ergebnisse tragen zwar zur Verbesserung unserer Kenntnis der technischen Systeme dieses Technokomplexes bei, doch die Versuche umfassendere Synthesen auszuarbeiten sind noch selten. Sicher, der Kenntnisstand erweist sich noch als uneinheitlich von einer Region und/oder einer Phase zur anderen, doch dieses Argument genügt nicht, um zu rechtfertigen, dass ausschließlich ein dokumentarisches Ziel verfolgt wird, das darin besteht, die Produktionsweisen der Lamellen zu charakterisieren. Um über die simple Feststellung von Variabilität/Analogien/Unterschieden hinauszugehen, möchten wir von der Untersuchung der Fundstätten des Gravettien (moyen, récent und final) in Frankreich, Portugal und Deutschland ausgehend zur Reflexion anregen. Wir haben die Produktionsweisen der zu unterschiedlichen chronologischen Phasen und ökologischen Milieus gehörenden Mikrolithen von folgenden Fundstellen (la Picardie in Preuilly-sur-Claise im Departement Indre-et-Loire; Grotte-du-Renne in Arcy-sur-Cure im Departement Yonne; Brassempouy im Departement Landes; Cirque de la Patrie in Nemours im Departement Seine-et-Marne; le Blot in Cerzat im Zentralmassiv im Departement Haute-Loire; Mainz-Linsenberg im Rheinland in Deutschland; Olga Grande 4 in Cardina 1 im Vale do Côa in Portugal, Vale dos Covões in Soure in Portugal; Terra do Manual in der Estremadura in Portugal) verglichen, um die Reflexion über die Zwänge nicht nur der technologischen und wirtschaftlichen, sondern auch der kulturellen Entscheidungen dieser Gruppen des Gravettien bereichern. Es geht uns darum zu klären, wie diese verschiedenen Faktoren die technologischen Entscheidungen der damaligen Menschen beeinflusst haben können, indem sie das gesamte technologische System der Steinverarbeitung verschiedenartig bedingt haben.

Übersetzung: Isa ODENHARDT-DONVEZ

\section{INTRODUGTION}

Depuis quelques années maintenant, certaines phases du Gravettien connaissent un regain d'intérêt s'accompagnant d'un développement croissant des études technologiques, en France (voir entre autres Digan, 2001, 2006 et 2008; Foucher, 2004; Goutas, 2003 et 2004; Guillermin, 2004, 2006a et b et thèse en cours; Klaric, 1999, 2000, 2003, 2007a et b; Lucas, 2000 et 2002; Nespoulet, 1996 et 2000; Pesesse, 2003, 2006 et thèse en cours; Pottier, 2005 et 2007; Simonet, 2005 et 2009) et ailleurs en Europe occidentale (par exemple: Almeida, 2000; Aubry et al., 1997; Conard, Moreau, 2006; Floss, 1994; Zilhão, 1997; Moreau, à paraître). En France, ces travaux ont surtout concerné les modalités de production des supports d'armatures retouchées des phases ancienne, moyenne, récente et finale. Si les résultats obtenus contribuèrent à améliorer nos connaissances et notre compréhension des systèmes techniques de ces différents moments du Gravettien, rares ont été les occasions de comparer ces données à une large échelle géographique. Certes, l'état des connaissances s'avère encore très disparate d'une région et/ou d'une phase à l'autre, mais de tels hiatus ne sauraient justifier que nous poursuivions un unique objectif documentaire visant à «caracté- riser les modes de production lamellaires". Si cette étape descriptive constitue un pré-requis indispensable, chacun s'accorde à reconnaître le risque d'une dérive qui conduirait rapidement à une typologie classificatoire de systèmes techniques. Pour tenter de dépasser le simple constat de variabilité - analogies et différences - cet article propose quelques pistes de réflexion fondées sur des données issues de travaux consacrés à plusieurs entités gravettiennes de France, du Portugal et du sud de l'Allemagne. La comparaison des modalités de production d'armatures décrites à partir de séries provenant de plusieurs sites (la Picardie à Preuilly-sur-Claise, la Grotte-du-Renne à Arcy-sur-Cure, Brassempouy dans les Landes, le Cirque de la Patrie à Nemours, le Blot à Cerzat, Mainz-Linsenberg en Rhénanie, Cardina 1 dans la vallée du Côa, l'abri de Vale dos Covões à Soure, Terra do Manual en Estremadura, Cabeço do Porto Marinho II, au Portugal, les Fieux à Miers, dans le Lot, les Peyrugues à Orniac, dans le Lot et l'abri Pataud aux Eyzies, dans la Dordogne) issus de phases chronologiques distinctes (fig. 1) et d'environnements différents permet d'alimenter la réflexion sur les choix techniques, économiques et culturels des groupes gravettiens pour les phases moyenne, récente et finale. Pour tenter d'expliquer la variabilité des productions de supports d'armatures, il 

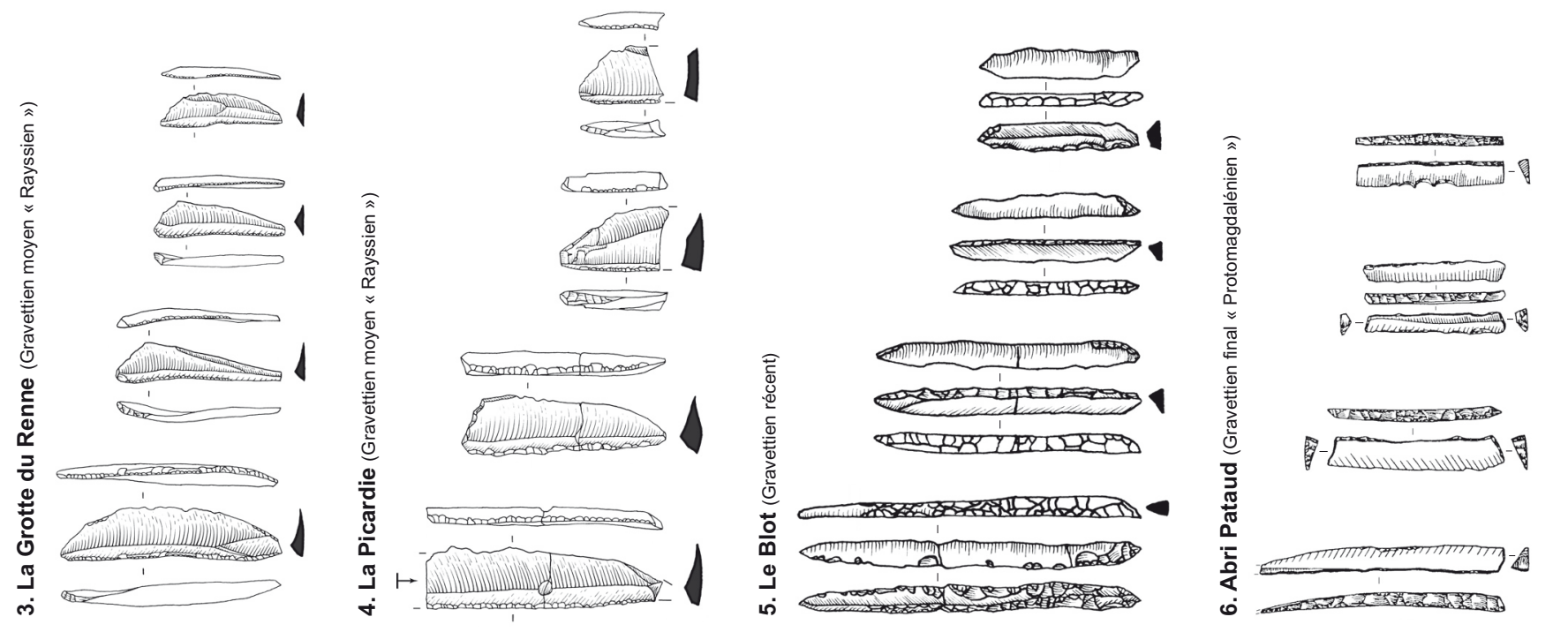

Os.

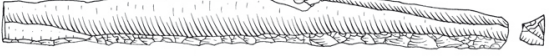

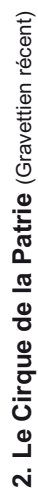
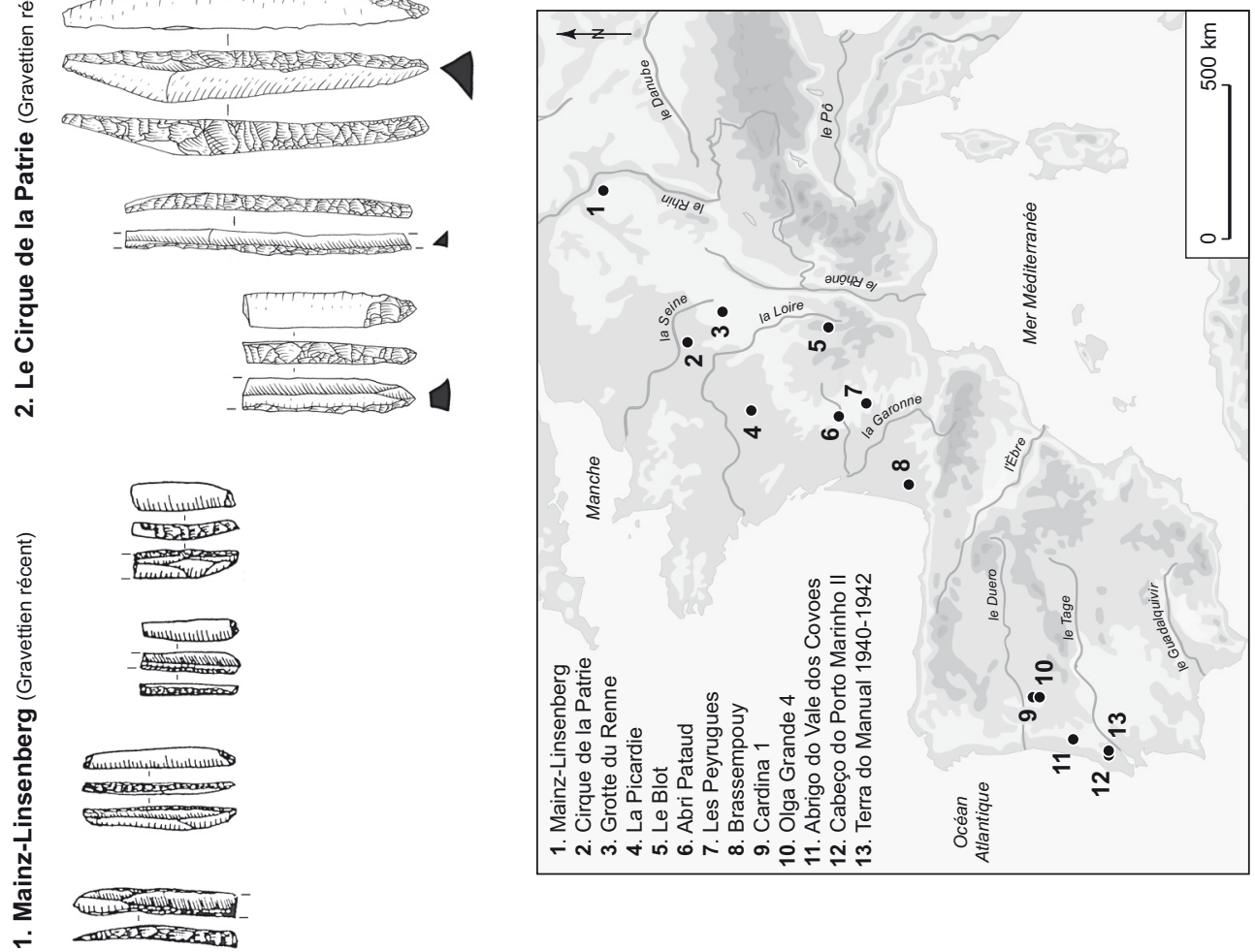

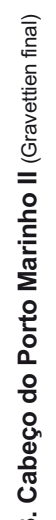

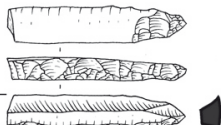

-

weresesin

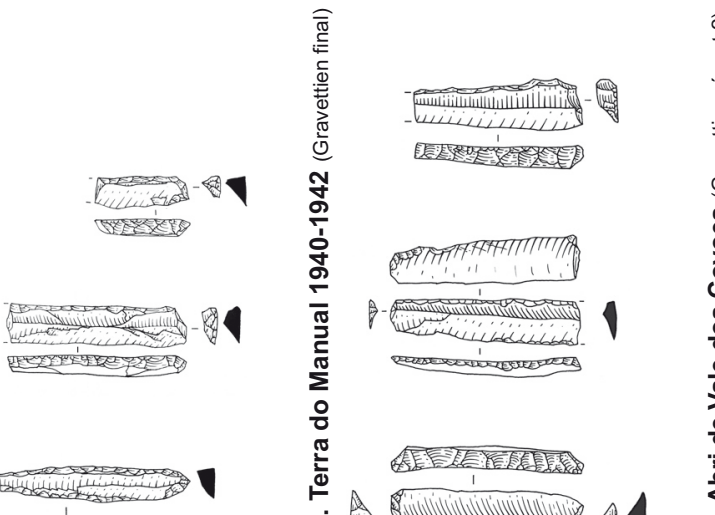

स '
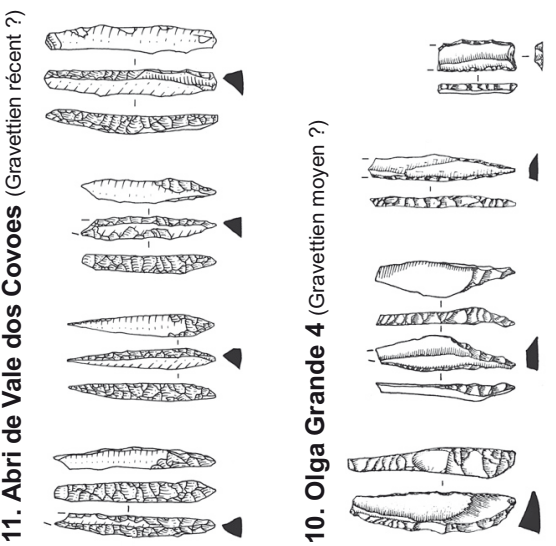

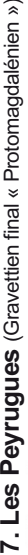

-

$\frac{2}{2} \cdot \frac{2}{2}$

视

Defres $\approx$

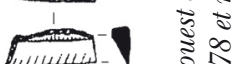

$\frac{2}{2}<$

i है

-

W

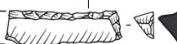

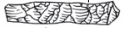

思-

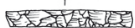

Tum

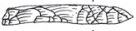

Mininuming

W.

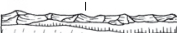

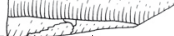

gen

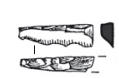

rim

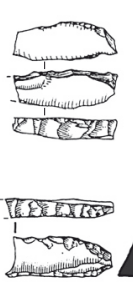


s'agira de comprendre comment ces différents facteurs, notamment ceux imposés par les contraintes du milieu, ont pu peser sur les comportements des hommes en conditionnant de manière variable tout ou partie de leurs systèmes techniques lithiques. Bien entendu, chaque sous-phase sera traitée en fonction de ses spécificités, ce qui se traduira par des pistes de réflexions variées, abordées de façons différentes selon les données disponibles. Dans une telle démarche, l'évaluation des biais taphonomiques et géoarchéologiques constitue évidemment une approche indispensable qui permet d'évaluer, de manière critique, la représentativité et l'homogénéité des assemblages considérés. En effet, ces biais peuvent, parfois, constituer des facteurs importants de variabilité dans la comparaison d'ensembles lithiques (voir par ex. Sonneville-Bordes, 1985; Bordes, 2000 et 2002; Klaric, 2003, chap. II). Pour l'heure, nous ne traiterons pas de ce problème, et nous nous contenterons de signaler que, dans la plupart des cas que nous présentons, les sites ont fait l'objet d'évaluations taphonomiques (d'ampleur variable) dont les résultats autorisent les comparaisons d'ordre systémique entre ensembles. Si, pour la plupart de nos exemples, les situations sont plutôt claires, deux sites posent malgré tout quelques problèmes plus importants en raison de l'ancienneté des fouilles (le Cirque de la Patrie et Terra do Manual). Aussi, nous sommes-nous efforcés de conserver une certaine prudence quant aux interprétations proposées à partir de ces gisements.

\section{«PRODUCTIONS LAMELLAIRES» ET «PRODUCTIONS LAMINAIRES » : DEUX PANS INDISSOCIABLES DU SYSTÈME TECHNIQUE?}

Travailler sur les «productions lamellaires» du Paléolithique supérieur consiste non seulement à étudier les modalités d'obtention des supports, mais aussi à définir les objectifs fonctionnels de ces productions. En Europe occidentale, les principaux objectifs des productions lamellaires gravettiennes sont des armatures microlithiques très diversifiées (lamelles à dos, microgravettes, lamelles à dos tronquées, lamelles à retouches marginales, etc.) (fig. 1). $\mathrm{Au}$ gré des phases et des régions considérées, les modalités de production des supports de ces microlithes apparaissent également variables (fig. 2). Certains exemples montrent aussi que des armatures similaires (comme les microgravettes ou les lamelles à dos) peuvent être confectionnées à partir de supports de natures différentes; c'est-à-dire qu'ils peuvent aussi bien être lamellaires que laminaires (fig. 2). Pour certaines industries, il est également difficile de parler d'une véritable production lamellaire autonome car il existe un continuum dimensionnel entre les nucléus à lames de grands et de petits gabarits. Comme le notait J. Tixier (Inizan et al., 1995, p. 73), il n'existe pas de règle généralisable à toutes les industries pour distinguer des supports laminaires d'autres lamellaires. Par conséquent, pour comparer différentes phases et/ou régions, il apparaît nécessaire de prendre en compte l'ensemble de la production des supports «allongés» (lames, lamelles et parfois éclats laminaires).

Peut-on placer une limite entre la production laminaire et la production lamellaire pour les exemples gravettiens étudiés? Il existe effectivement des cas de distinction évidents, lorsque les schémas opératoires de production de supports allongés sont nettement disjoints. C'est le cas à la Picardie où une production lamellaire autonome côtoie une production laminaire indépendante de gabarit complètement différent et dont aucun des supports obtenus n'a pu être utilisé comme support d'armature microlithique (Klaric, 2003). C'est également le cas de la série du Gravettien récent de l'abri du Blot (ensemble moyen) où la majeure partie de la production lamellaire réalisée sur place semble avoir été obtenue à partir de «burins-nucléus » polyédriques (Klaric, 1999 et 2000). Même constat à Cardina 1, dans la vallée du Côa, où la production lamellaire a été menée à partir de supports (éclats ou fragments de lames) «débités» par percussion posée sur enclume (typologiquement classables comme "pièces esquillées", voir Aubry, 1998 et 2001; Aubry et al., 1997). Dans d'autres cas, tout aussi fréquents, la distinction est moins aisée, car les schémas opératoires lamino-lamellaires peuvent être successifs et/ou imbriqués. Ainsi à Brassempouy ou encore au Cirque de la Patrie, les nucléus sur blocs sont de différents gabarits, les plus petits pouvant alors correspondre à la réduction des plus grands (Klaric, 2003). Par ailleurs, la possibilité d'une production lamellaire intercalée (voir, par exemple, le cas du Gravettien de la VigneBrun, Villerest, Loire, voir Digan, 2006, p. 138) au sein du débitage laminaire complique également la distinction de productions spécifiques de lames ou de lamelles. Les contraintes imposées par la disponibilité et les dimensions initiales des blocs de matière première constituent un autre facteur, trivial, certes, mais sans doute limitatif pour cette question. En effet, les modules ne permettent pas toujours la production de lames et lamelles de gabarits clairement différenciés: il peut donc en résulter des différences nettes entre deux sites rattachés à une même phase culturelle (le 
1. Nucléus bipolaire sur enclume (type " pièce esquillée ")

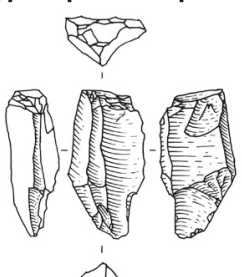

lamelle de « pièce esquillée »

lamelle à dos
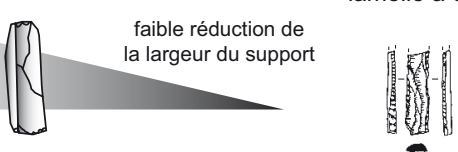

車

2. Nucléus du Raysse

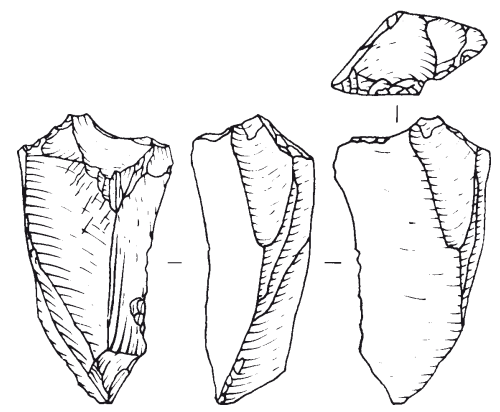

lamelle « de Raysse » brute

lamelle de la Picardie
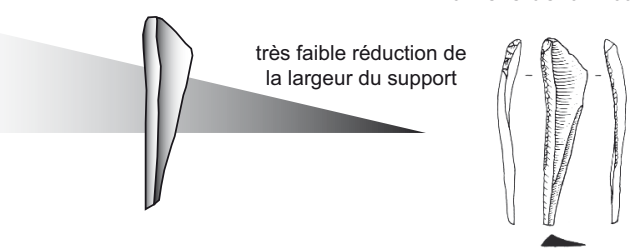

3. Nucléus de type burin-polyédrique

4. Nucléus à lames
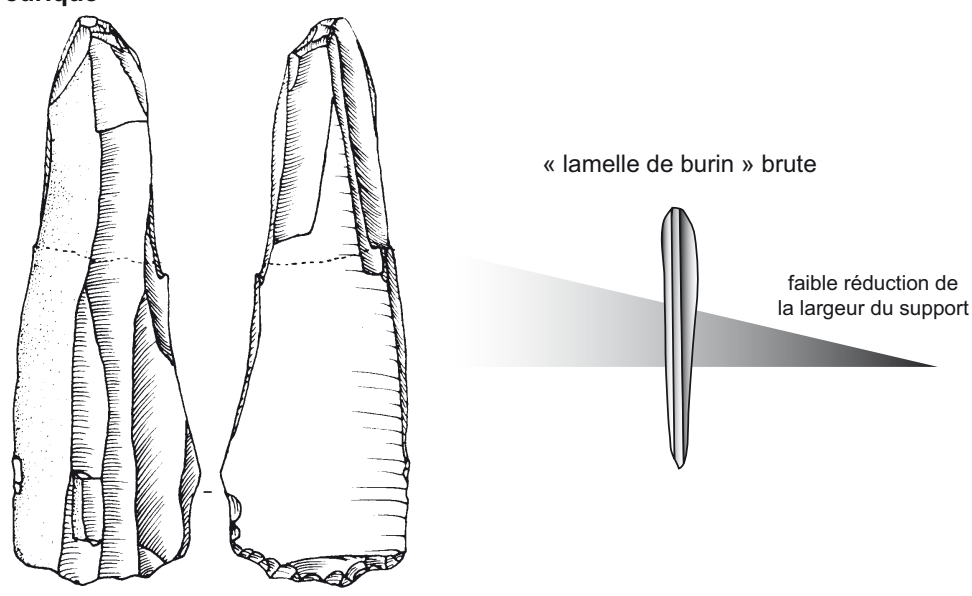

microgravette
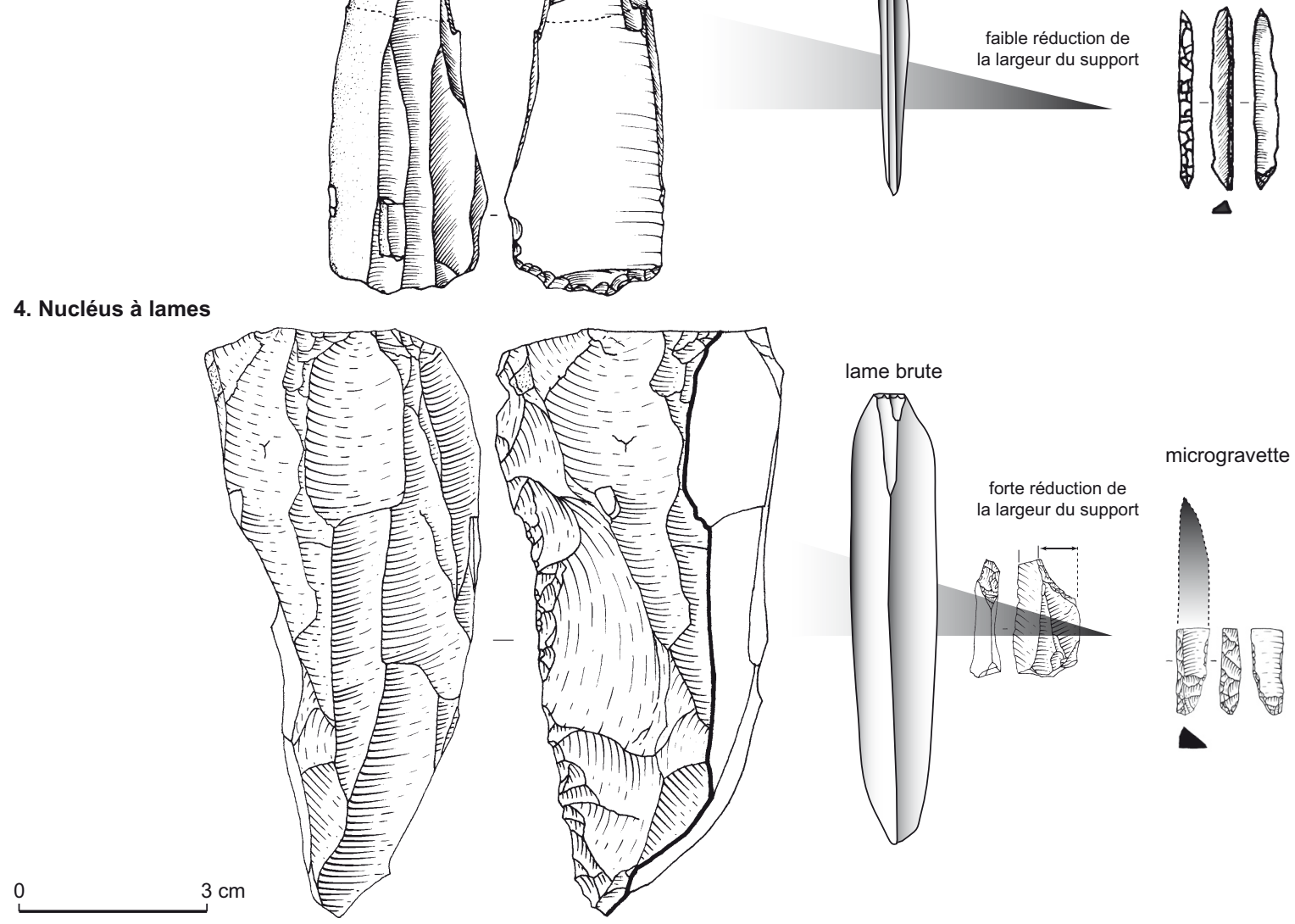

Fig. 2 - Quelques exemples caricaturaux de la variabilité des types de débitage de supports de microlithes sur différents sites gravettiens: 1, Cardina 1; 2, la grotte du Renne; 3, le Blot; 4, Brassempouy (dessins et DAO: L. Klaric, CNRS). 
Gravettien final de Cabeço do Porto Marinho II et celui de Cardina 1 par exemple, cf. infra, p. 143-144).

Si l'on souhaite comparer des méthodes de production de supports d'armatures (et pas uniquement des «productions lamellaires »), la question de la production laminaire ne peut être éludée. C'est pourquoi, en ce qui concerne les sites gravettiens présentés dans cet article, nous traitons parfois conjointement des deux types de production lorsqu'il a été établi que les nucléus à lames ont bien fourni des supports destinés à être transformés en armatures retouchées. D'ailleurs, nous parlerons plutôt de "production de supports de microlithes » ou encore de «production de supports à vocation microlithique» plutôt que de «productions lamellaires».

\section{LES PRODUCTIONS DE SUPPORTS DE MICROLITHES : OBJECTIFS ET VARIABILITÉ, AUTANT D'«OUTILS » POUR DISTINGUER DES ENTITÉS AU SEIN DU GRAVETTIEN MOYEN EN FRANCE}

\section{DES CRITÈRES DE DISTINCTION NOAILLIEN/RAYSSIEN}

La comparaison des schémas de production de supports de microlithes du site noaillien de Brassempouy et des sites rayssiens de la Picardie (Preuilly-sur-Claise, Indre-et-Loire) et de la grotte du Renne (Arcy-sur-Cure, Yonne) nous a permis de souligner les caractéristiques conceptuelles fondamentales qui distinguent les deux industries (fig. 3).

\section{LES ARMATURES}

La distinction se manifeste tout d'abord à travers les types de microlithes présents sur les sites. Au Rayssien, on rencontre quasi exclusivement un type d'armature particulier dénommé «lamelle de la Picardie» (Klaric et al., 2002). Il s'agit de petites lamelles dont le bord droit porte systématiquement une retouche marginale peu envahissante (mais qui forme, parfois, une sorte de dos marginal), alors que le bord opposé est tranchant et effilé (fig. 3, nos 9-12). Ces artéfacts sont presque toujours naturellement pointus en partie distale et la partie proximale du support est toujours considérée comme la base de l'armature (cette partie n'étant presque jamais retouchée). Ces microlithes présentent souvent une section dissymétrique, le pan droit (celui qui porte la retouche) est toujours le plus court et le plus abrupt. À la différence des microgravettes, ces lamelles sont peu retouchées pour concrétiser le concept final de l'armature (Klaric, 2007b). À la Picardie, comme à la grotte du Renne, ces microlithes sont toujours bien représentés: respectivement 165 pièces sur plus de 700 outils ${ }^{1}$ (Klaric, 2003; Chevassut, 2007 et 2008) et 297 sur 1300 outils environ (Klaric, 2003; Schmider et al., 2004). Par ailleurs, chacun de ces échantillons montre un fort degré de normalisation morphodimensionnelle, conséquence logique d'une méthode de production des supports assez stéréotypée ( $c f$. infra, p. 118-119). On peut néanmoins signaler l'existence de rares pièces de gabarit plus important obtenues, elles aussi, selon la même méthode.

À l'inverse, la série noaillienne de Brassempouy compte 205 armatures (sur 1984 outils) se répartissant entre différents types. Pour les plus significatifs, il s'agit principalement de pointes de la Gravette $(4,9 \%)$, de microgravettes $(7,8 \%)$, de lamelles à dos tronquées et bitronquées $(11,2 \%)$ et enfin de lamelles à dos simples (6,3\%) (fig. 3, nos 3-6). À ces catégories s'ajoutent des pointes à cran $(2,4 \%)$, des petites lamelles à retouche marginale (10,2\%), des petites lames à bord abattu $(11,7 \%)$ et enfin des fragments mésiaux de pièces à dos indéterminées $(36,1 \%)$ et des fragments de lames à dos $(9,3 \%)$. Certaines petites lamelles à retouche marginale auraient pu être rapprochées des lamelles de la Picardie, mais l'analyse typologique et dimensionnelle montre de nettes différences (Klaric, 2003, p. 255). L'examen de l'ensemble des armatures à dos abrupt de Brassempouy révèle qu'elles ont majoritairement été réalisées sur des supports laminaires de gabarits variables provenant des nucléus laminaires associés (fig. 3). En outre, il faut relever qu'une grande partie de ces microlithes (microgravettes, lamelles à dos tronquées, lamelles à dos simples) ont subi une retouche (et une réduction) importante pour parvenir au concept recherché (fig. 3, $n^{\text {os }}$ 3-6). Le contraste avec le Rayssien est donc assez marqué puisqu'il repose sur l'opposition monotonie/diversité des types, sur l'emploi de lames et petites lames plutôt que de véritables lamelles et enfin sur un investissement différent dans la transformation du support originel.

\section{LA PRODUCTION}

Les différences exprimées au niveau des armatures sont en adéquation avec celles que l'on peut observer au niveau de la production des supports. En effet, nous avons souligné que les supports privilégiés présentaient des caractéristiques morphodimensionnelles nettement différentes qui

1. Les décomptes définitifs ne sont pas achevés. 

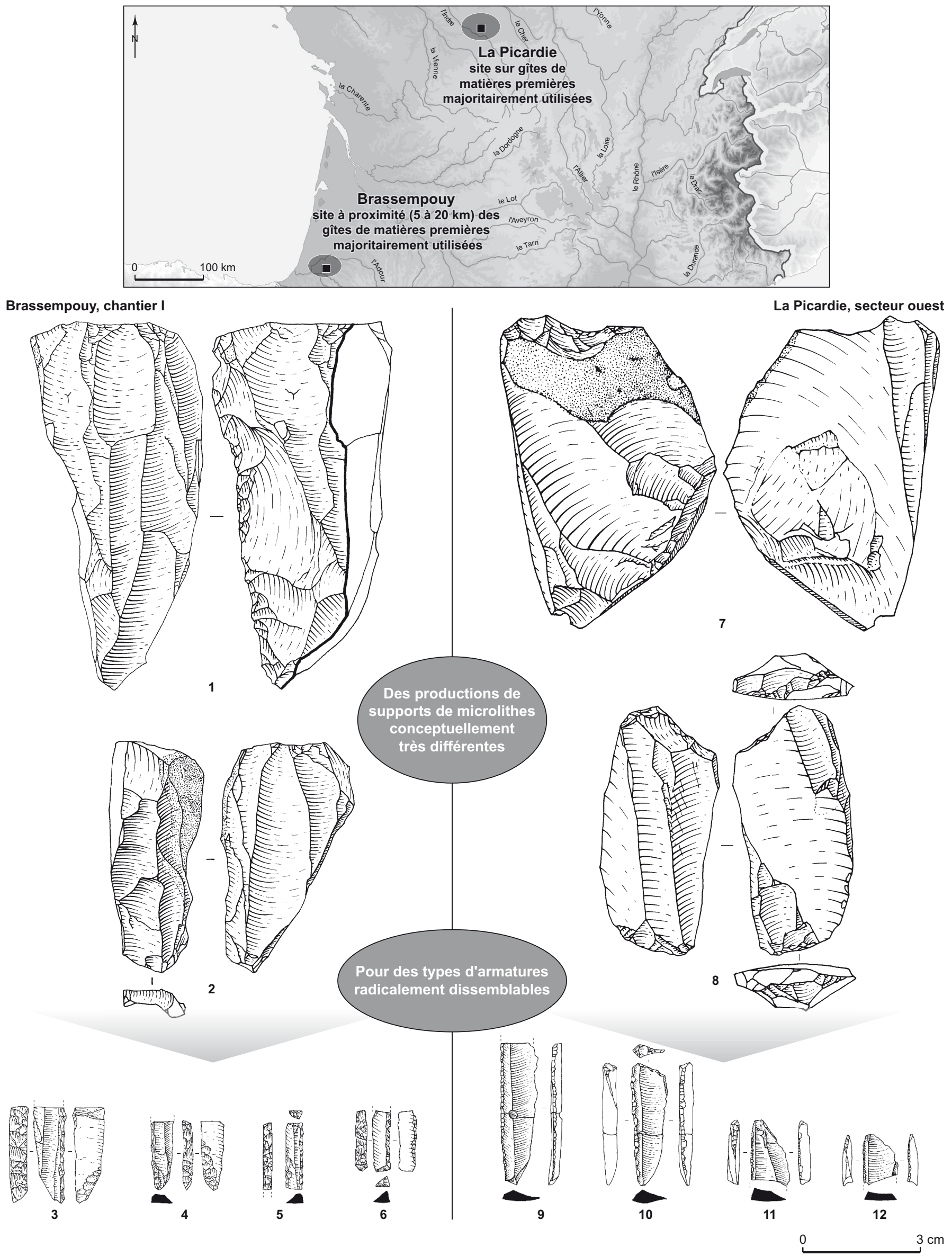

Fig. 3 - Comparaison des méthodes de production de supports de microlithes sur les sites du Gravettien moyen de Brassempouy (Noaillien) et de la Picardie (Rayssien) (dessins et DAO: L. Klaric, sauf n 1 dessin: T. Aubry). 
découlent de leur mode de production. Pour le Rayssien, il s'agit d'une production lamellaire autonome sur éclat ou lame, c'est-à-dire strictement séparée de la production laminaire sur bloc volumineux à vocation domestique (Klaric, 2003). Si les deux schémas présentent de fortes analogies conceptuelles, le débitage lamellaire obéit à des règles beaucoup plus rigides qui apparentent la méthode à une sorte de «routine». Nous ne reprendrons ici que les principaux traits de cette méthode de débitage originale déjà abondamment décrite (Klaric et al., 2002; Klaric, 2003, 2007a et b) Il s'agit d'un débitage strictement unipolaire et systématiquement latéralisé (sénestre) sur bord de lame ou tranche d'éclat. La progression du débitage est demi-tournante du bord vers la face inférieure (fig. $3, \mathrm{n}^{\text {os }} 7-8$ ). Le plan de frappe est constitué d'une troncature directe (souvent oblique ou concave), très fréquemment réaménagée, et les préparations en vu du détachement des lamelles sont faites par facettage. Les produits recherchés sont préférentiellement obtenus au détriment de la nervure de jonction de la face inférieure et de la table lamellaire. Détail important, les talons des lamelles sont préparés par un facettage latéralisé oblique, aisément reconnaissable (Klaric et al., 2002), dont on peut retrouver un vestige en partie proximale de la lamelle (fig. 3, $\mathrm{n}^{\text {os }} 10-12$ ).

En ce qui concerne le Noaillien de Brassempouy, la production de supports des microlithes à dos abrupt est réalisée à partir de nucléus laminaires sur bloc de gabarit variable (fig. 3, $\mathrm{n}^{\text {os }} 1-2$ ). L'étude réalisée n’a pas permis de déterminer s'il existait une chaîne opératoire exclusivement dédiée à l'obtention des supports d'armatures. Les données recueillies penchent plutôt en faveur de l'hypothèse d'une production «imbriquée» qui associerait indifféremment supports d'armatures et supports d'outils domestiques au sein des mêmes débitages; il ne s'agit pas pour autant de ce que l'on connaît sous le terme de production «intercalée » (voir Digan, 2006, p. 137). Cependant, seuls les nucléus les plus réguliers ont pu livrer des supports d'armatures. En effet, il existe, à Brassempouy, des débitages plus expédients dont la vocation n'est sans doute pas de produire des supports d'armatures, mais bien des supports plus «variés» destinés à d'autres types d'outils moins exigeants en termes de régularité et de rectitude (Klaric, 2003, p. 300-303). En outre, il est vraisemblable que le débitage des plus grands nucléus ait pu se poursuivre jusqu'à l'obtention de volumes nettement plus petits. Si le schéma opératoire employé est majoritairement unipolaire, certains nucléus sont bien bipolaires. Dans ces derniers cas, le second plan de frappe aurait surtout une vocation d'entretien ou correspondrait à une réimplantation du débitage à la suite de difficultés relatives à l'exploitation de la première table laminaire. À l'état d'abandon, nous n'avons pas observé de nucléus exploité selon un schéma bipolaire alternatif. Les plans de frappe sont en général lisses et la préparation des talons est simplement réalisée par abrasion du plan de frappe vers la table. Les tables laminaires plutôt rectilignes sont, en général, en position frontale et étroitement cintrées. Le cintrage est souvent assuré par des flancs aménagés par des enlèvements transversaux tirés d'une crête postérieure et/ ou par des extractions axiales (laminaires ou non) pratiquées à partir du plan de frappe (parfois encore, un flanc a pu être laissé cortical s'il s'avérait assez régulier). Le recul du débitage semble, lui aussi, avoir été frontal. Enfin, la technique de détachement principalement utilisée pour ces débitages est la percussion tendre organique. C'est donc l'ensemble du schéma opératoire qui diffère entre Rayssien et Noaillien. À la «routine rigide» du schéma autonome rayssien s'oppose la relative souplesse du schéma «intégré» noaillien. Ce dernier offre une plus grande marge de manœuvre opératoire, mais livre des supports qui nécessitent une transformation plus importante pour concrétiser les différents types d'armatures recherchés.

Cette comparaison terme à terme des systèmes de production de supports de microlithes s'avère particulièrement efficace puisqu'elle a permis de bien distinguer deux entités au sein du Gravettien moyen: le Noaillien et le Rayssien (Klaric, 2003). Or, jusqu'à présent, ces entités étaient toujours considérées comme relevant d'une seule et même phase chronologique. À l'intérieur de cette phase, la variabilité des industries avait jusqu'alors été interprétée soit comme le résultat de faciès fonctionnels (Laville et Rigaud, 1973; Rigaud, 1988) soit comme deux stades d'évolution du «Noaillien» (David, 1985). La mise en exergue des différences entre les productions de supports d'armatures de ces ensembles a donné naissance à une nouvelle interprétation : le Rayssien aurait pu constituer une tradition technique à part entière, sorte d'isolat technoculturel au sein des industries gravettiennes caractérisées par la fabrication et l'emploi des pointes à dos abrupt (Klaric, 2003 et 2007a).

\section{AU SEIN DU RAYSSIEN : DIVERS FACTEURS DE VARIABILITÉ À DÉCRYPTER}

Si les productions de supports de microlithes du Noaillien et du Rayssien se distinguent aisément, elles présentent aussi un certain degré de variabilité à l'intérieur de chacune de ces «sous-phases». Pour l'instant, trop peu de 
séries noailliennes ont été étudiées sur le plan technologique pour pouvoir mettre en évidence et expliquer la variabilité interne de cette entité très vaste géographiquement (centre et sud de la France, Pyrénées orientales et occidentales, Cantabres espagnoles et façade méditerranéenne de l'Italie) et chronologiquement (peut-être deux ou trois millénaires). Le Rayssien connaît une extension spatiale et temporelle beaucoup plus limitée (Klaric, 2003 et 2007a). Les différentes études réalisées sur des séries rayssiennes montrent la grande uniformité conceptuelle de la méthode de débitage lamellaire employée (Klaric et al., 2002; Klaric, 2003; Lucas, 2000 et 2002; Pottier, 2005). Il n'en reste pas moins que des différences techniques existent (dimensions, absence de certains critères de la définition princeps des lamelles, etc.). Nous avons essayé d'en saisir l'essence pour dépasser le simple constat analogies/différences. Généralement, cette variabilité est éludée de manière un peu rapide en invoquant les contraintes du milieu (approvisionnement en matière première), la fonction du site (habitat, halte de chasse, etc.), ou une différence diachronique (difficilement mesurable). Cependant, au sein de ces évidences, certains mécanismes plus précis peuvent être identifiés et décryptés pour expliquer les différences entre industries se rattachant à cet ensemble. À la lueur d'une comparaison entre la Picardie et la grotte du Renne, nous proposons ici d'en examiner quelques-uns, en suivant un gradient croissant quant à leur difficulté d'appréhension.

\section{LES CONTEXTES D'APPROVISIONNEMENT EN MATIÈRE PREMIÈRE}

Si les grands traits conceptuels de la production de supports d'armatures sont rigoureusement les mêmes à la Picardie (site de plein air) et à la grotte du Renne (Klaric, 2003), il existe pourtant quelques différences (Klaric, 2007b). Outre le contraste frappant qui peut subsister à l'intérieur de chaque ensemble, où (comme nous l'avons déjà signalé) de rares armatures de grand gabarit côtoient un groupe homogène et majoritaire de microlithes beaucoup plus petits ${ }^{2}$, ces différences s'expriment notamment au niveau des dimensions des nucléus et des armatures (fig. 4). Ainsi à la Picardie, les nucléus apparaissent, en moyenne, beaucoup plus volumineux qu'à la grotte du Renne. Corrélativement, les armatures de la Picardie sont d'un gabarit légèrement

2. Ce phénomène trouve peut-être une explication fonctionnelle se rapportant à des utilisations distinctes (petites pointes/grandes pointes) à l'intérieur même de l'équipement cynégétique (Chevassut, 2007). supérieur à celles de la grotte du Renne qui semblent plus graciles (Klaric, 2007b, p. 203). Bien entendu, une grande marge de recouvrement existe entre les deux ensembles de microlithes. Ce qu'il faut surtout relever c'est que, à la grotte du Renne, les supports d'armatures sont moins strictement normés morphologiquement (Klaric, 2003, p. 140). En effet, sur ce site, les supports d'armatures ne semblent pas avoir été aussi rigoureusement sélectionnés en raison de caractéristiques moins constantes qu'à la Picardie (absence de pan-revers, torsion plus marquée, irrégularité plus importante du support, absence de talon à facettage latéralisé oblique, etc.). Indépendamment des variations qualitatives et techniques des supports d'armatures, notons aussi qu'il existe un plus grand nombre de nucléus du Raysse doubles ou associant un Raysse et un outil à la grotte du Renne alors que ce dernier cas de figure est assez rare à la Picardie. Dans l'ensemble, la matière première semble avoir été économisée de manière drastique à la grotte du Renne alors qu'elle n'a pas particulièrement fait l'objet d'une économie stricte à la Picardie. Ces variations «mineures» s'expliquent par les conditions d'accès aux gîtes de matières premières. Les deux sites se trouvent, en effet, dans des contextes d'approvisionnement radicalement différents. Le site de la Picardie est à proximité immédiate des gîtes de silex du Turonien supérieur qui ont été utilisés pour l'ensemble des opérations de débitage sur le site. À l'inverse, la grotte du Renne se trouve éloignée de $35 \mathrm{~km}$ à $120 \mathrm{~km}$ des gîtes de matières premières qui ont servi pour le débitage (Mauger, 1994; Schmider et al., 2004). De ce fait, il semble logique que l'économie et l'utilisation poussée des supports, de mise à la grotte du Renne, n’aient pas été nécessaires à la Picardie. Cependant, devant l'impossibilité de déterminer la durée et le nombre d'occupations qui correspondent à la couche $\mathrm{V}$, il est délicat de se prononcer sur la représentativité de l'assemblage. Un point paraît pourtant acquis : quel que soit le type de contexte de matière première (riche ou pauvre), le schéma de production des supports n'a pas été modifié. Si l'on admet que les deux sites sont plus ou moins contemporains et si l'on fait abstraction de la question de la représentativité de l'assemblage de la grotte du Renne, il semblerait donc que l'on soit confronté à une adaptation économique mineure qui n'engendre que des variations limitées du point de vue du système de production des supports de microlithes. Cela se traduirait par une utilisation plus intense de tous les types de supports disponibles et par l'acceptation d'une norme moins stricte pour la confection des armatures. Toutefois, cette différence pourrait être aussi en partie liée à une durée de constitution de l'assem- 

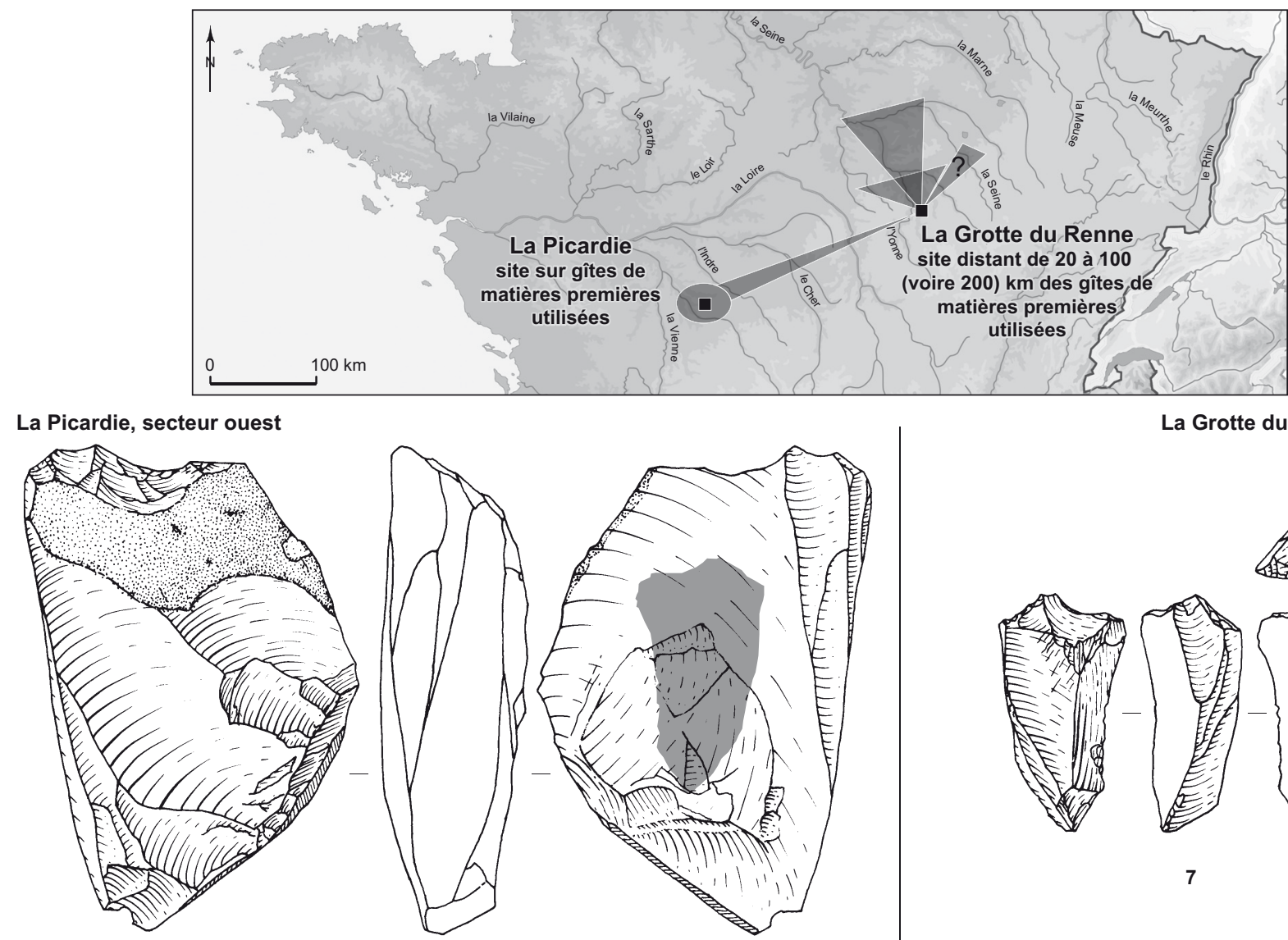

La Grotte du Renne, couche V
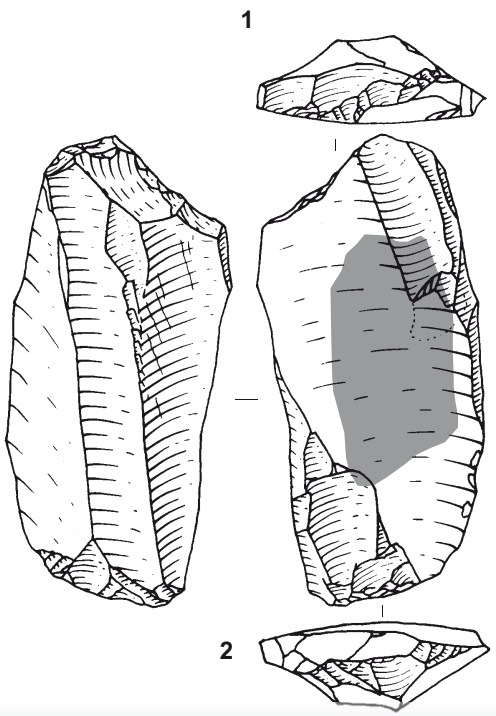

Même méthode

de débitage, mais

nette différence

dimensionnelle
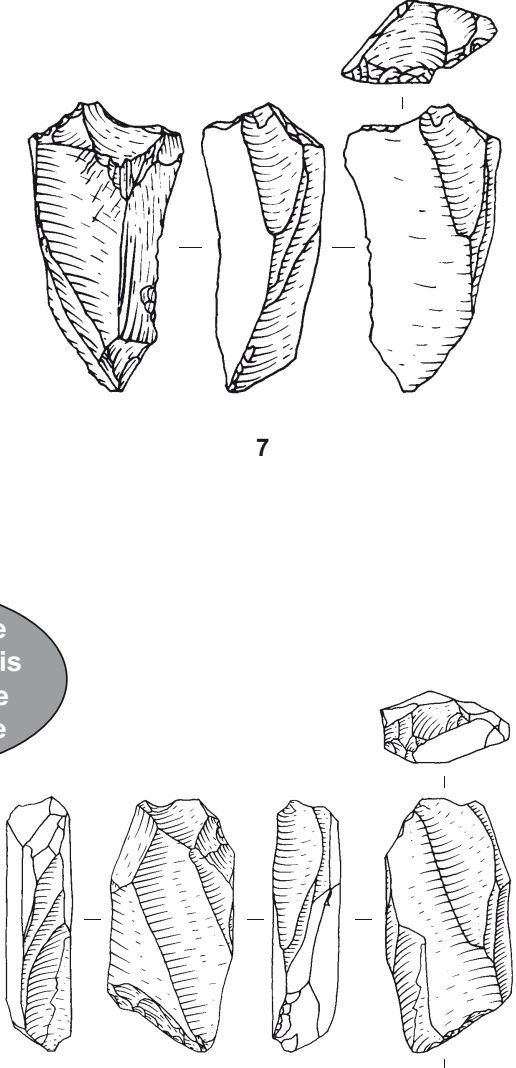

Pour des objectifs

identiques avec

seulement une légère

différence

dimensionnelle
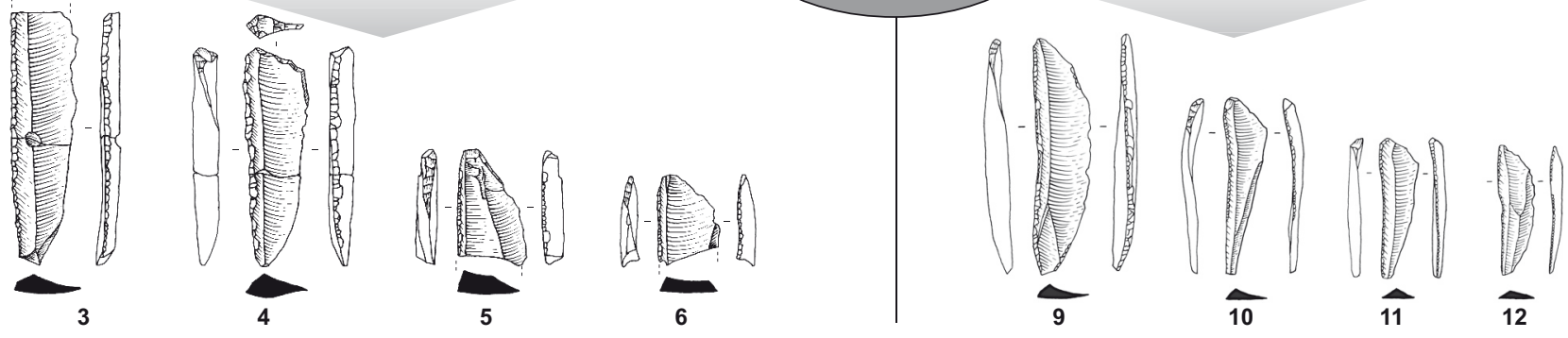

0

$3 \mathrm{~cm}$

Fig. 4 - Comparaison des méthodes de débitage de lamelles sur les sites du Gravettien moyen (Rayssien) de la Picardie et de la grotte du Renne avec une mise en perspective des approvisionnements en matériaux à grain fin (dessins et DAO: L. Klaric, CNRS). 
blage plus longue à la grotte du Renne qu'à la Picardie. On peut se demander si de nombreux épisodes d'occupations, peut-être étalés sur plusieurs générations, conduiraient à une plus grande variabilité technique de l'assemblage. Quoi qu'il en soit, la méthode du Raysse semble bien adaptée à différents types de contexte de matière première; sa rigidité conceptuelle et opératoire est largement compensée par la possibilité de l'appliquer à différents types de supports (lames, éclats laminaires, éclats), y compris à ceux ayant déjà servi pour d'autres activités, à savoir les anciens supports d'outils. Au vu de cette comparaison, la disponibilité locale en matière première ne constituerait donc qu'un faible facteur de variabilité du système de production des supports de microlithes.

\section{LE TYPE D'OCGUPATION ET LA FONCTION DU SITE}

On peut raisonnablement postuler que, en fonction de la nature de l'occupation, les activités techniques (lithiques et autres) peuvent varier d'un site à l'autre (Perlès, 1991). Ce postulat des «différences fonctionnelles» a d'ailleurs été à la base d'une des hypothèses d'interprétation des assemblages lithiques du Périgordien V (Delporte, 1961 et 1982) ou du Noaillien (Laville et Rigaud, 1973). En ce qui concerne plus particulièrement le Noaillien ${ }^{3}$, l'hypothèse était que les variations des différents fossiles directeurs (pointes de la Gravette, burins de Noailles, et burins du Raysse) présents sur les sites du Périgord correspondaient, en fait, à des spécialisations fonctionnelles plus ou moins contemporaines (ibid.). Cette conjecture négligeait toutefois l'échelonnement chrono-stratigraphique de certaines de ces industries (comme à Pataud, c.4 notamment, où un ensemble à burins du Raysse succède à un ensemble à burins de Noailles). Par ailleurs, elle ne pouvait pas prendre en compte la présence d'un autre fossile directeur (les lamelles de la Picardie), fondamental pour les industries à burins du Raysse. Les nouvelles données technologiques de la Picardie ont finalement permis de démontrer que les variations observées dans le Noaillien (David, 1985, sensu) relèvent davantage de différences d'ordre chronologique que fonctionnel (Klaric, 2003 et 2007a; Pottier, 2005). En effet, des comparaisons typo-technologiques ont révélé que les systèmes techniques lithiques rayssiens (de la Picardie et de la grotte du Renne) et noaillien (de Brassempouy) diffèrent radica-

3. Rappelons ici que le Noaillien en question correspondait en fait à la définition proposée par N. David (1985) et qu'il incluait alors deux entités désormais distinctes: le Gravettien à burin de Noailles (Noaillien stricto sensu) et le Gravettien à burin du Raysse (Rayssien). lement (Klaric, 2003, p. 387-393). Si le postulat des «différences fonctionnelles » n'a pas opéré dans ce cas précis, c'est parce qu'il était appliqué des échelles de temps trop longues (et de fait à des sites appartenant à des phases chronoculturelles distinctes).

Pourtant, il est logique de penser que l'examen de ce facteur pour des industries subcontemporaines (c'est-à-dire se rattachant à la même sous-phase chronoculturelle) peut s'avérer pertinent pour apprécier certaines variations des assemblages. Plusieurs exemples archéologiques de sites centrés sur les activités de production lithique (Corbiac Vignoble 2, voir Tixier et Reduron, 1991 ; les Maîtreaux, voir Aubry et al., 2007), d'habitat (Pincevent, voir Leroi-Gourhan et Brézillon, 1972; Bodu et al., 2006; Bodu et al., (dir.), 2006; Étiolles dans l'Essonne, voir Pigeot, 1988 et 2004) ou d'abattage/boucherie (Solutré, voir Combier et MontetWhite, 2002, p. 230-231) sont désormais bien connus pour le Paléolithique supérieur. Il apparaît donc en effet possible de réfléchir à l'impact de la (ou des) fonction(s) d'un site sur l'état technique et la représentativité des industries qu'il livre. L'intention est alors d'essayer de comprendre les «déclinaisons possibles de l'allure des industries» à la lueur des différentes activités qui ont été pratiquées sur les gisements (quelles parts du système technique sont représentées, quel est le degré d'utilisation/réfection/transformation des équipements produits ou apportés, etc.).

Pour aller plus loin, il faut également tenter de remettre en perspective ces différents types d'occupation au sein d'un fonctionnement territorial régional qui permettrait de mieux apprécier les raisons des variations des productions lithiques d'un site à l'autre. On y parvient désormais pour des périodes bien documentées comme le Magdalénien supérieur (Verberie dans l'Oise, voir Audouze, 2006; Pincevent à La Grande Paroisse en Seine-et-Marne, voir Bodu et al. (dir.), 2006) et l'Azilien (le Closeau, à RueilMalmaison dans les Hauts-de-Seine, voir Bodu et al., 2006) du Bassin parisien et de la Grande plaine européenne (Rekem, Belgique, voir De Bie et Van Gils, 2006); Champréveyres et Monruz à Neuchâtel en Suisse, voir Müller et al., 2006; Gönnersdorf et Andernach-Martinsberg (Allemagne, voir Street et al., 2006). On commence aussi à pouvoir proposer des modèles régionaux pour certaines phases du Solutréen supérieur français (Aubry et al., 2007). Mais, en France, pour le Paléolithique supérieur ancien, et le Gravettien en particulier, nous ne disposons pas encore d'une documentation aussi précise, y compris dans le sud-ouest de la France où, malgré le grand nombre de sites, trop peu de gisements de plein air ont été fouillés. Pour le Gravettien moyen, rares 
sont les sites qui contiennent à la fois des vestiges lithiques et fauniques et pour lesquels on peut apprécier finement les saisons et durées d'occupation probables. Ainsi, les meilleures références disponibles présentent au mieux un ou deux points positifs, mais posent souvent quelques difficultés majeures. La Picardie, par exemple, présente un assemblage lithique riche et homogène sur le plan technologique, mais le site ne contient aucun vestige faunique (donc pas de spectre des faunes chassées, de saisonnalité, d'industrie osseuse, etc.). À l'inverse, la grotte du Renne fournit plusieurs assemblages avec vestiges lithiques et fauniques (Schmider et al., 2004), mais ces séries correspondent sans doute à une sorte de palimpseste et posent des problèmes d'ordre taphonomique (Klaric, 2003, chap. II).

Toutefois, ces difficultés ne sont pas insurmontables. En effet, il est tout à fait possible de réfléchir à l'impact de la (des) fonction(s) de ces sites sur la représentativité des assemblages lithiques que l'on y retrouve. Cela passe évidemment par une réflexion globale sur l'ensemble des faits que l'on peut reconstituer à partir des données archéologiques. Ainsi, à la Picardie, la plupart des données lithiques convergent pour étayer l'hypothèse d'une occupation de type habitat: représentation de l'ensemble des chaînes opératoires qui composent le système technique lithique, présence de très nombreux outils, utilisés et abandonnés, avec des traces d'utilisation propres à diverses activités cynégétiques (armatures cassées) ou domestiques (travail de la peau, découpe de viande, raclage de matériaux organiques, etc., voir Araujo Igreja, 2006 in Klaric (dir.), 2006). Considérant que le site de la Picardie s'apparente à un habitat, on peut postuler qu'une partie de l'assemblage lithique au moins peut être le fruit de tailleurs en cours d'apprentissage, à l'instar de ce qui a été mis en évidence sur d'autres grands gisements de plein air du Paléolithique supérieur (Pigeot, 1988, 1990 et 2004; Karlin et al., 1993).

À l'occasion de l'examen attentif d'un échantillon de 106 nucléus à lamelles (représentant l'intégralité des nucléus à lamelles d'une zone de six mètres carrés), nous avons détecté de nombreux artéfacts (environ 25\%) qui s'écartent notablement des standards de la méthode du Raysse. Une étude approfondie (Klaric, en préparation) nous a d'ores et déjà révélé qu'une bonne partie de ces nucléus atypiques (fig. 5) sont sans doute le produit de tailleurs non confirmés s'exerçant à tailler des lamelles selon la méthode du Raysse (comm. Klaric, 2006). Avec près de $25 \%$ de nucléus atypiques, le degré de variabilité de cette méthode de débitage apparaît alors très important à l'intérieur même du site. Sans une étude technologique approfondie, cette variabilité notable pourrait être interprétée de manière erronée (schéma opératoire simplifié, débitage ubiquiste sur tranche d'éclat, indices se rapportant à une autre phase du Paléolithique supérieur, etc.). Or, si ces nucléus sont atypiques, l'analyse technologique a révélé qu'ils présentent tous les principes conceptuels élémentaires de la méthode du Raysse (nucléus sur support, unipolarité du débitage, latéralisation sénestre de la table lamellaire, exploitation préférentielle de la face inférieure, utilisation d'une troncature directe comme plan de frappe) et qu'ils ne peuvent pas se rapporter à une production «simplifiée» (absence d'outils sur supports provenant de tels nucléus, inconsistance et irrégularité de la production). Ils semblent plutôt correspondre au travail de tailleurs malhabiles ou d'apprentis (Pelegrin, 1995, p. 34-35). Dans le cadre d'une occupation regroupant des individus d'une ou plusieurs cellules familiales, on peut raisonnablement supposer la présence de tailleurs «novices» (probablement jeunes). Nous sous-estimons sans doute grandement ces comportements d'apprentissage tant ils sont parfois difficiles à mettre en évidence. Or, ils peuvent évidemment représenter une part de variabilité importante au sein d'un assemblage (Almeida, 2005; Pigeot, 1988 et 2004; Stapert, 2007 ; Fischer, 1990 ; Simonet, 2008) et, de ce fait, expliquer une part des différences avec d'autres sites. On peut en effet postuler que, dans des sites où la matière première est plus rare, ces comportements d'apprentissage soient plus limités, voire même absents. On peut émettre l'hypothèse qu'un groupe de chasseurs en expédition ne se composait que d'adultes ou réunissait adultes et jeunes sans que, par exemple, ces derniers aient le droit de s'exercer sur les réserves de silex emportées. Il est donc établi que, si la fonction du site peut influer sur les systèmes techniques, les comportements individuels d'apprentissage corrélatifs à des sites de type «habitat», ou «atelier», peuvent également constituer des facteurs de variabilité technique importants au sein de certains assemblages lithiques.

\section{L'ÉCART CHRONOLOGIQUE POUVANT EXISTER ENTRE LES GISEMENTS}

Un autre élément explicatif de la variabilité inter-site des productions de supports de microlithes pourrait résider dans l'écart chronologique existant entre chaque gisement. Étant donné les méthodes et les datations absolues disponibles, il est, pour l'instant, impossible d'avoir une idée, même approximative, de l'ampleur de ce phénomène pour certaines phases du Paléolithique supérieur ancien. En 
Trois exemples de nucléus s'apparentant à des Raysse atypiques (probables pièces « d'apprentis »)
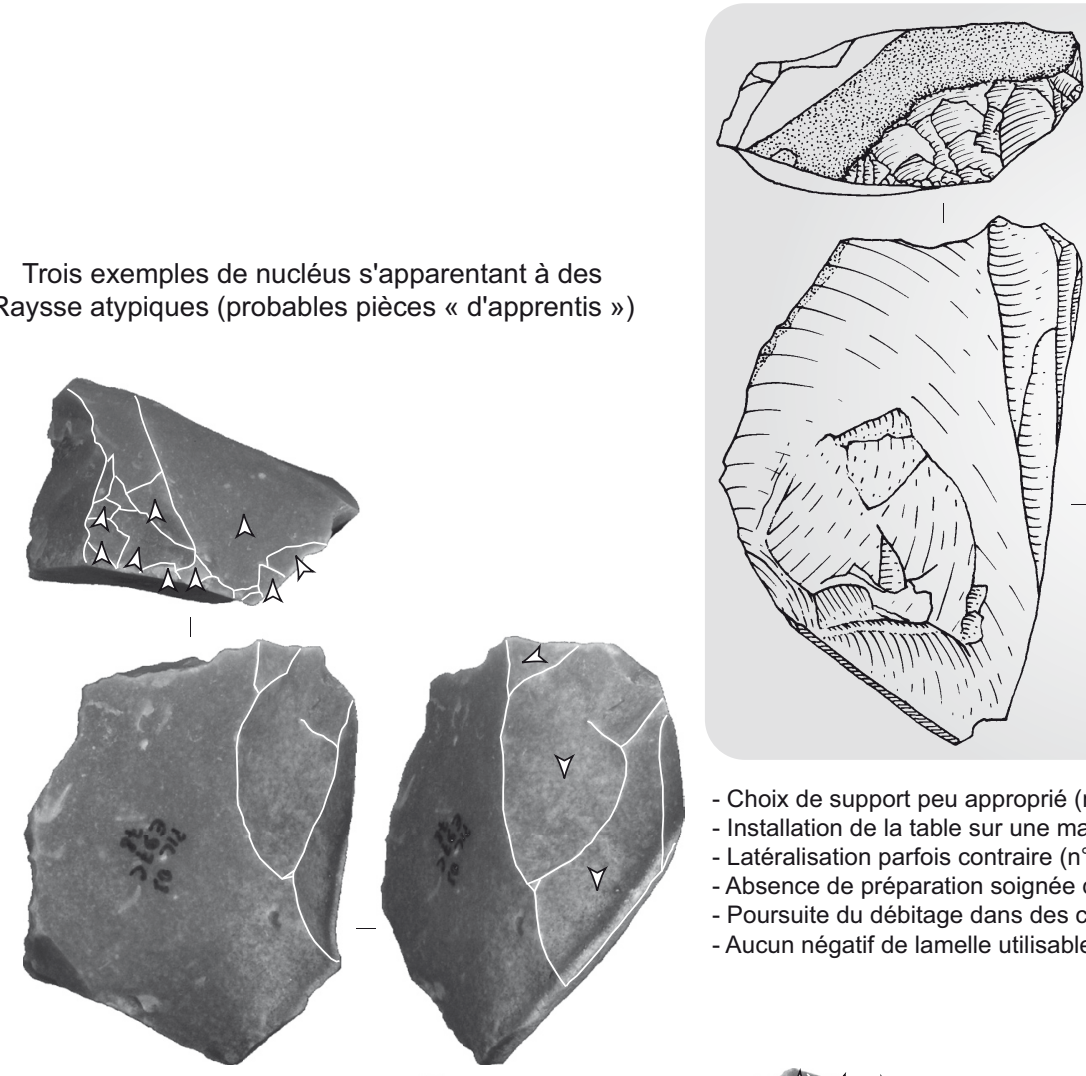

Pour comparaison, exemple d'un nucléus du Raysse typique

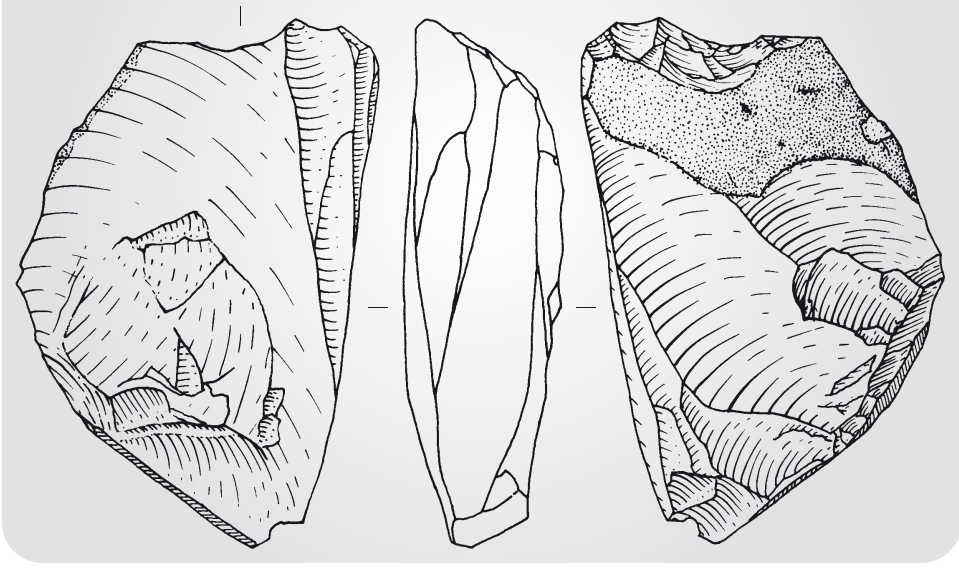

- Choix de support peu approprié $\left(n^{\circ} 2\right)$

- Installation de la table sur une mauvaise convexité $\left(n^{\circ} 2-3\right)$

- Latéralisation parfois contraire $\left(n^{\circ} 3\right)$

- Absence de préparation soignée du plan de frappe ( $n^{\circ} 1$ à 3 )

- Poursuite du débitage dans des conditions inappropriées (accident quasi certain) ( $\left.n^{\circ} 1-3\right)$

- Aucun négatif de lamelle utilisable ( $n^{\circ} 1$ à 3$)$
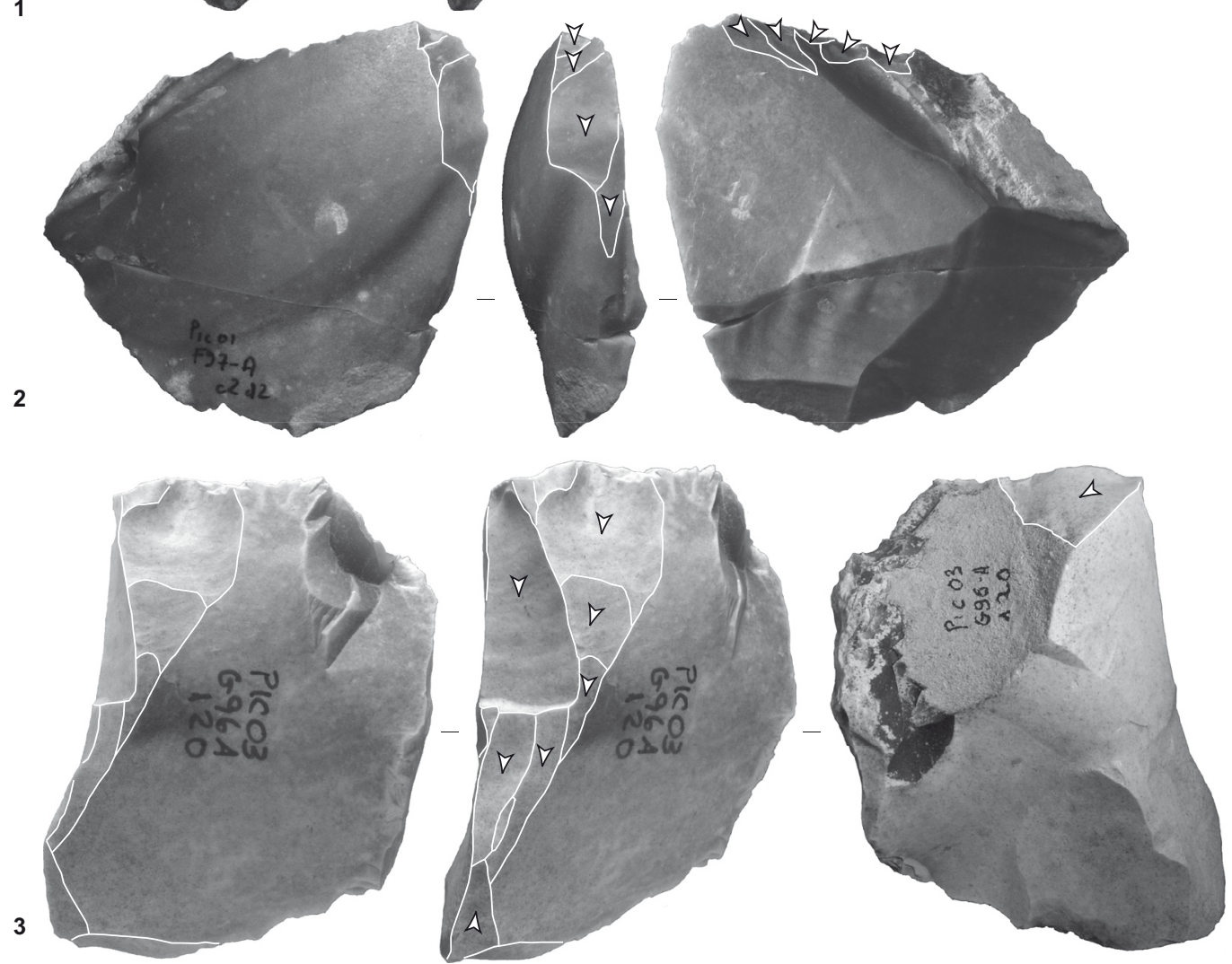

$3 \mathrm{~cm}$

Fig. 5 - Quelques critères avancés pour la reconnaissance des nucléus du Raysse atypiques considérés comme le produit de tailleurs malhabiles (dessins, photographies et DAO: L. Klaric, CNRS). 
effet, nous ne disposons que de très peu de dates pour l'ensemble des sites rayssiens en France (une vingtaine en tout, voir Klaric, 2003 et 2007a). En l'occurrence, la couche V de la grotte du Renne a fait l'objet de deux datations (Ly-340 A: $11400 \pm 250$ BP et Ly-2161: $20150+/-500$ BP). Aucune des deux ne semble recevable en regard des fourchettes connues sur d'autres gisements (Schmider et al., 2004; Klaric, 2007a). En outre, la Picardie n'a pas pu faire l'objet de datation radiocarbone puisque aucun matériau organique n'est conservé sur le site (d'autres méthodes de datations seraient peut-être envisageables - TL ou OSL -, mais leur précision et la nature des sédiments du site - pour l'OSL s'avéreraient probablement limitatives pour résoudre cette question). Par conséquent, il est impossible de préciser si les deux sites sont approximativement contemporains où s'ils correspondent à des occupations très éloignées dans le temps. À cette incertitude s'ajoute le problème de la durée d'occupation de ces gisements. En effet, si l'on peut soupçonner qu'à la Picardie le site n'a probablement été occupé qu'une ou quelques fois, il n'en va sans doute pas de même pour la grotte du Renne où les accumulations de vestiges des couches IV, V et VI suggèrent de multiples réoccupations pouvant correspondre à un véritable palimpseste. Ce problème est d'ailleurs récurrent puisqu'il se pose aussi pour les occupations à forte densité de vestiges des sites du sud-ouest de la France, tels l'abri Pataud (Bricker, 1995) ou encore le Flageolet I en Dordogne (Rigaud, 1982; Lucas, 2000). Il est alors extrêmement difficile d'apprécier l'éventuelle variabilité liée à une évolution diachronique, tout au moins à partir des données dont nous disposons.

\section{CONCLUSION}

Des limites imposées par les trois facteurs de variabilité évoqués (variabilité des contextes d'approvisionnements, fonction du site au sein du territoire/activités intra-site et écart chronologique des occupations non appréciables de manière fine), il découle que nos tentatives de modélisation de fonctionnements territoriaux ou sociaux à large échelle ne sont que des approximations empreintes d'un fort degré d'incertitude pour ces périodes. En ce qui concerne le Rayssien, les industries qui se rattachent à cette entité demeurent nettement différentes des industries à pointes à dos classiques du Gravettien (Klaric, 2007a). Toutefois, parfaitement conscient d'une possible variabilité interne du Rayssien, nous avons proposé deux scénarios interprétatifs entre lesquels nous ne pouvons trancher pour l'instant: celui d'une filiation effective entre Noaillien et Rayssien ou celui de l'existence d'un «faciès" en rupture complète (sur un plan technologique) avec le reste de la lignée gravettienne (ibid.). Le premier, considérerait que le Rayssien tire ses origines du Noaillien et les grandes séquences du sud-ouest (l'abri Pataud et le Flageolet) en seraient révélatrices. Ce scénario pose malgré tout la question des mécanismes de transition d'un système technique à l'autre puisque, à ce jour, ce phénomène n'a pas été expliqué de manière convaincante. Le second, plus fragile, consisterait à considérer le Rayssien comme un phénomène à part entière ne prenant pas ses origines dans le Noaillien. Dans ce cas, se pose la question de l'origine géographique et culturelle d'un tel phénomène, car, pour l'instant, aucun candidat sérieux n'a pu être proposé. Il n'en reste pas moins que l'originalité du Rayssien et sa possible contemporanéité partielle avec des ensembles noailliens plus méridionaux étayent fortement l'hypothèse d'une mosaïque culturelle (ibid.).

\section{ENTRE ANALOGIES À GRANDES DISTANCES ET VARIABILITÉS RÉGIONALES DES PRODUCTIONS MICROLITHIQUES : LE CAS DU GRAVETTIEN RÉCENT}

Des années 1970 à nos jours, les termes «Gravettien ancien, moyen, récent et final» se sont progressivement substitués à ceux obsolètes du Périgordien (IV, V, VI, VII) de Peyrony (pour un court historique, voir Klaric, 2003, p. 11-23). Néanmoins, ces découpages plus neutres ne constituent que des subdivisions «d'attente» demandant à être revisitées à plus ou moins court terme (Klaric, 2003; Goutas, 2004; Digan, 2006). Ces subdivisions, à l'instar du Gravettien moyen, seront sans doute à nouveau découpées en sous-phases pouvant varier d'une région à l'autre. Les données disponibles pour le Gravettien récent laissent pressentir de telles possibilités dans les années à venir.

\section{LE PROBLÈME DES ANALOGIES À GRANDES DISTANCES : LE BLOT, MAINZ-LINSENBERG ET VALE DOS COVÕES : VÉRITABLES PARENTÉS CONGEPTUELLES OU SIMPLES PHÉNOMÈNES DE CONVERGENCE DES SYSTÈMES TECHNIQUES?}

Si le Rayssien reste un phénomène géographique pour l'instant nettement circonscrit, que dire du Gravettien récent pour lequel plusieurs exemples montrent des analogies 
conceptuelles des systèmes techniques lithiques à très grandes distances à l'échelle de l'Europe du sud-ouest? Et surtout, quelle valeur accorder alors à de telles analogies?

\section{LE BLOT ET MAINZ-LINSENBERG}

Le premier cas auquel nous avons été confrontés est celui de l'ensemble moyen de l'abri du Blot (Massif central) et du site de plein air de Mainz-Linsenberg (Rhénanie, Allemagne; Hahn, 1969). Bien que de nature différente, ces gisements possèdent des assemblages lithiques qui présentent des ressemblances frappantes, tant du point de vue des particularités typologiques des armatures (microgravettes et lamelles à dos principalement) (fig. $6, \mathrm{n}^{\text {os }} 4-7$ et 11-15) que du point de vue des modalités de production de leurs supports sur «burin-nucléus» polyédriques (Klaric, 2000, 2003 et 2007 b) (fig. 6 , $\mathrm{n}^{\text {os }} 1-3$ et 8-10). Il s'agit d'un schéma préférentiellement unipolaire (fig. 6, $\mathrm{n}^{\mathrm{o}} 2$ ). Cependant, plusieurs nucléus montrent des exploitations multiples d'apparence bipolaire (fig. 6, $\mathrm{n}^{\text {os }} 1-3$ et $8-10$ ). Il s'agit en fait souvent de correction ou de réorientation du débitage (unipolaire successif) visant à une exploitation poussée des différentes parties des lames-supports. La ou les tables lamellaires sont alors installées dans l'axe longitudinal du support et se développent de manière tournante aussi bien sur les bords que sur les faces inférieure et supérieure. Il n'existe pas de zone spécifique où les lamelles sont préférentiellement recherchées. Tout support lamellaire régulier, rectiligne et pas trop épais peut être utilisé pour la confection d'une armature. Durant le débitage, les tailleurs ont combiné différents types d'extraction (sur bord, face inférieure et supérieure) pour entretenir régulièrement le cintre de la table et obtenir une certaine récurrence, d'où la morphologie très "polyédrique» des nucléus. L'examen de quelques-uns de ces «burins-nucléus» suggère que la méthode peut être relativement productive, car elle permet une exploitation poussée du volume d'une lame-support (fig. 6, $\mathrm{n}^{\mathrm{o}} 3$ ) tout en conservant une grande souplesse $\mathrm{du}$ point de vue opératoire. Par ailleurs, nous avons noté la présence de pièces (fig. $6, \mathrm{n}^{\text {os }} 2$ et 8 ) interprétées comme des lames «aménagées par technique de Kostienki» (ou «couteaux de Kostienki») dans les deux ensembles (Klaric, 2000). Or, si ces artéfacts sont effectivement analogues d'un site à l'autre (ibid.), une analyse typo-technologique des «couteaux de Kostienki» du site de Zaraysk (Russie) est en passe de démontrer qu'il ne s'agit absolument pas d'artéfacts analogues à ceux des sites d'Europe orientale
(Kozlowski, 1984; Klaric, 2007b, p. 216; Klaric et al., en préparation; Lev et al., 2009).

Cependant, les similarités relevées entre le Blot et Mainz-Linsenberg ne doivent pas occulter les variations rapportables aux états techniques des pièces au sein de chacun des ensembles. En effet, certains nucléus affichent parfois des états techniques nettement différents. Ces derniers diffèrent parfois au point que ces pièces ont, par le passé, pu être classées dans différentes catégories d'outils («burins polyédriques», «burins multiples mixtes», «lames aménagées par technique de Kostienki») alors qu'il s'agit seulement de nucléus débités selon la même méthode, mais abandonnés à des stades d'exhaustion différents. Par ailleurs, les variations dimensionnelles des nucléus (parfois nettement marquées) ne sont probablement que le reflet de débitages plus ou moins poussés (comparer par exemple fig. $6, \mathrm{n}^{\text {os }} 1$ et 3 ).

\section{LE BLOT ET VALE DOS COVÕES}

La comparaison de la série du Blot avec les assemblages issus de la séquence de l'abri de Vale dos Covões s'avère moins évidente. Au sein de ce gisement, les séries lithiques des unités stratigraphiques 5 , 6 et 7 présentent au moins deux critères, typologique et technique, qui nous poussent à rapprocher ces ensembles du Gravettien récent caractérisé au Blot. Il s'agit tout d'abord de la présence de microgravettes typiques (dos abrupts à retouche croisée, aménagement basal et/ou apical inverse ou direct) (fig. 7, $\mathrm{n}^{\text {os }} 4-6,11-13$ et 15) et de nombreux exemplaires de lamelles à dos moins nettement typées (fig. 7, $\mathrm{n}^{\text {os }} 7$ et 14). En outre, l'examen des modalités de production de ces microlithes révèle que la méthode employée est très comparable à celle évoquée pour le Blot et Mainz-Linsenberg. Il s'agit (pour l'instant) exclusivement de petits nucléus sur éclats ou lames prenant la forme d'un «burin-nucléus» polyédrique exploité de manière uni ou bipolaire à partir d'une troncature (fig. 7, $\mathrm{n}^{\text {os }} 8-10$ ). Comme pour le Blot (fig. 7, $\mathrm{n}^{\text {os }} 1-3$ ), la méthode vise à une exploitation poussée du volume puisque différentes zones peuvent être investies. La petite taille des nucléus pourrait aussi suggérer une volonté d'exploitation intense en raison des faibles dimensions des blocs issus des gîtes de matière première de bonne qualité situés au moins à une trentaine de kilomètres plus au sud-sud-ouest (fig. 7). Ainsi, les dimensions réduites des nucléus sur supports débités pourraient n'être qu'une conséquence des faibles dimensions initiales des supports en question. Les séries de Vale dos Covões présentent toutefois une certaine originalité par 

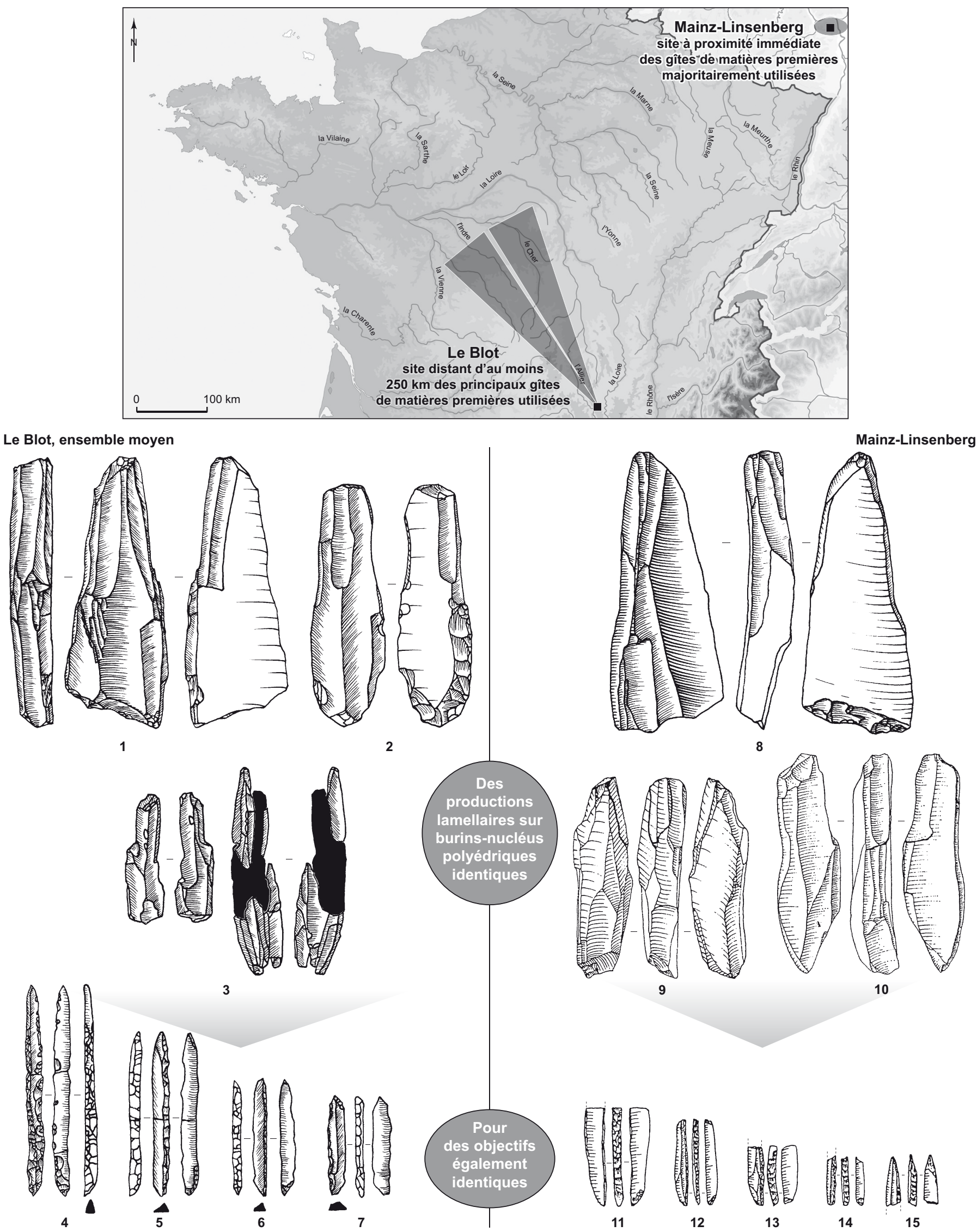

0 $3 \mathrm{~cm}$

Fig. 6 - Comparaison des méthodes de débitage de lamelles sur les sites du Gravettien récent du Blot (ensemble moyen) et de Mainz-Linsenberg avec une mise en perspective des approvisionnements en matériaux à grain fin (dessins et DAO: L. Klaric, CNRS, sauf nos 11-15 dessins d'après Hahn, 1969, p. 57 et $n^{\text {os }}$ 9-10 dessins d'après Fehlings, 1993). 


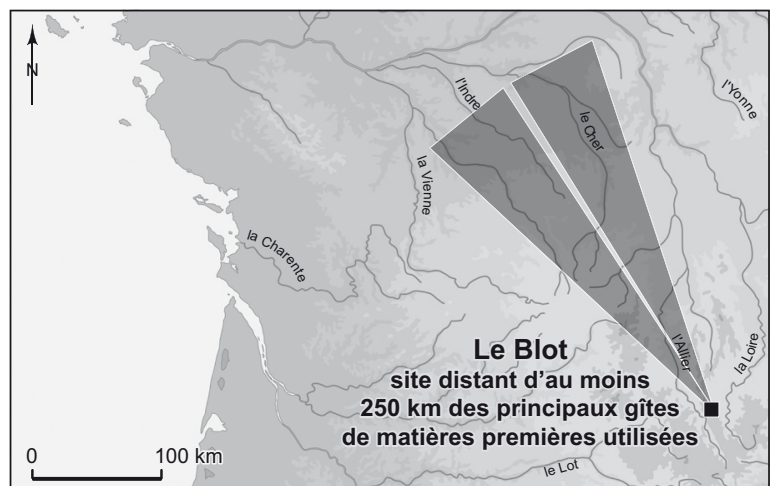

Le Blot, ensemble moyen

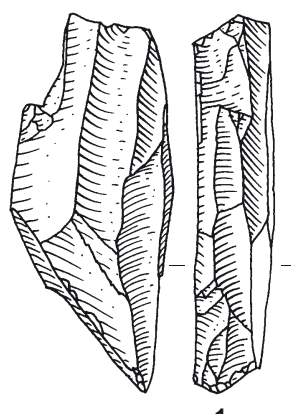

1

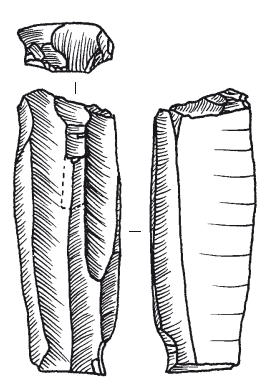

3

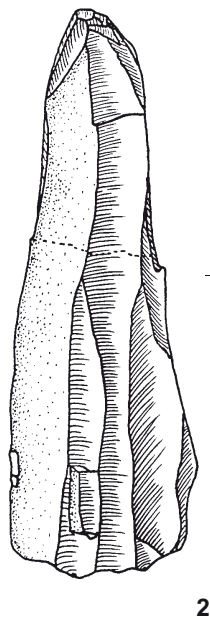

2

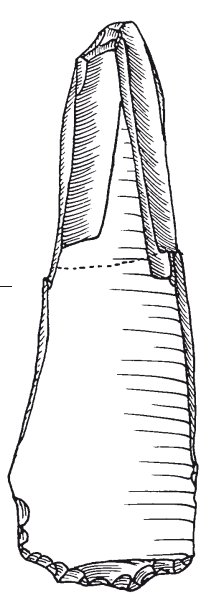

(1)
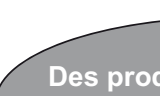

Des productions lamellaires sur burins-nucléus polyédriques
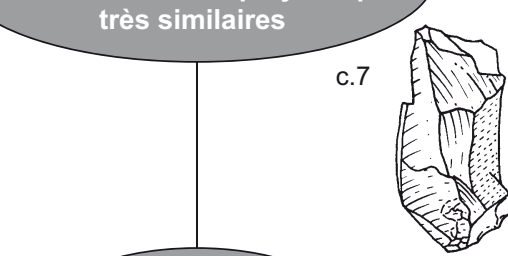

Pour des objectifis typologiquement quasi identiques

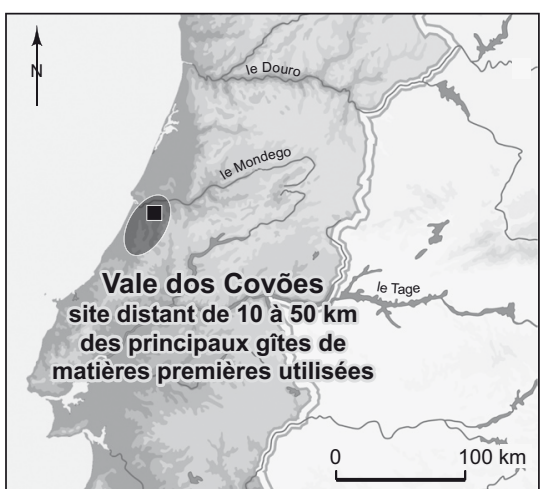

Vale dos Covões, c.5, c.6, c.7

c. 5

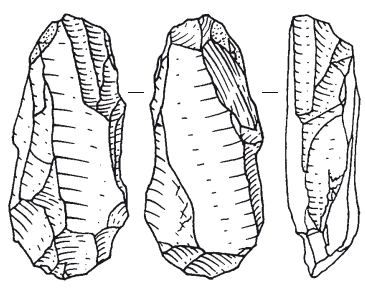

8

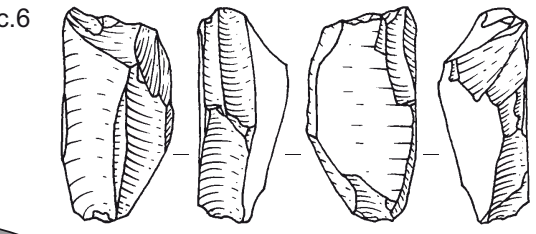

9

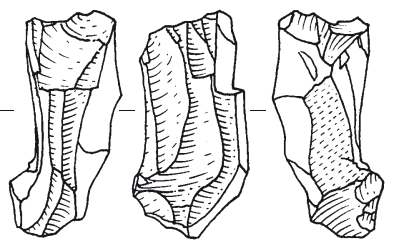

10
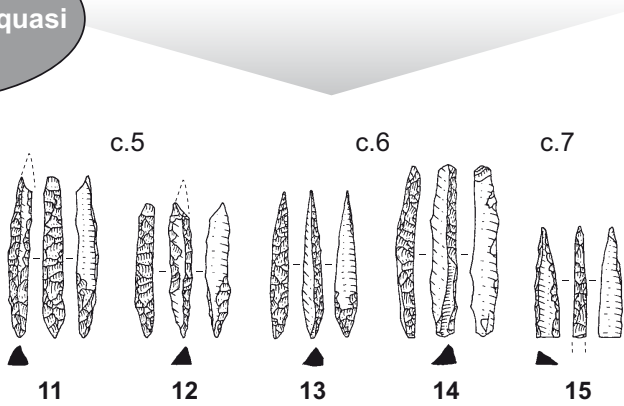

15

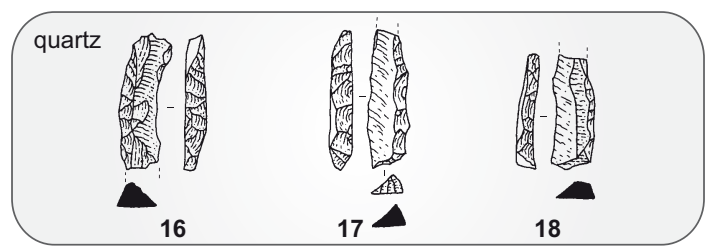

Fig. 7 - Comparaison des méthodes de débitage de lamelles sur les sites du Gravettien récent du Blot (ensemble moyen) et de Vale dos Covões $(c .5$, c.6, c.7) avec une mise en perspective des approvisionnements en matériaux à grain fin (dessins et DAO: L. Klaric, CNRS). 
rapport au Blot. Celle-ci se manifeste par la présence de plusieurs lamelles à dos en quartz filonien (fig. 7, $\mathrm{n}^{\text {os }} 16-18$ ) dont la majorité ne semblerait pas avoir été produite sur place puisqu'un seul nucléus à négatifs lamellaires a été découvert. Or, si le même genre de matériau était disponible dans le Massif central à proximité du Blot, comme l'atteste l'exploitation qu'en ont fait les Badegouliens (Bracco, 1997, p. 287), nous n'avons pas d'indice témoignant de son utilisation pour la confection d'armature par les occupants gravettiens du site.

Si cette analogie à grande distance nous interpelle, c'est que, à l'heure actuelle, le Portugal ne compte aucun autre gisement présentant un si grand nombre de microgravettes aussi typiquement gravettiennes (Zilhão, 1997 et 2000). C'est d'ailleurs grâce à cet argument et à plusieurs observations d'ordre taphonomique ${ }^{4}$ que nous persistons à le considérer comme Gravettien malgré plusieurs datations qui renvoient plutôt au Magdalénien supérieur ${ }^{5}$ (tabl. I).

Cela dit, il serait tentant de considérer les analogies du Blot et de Vale dos Covões comme des preuves de contacts et/ou de déplacements à grandes distances ou encore d'homogénéité très forte entre différentes aires géographiques. Une telle posture reviendrait à renforcer le consensus qui considère le Gravettien comme une véritable culture pan-européenne. Si force est de reconnaître que ces analogies sont particulièrement saisissantes pour le Blot et Mainz-Linsenberg, il n'en est pas de même pour Vale dos Covões. En effet, malgré les ressemblances typo-technologiques, plusieurs particularités distinctives doivent être relevées. Il s'agit non seulement de l'utilisation du quartz pour certaines armatures à dos (fig. 7, $\mathrm{n}^{\text {os }} 16-18$ ), mais aussi de l'absence des formes particulières du type «lames aménagées par technique de Kostienki». Par ailleurs, à Vale dos Covões, seules des lames de faible gabarit ont été utilisées comme support de nucléus à lamelles. Ce fait paraît

4. Outre la faible surface fouillée $\left(9 \mathrm{~m}^{2}\right)$, les unités 5,6 et 7 de Vale dos Covões posent au moins deux problèmes. Le premier, d'ordre taphonomique, est lié à la mise en place des dépôts qui correspondrait à un processus d'accumulation des vestiges par ruissellement vers l'intérieur de l'abri après la chute du surplomb et impliquerait donc des remaniements plus ou moins importants des industries (Aubry et al., 2007). Le second problème est lié aux résultats stratigraphiquement incohérents obtenus pour les datations réalisées sur les charbons et os issus de ces dépôts (tabl. I) : l'équivalence des résultats obtenus sur les charbons récoltés au sommet et à la base de la séquence (c.8b) pourrait alors témoigner de phénomènes de percolation des charbons postérieurement à la mise en place des dépôts.

5. Précisons qu'aucune série du Magdalénien portugais n'a pas, pour l'instant, livré de micropointes de la Gravette comparables à celles de Vale do Covões.
Tabl. I - Les dates radiocarbone de Vale dos Covões (Portugal).

\begin{tabular}{|c|c|c|}
\hline $\begin{array}{c}\text { Unité } \\
\text { stratigraphique }\end{array}$ & Os & Charbons \\
\hline c. 5 & $10540 \pm 95$ (Ua 33479) & $12340 \pm 50$ (Beta 201013) \\
\hline c.6 & - & - \\
\hline c. 7 & $9725 \pm 75$ (Ua 33480) & - \\
\hline c.8b & $9315 \pm 90$ (Ua 33481) et & $12050 \pm 70$ (Ua 33482) et \\
& $10010 \pm 90$ (Ua 24593) & $12220 \pm 24$ (Gif) \\
\hline
\end{tabular}

cependant logique si l'on considère l'utilisation fréquente du quartz et le caractère marginal (voire même l'absence) des productions laminaires de grands modules dans la grande majorité des séries du Paléolithique supérieur portugais (Zilhão, 1997). Ce dernier point peut en partie être lié aux faibles dimensions des blocs disponibles dans les contextes d'approvisionnement du pays, mais il ne s'agit sans doute pas du seul facteur explicatif (Aubry et Araujo Igreja, en préparation). Certaines différences sont donc manifestement surdéterminées (ou contraintes) par le contexte et ne peuvent donc pas exclusivement être attribuées à de véritables choix de la part des groupes humains.

Il est finalement difficile d'interpréter ces analogies à grande distance puisqu'elles s'expriment à des degrés différents et sur des échelles de temps que l'on ne mesure pas pour l'instant. Cette difficulté est évidemment aggravée par la limite des possibilités de datations pour Mainz-Linsenberg ${ }^{6}$ et par le problème des dates de la séquence de Vale dos Covões. Tout au plus peut-on noter qu'au sein du Gravettien récent de l'Europe du sud-ouest, plusieurs exemples montrent que les méthodes de production de supports de microlithes à partir de «burins-nucléus » polyédriques semblent connaître un vif succès. Il est prématuré de conclure quant aux raisons ayant conduit à cet état de fait. S'agirait-il d'une innovation technique (dont le foyer d'émergence resterait à définir) connaissant, en raison de son « adaptabilité », une large diffusion via des réseaux de contacts ou d'échanges très développés ou, au contraire, s'agirait-il plutôt de multiples innovations indépendantes répondant à des besoins particuliers pouvant varier au gré de l'évolution des conditions environnementales des différentes régions considérées (cette hypothèse ne mettant pas forcément en jeu des contacts à longue distance)? De nombreuses situations intermédiaires sont évidemment envisageables mais, pour le moment, nous

6. En fait, une date radiocarbone congruente avec une attribution au Gravettien récent a récemment pu être obtenue sur Mainz-Linsenberg (comm. Terberger et al., 2009). 
ne disposons guère d'arguments permettant de plaider en faveur de l'une ou de l'autre. En revanche, il semble malgré tout possible d'exclure certaines explications trop simplistes et de privilégier certaines pistes de réflexion sur la base des exemples que nous avons proposés.

\section{RÉSISTER À LA TENTATION D'INTERPRÉTATIONS TROP SIMPLISTES : LE BLOT, LE CIRQUE DE LA PATRIE VS MAINZ-LINSENBERG}

Les données du Blot et de Vale dos Covões pourraient laisser penser que les systèmes de production de supports de microlithes sur lames ou éclats sont des solutions économiques adaptées à des contextes de matière première où les matériaux à grain fin font défaut dans l'environnement immédiat du site. En effet, au Blot (Haute-Loire), comme à Vale dos Covões (massif du Sicó), l'environnement local du gisement ne livre que des matériaux de qualité médiocre qui n'ont pratiquement jamais été employés pour la confection des armatures. Au Blot, la plupart des matériaux dédiés à la production des supports lamellaires proviennent de régions distantes de plus de $250 \mathrm{~km}$ à vol d'oiseau ${ }^{7}$ (Turonien supérieur de la région du Grand-Pressigny et Turonien inférieur de la vallée de la Loire ou du Cher) (Masson, 1981). Les matériaux locaux, eux, n'ont été que peu exploités pour la production de supports de microlithes. Des réserves de matière première de bonne qualité sont donc arrivées sur le site soit sous forme de grandes lames brutes ensuite transformées en nucléus, soit déjà sous la forme de «burins-nucléus » polyédriques, ou encore les deux à la fois. Au Blot, ces pièces pourraient alors correspondre à une adaptation du système de production de supports à un contexte où les matériaux siliceux à grain fin font défaut dans l'environnement local.

Pour aller plus loin, la présence de ces «burins-nucléus » au Blot permet d'inférer l'existence de sites de production de «grandes lames-supports» en Touraine et dans la basse vallée du Cher (les régions d'origine des silex utilisés). Mais, pour l'instant, on ne connaît dans ces régions qu'un seul site fouillé avec des dates absolues qui permettent de l'attribuer de manière fiable au Gravettien récent: le site de la Croix

7. Il faut toutefois rester prudent à propos de ces déterminations car il n'existe pas d'analyse précise de l'ensemble des matières premières siliceuses des niveaux du Gravettien récent du Blot. Notre raisonnement s'appuie donc exclusivement sur les premières observations et déterminations d'Annie Masson (1981). Sans doute faudrait-il effectuer de nouvelles analyses afin de préciser le spectre des matériaux utilisés. de Bagneux (Mareuil-sur-Cher, Loir-et-Cher) mis au jour par les travaux de l'INRAP en 2005 (fouilles F. Kildea et L. Lang; Kildea dir., 2008). Il faut, sinon, remonter plus au nord pour trouver un autre gisement (Le Cirque de la Patrie, Seine-et-Marne) rapporté au Gravettien récent (sur une base typo-technologique) avec des lames atteignant des gabarits proches de celles du Blot. L'industrie de ce gisement présente effectivement d'assez grands débitages (Cheynier, 1962; Klaric, 2003, chap. IV), mais les artéfacts assimilables à des «burins-nucléus » polyédriques y sont très anecdotiques. Sur ce site, très proche de sources de matières premières de bonne qualité de la vallée du Loing (entre $5 \mathrm{~km}$ et $25 \mathrm{~km}$ pour les gîtes les plus proches), la production des supports d'armatures (fig. 8, $\mathrm{n}^{\text {os }} 10-13$ ) a surtout reposé sur des débitages laminaires (de gabarits variables) sur blocs (fig. $8, \mathrm{n}^{\text {os }} 7-8$ ) et peut-être sur une production lamellaire intercalée (fig. 8, no 9 ). En ne prenant que les données du Blot et du Cirque de la Patrie, on pourrait donc formuler l'hypothèse suivante: les hommes préhistoriques auraient produit leurs supports d'armatures sur blocs lorsque cela était possible et auraient eu recours à des nucléus sur supports, plus aisément transportables, dans des contextes géologiques défavorables. On serait alors confronté à des adaptations ponctuelles du système technique en fonction des déplacements des groupes au sein du territoire. Ces variations seraient, de fait, en relation indirecte avec la nature et la fonction des sites. Le Cirque de la Patrie pourrait donc correspondre à une occupation de type résidentiel, au vu de la richesse de l'assemblage et de la diversité des outils, alors que le Blot serait plutôt considéré comme un campement saisonnier fréquenté par de petits groupes pour la chasse de grands herbivores (Buisson, 1991).

Pourtant, cette séduisante hypothèse d'un schéma de production ponctuellement adapté à un contexte de "pénurie » semble discutable à la lueur des observations faîtes sur les sites rayssiens où les «burins-nucléus» sur supports sont employés quels que soient les contextes de matière première environnant les gisements. Par ailleurs, elle est en partie contestable lorsqu'on la transpose à d'autres contextes régionaux comme celui de Mainz-Linsenberg. À l'inverse du Blot, cet autre site du Gravettien récent (Hahn, 1969) se trouve à proximité de gîtes de matériaux de bonne qualité (quartzite à grain très fin et silex local dans un rayon de $20 \mathrm{~km}$ ) (Floss, 1994 et 2000). Comment expliquer, alors, que cette modalité de production économique sur «burinsnucléus» polyédriques se retrouve dans ce contexte où la matière première de bonne qualité est bien présente? $\mathrm{Au}$ moins deux hypothèses non exclusives doivent alors 


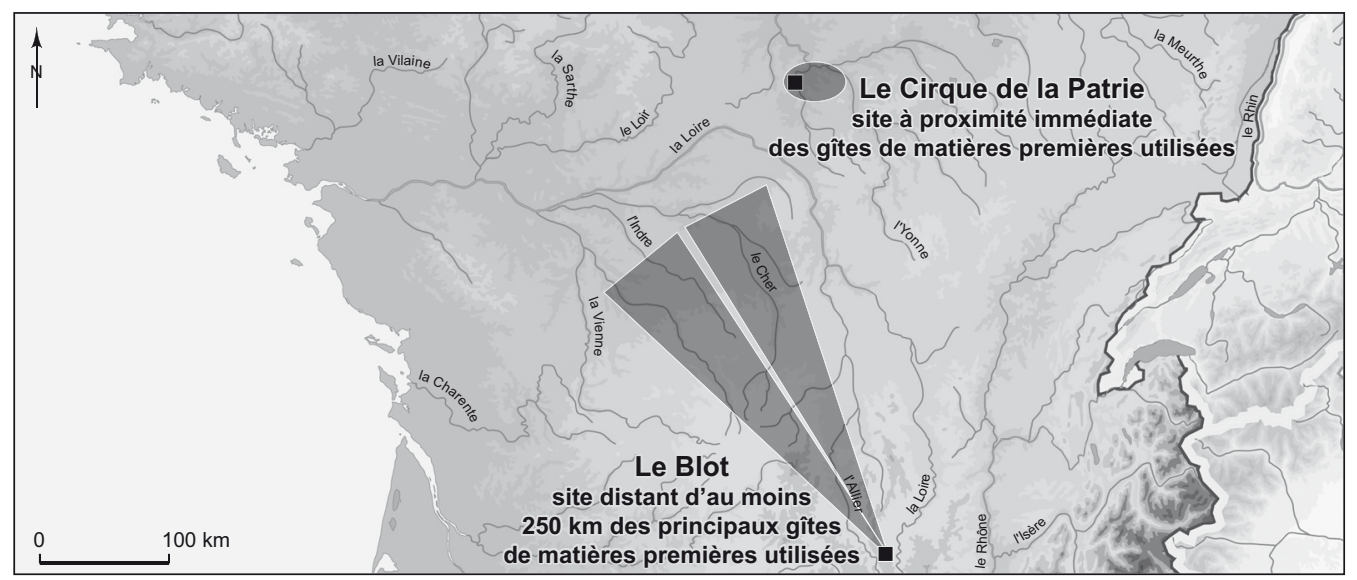

\section{Le Blot, ensemble moyen}
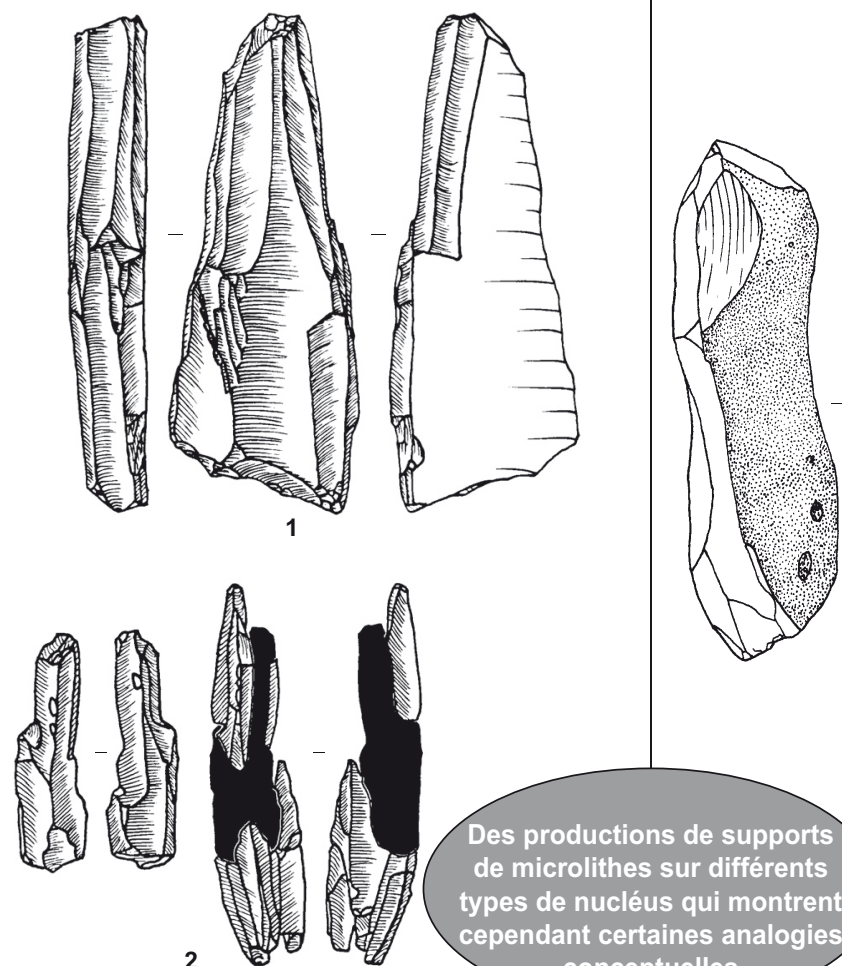

Des productions de supports de microlithes sur différents types de nucléus qui montrent cependant certaines analogies

\section{2}
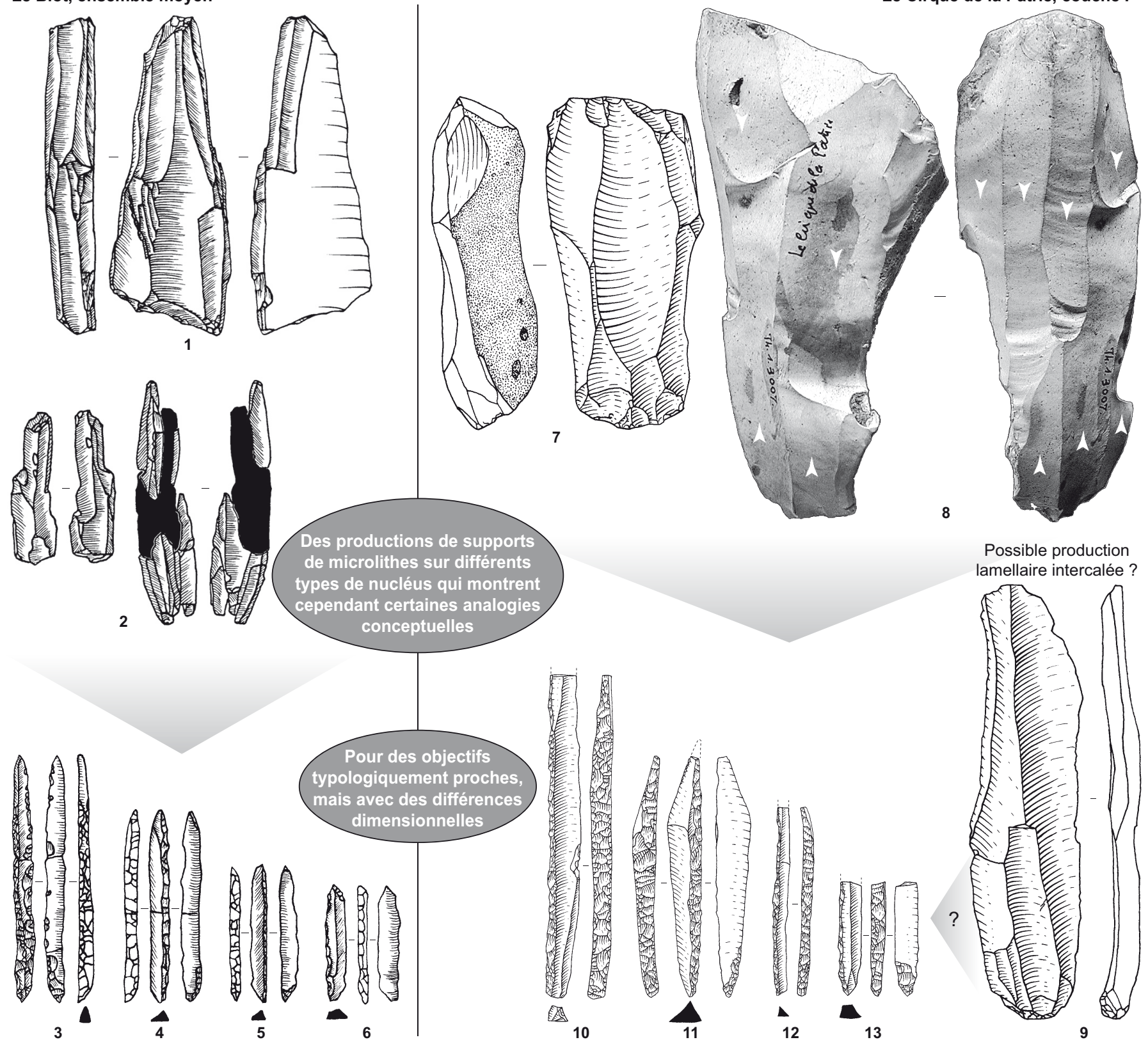

Possible production lamellaire intercalée ?

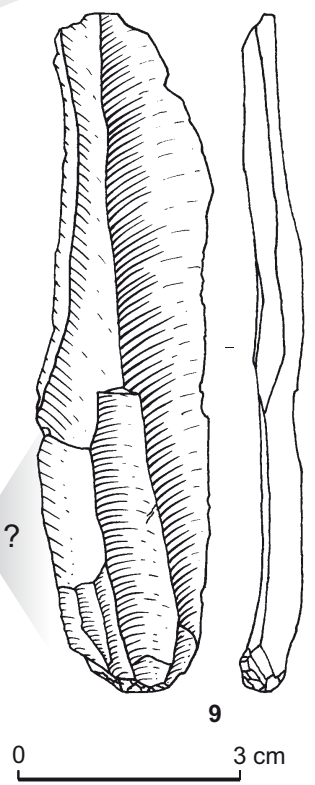

Fig. 8 - Comparaison des méthodes de débitage de lamelles sur les sites du Gravettien récent du Blot (ensemble moyen) et du Cirque de la Patrie (habitat central, c. I) avec une mise en perspective des approvisionnements en matériaux à grain fin (dessins, photographie et DAO: L. Klaric, CNRS). 
être envisagées: d'une part, la possibilité d'adaptation du système technique en fonction de la nature et des conditions de l'occupation (site résidentiel, halte de chasse, halte de réapprovisionnement en matériaux lithiques, etc.) et, d'autre part, l'existence de différentes sous-phases (ou variantes culturelles locales) non clairement identifiées au sein du Gravettien récent. Dans ce dernier cas de figure, on pourrait alors envisager que, pour l'une d'elles, l'emploi des «burins-nucléus» polyédriques soit la norme, alors que l'autre serait caractérisée par une production de supports d'armatures sur bloc. Ainsi, le Blot et Mainz-Linsenberg pourraient correspondre à des épisodes rapprochés dans le temps alors que le Cirque pourrait en être beaucoup plus éloigné.

Lefaible nombre dedatations radiocarbone rend pourtant, là encore, délicat l'établissement d'une chronologie relative entre gisements. En effet, si le Gravettien récent s'étend bien surdeux ou trois millénaires commelesuggèrentles dates (non calibrées) disponiblespourlaFrance (Klaric2003et2007a), ilest impossible, pourl'instant, d'établirl'échelonnementchronologique des gisements en question.

\section{UNE ÉQUATION COMPLEXE ENTRE PROBLÈMES DE DIACHRONIE, CONTEXTES D'APPROVISIONNEMENT, FRAGMENTATION DES CHAÎNES OPÉRATOIRES ET FONGTION DE SITE?}

Cette hypothèse de chronologie interne du Gravettien récent resterait une position théorique si les nouvelles données d'un gisement du sud-ouest de la France (l'abri des Peyrugues, Orniac, Lot) ne venaient apporter des informations étayant fortement ces présomptions déjà anciennes.

\section{DE NOMBREUX INDICES DE L'EXISTENCE DE DIFFÉRENTS STADES AU SEIN DU GRAVETTIEN RÉCENT}

Cette possibilité de chronologie interne du Gravettien récent avait déjà été pressentie par quelques auteurs sur certains gisements d'Europe occidentale. Ainsi Joachim Hahn avait perçu le caractère très évolué de l'assemblage de Mainz-Linsenberg (Hahn, 1969, p. 85): «Comparé au Périgordien supérieur de France, il correspondrait plutôt au Périgordien final avec à la fois les caractères du Périgordien VI et du Proto-magdalénien. » C'est aussi ce qui avait été pressenti plus tard sur les sites de Laugerie-Haute (près des Eyzies, Dordogne) (Bordes et Sonneville-Bordes, 1966) ou de Corbiac (près de Bergerac, Dordogne) où au moins deux niveaux d'un Gravettien dit «évolué» ont été décrits (Bordes, 1968a et b). De même, une véritable superposition de niveaux a également été clairement identifiée au sein du niveau 3 de l'abri Pataud (Bricker, 1995). Cependant, les études concernant ces gisements n'ont, sur cette question précise, jamais été suffisamment approfondies pour pouvoir étayer l'idée de différents stades évolutifs. Plus récemment, certains auteurs relayèrent également cette hypothèse en se fondant sur d'autres types d'observations (pour le site de Rabier, voir Morala, 1990; Lorin, 2000 et, de manière générale, Djindjian et Bosselin, 1994). Mais c'est finalement l'abri des Peyrugues (Orniac, Lot) qui apporte un argument décisif en faveur de cette hypothèse. En effet, ce site constitue un témoignage exceptionnel avec deux niveaux nettement stratifiés et attribués au Gravettien récent (C22 et C20) auxquels se superpose un niveau (C18) rapporté au Gravettien final et décrit comme Protomagdalénien (Allard, 1996; Allard et al., 1997; Allard et al., 2005). Cette séquence offre, par ailleurs, la possibilité de comparaisons entre systèmes de production de supports de microlithes tout en contrôlant certains paramètres de variabilité, notamment ceux liés à la disponibilité des matières premières lithiques.

\section{VARIABILITÉ DES ARMATURES ET DES SCHÉMAS DE PRODUCTION AUX PEYRUGUES}

Les armatures de l'ensemble C22 sont largement dominées par les pointes et micropointes de la Gravette (fig. 9, $\mathrm{n}^{\text {os }}$ 3-6), tandis que celles de l'ensemble C20 sont représentées par des microlithes plus variés (lamelles à dos tronquées, lamelles à dos simples, microgravettes et lamelles retouchées) (fig. 9, n ${ }^{\text {os }} 10-14$ ). En C18, cette catégorie d'outils est représentée par des lamelles à dos parfois tronquées, voire bitronquées (fig. 10, nos 9-12). À première vue, les schémas opératoires employés dans les ensembles C22 et C20 pour la confection des supports sont très proches (fig. 9 , $\mathrm{n}^{\text {os }} 1-2$ et 7-9). Il existe, d'une part, un débitage laminaire sur bloc avec une exploitation recourrant souvent à deux plans de frappe hiérarchisés et, d'autre part, une exploitation de «burins-nucléus» polyédriques (Guillermin, 2006a et thèse en cours; Guillermin et Morala, à paraître). Néanmoins, ces deux types de débitage sont représentés de manière très différente dans chacun des ensembles concernés. En effet, le schéma laminaire sur bloc (dont une partie est dédiée à la confection de pointes de la Gravette) est largement plus représenté au sein de C22. En C20, le débitage sur bloc vient seulement compléter la production de supports de microlithes à partir de l'exploitation des burins polyédriques. La 


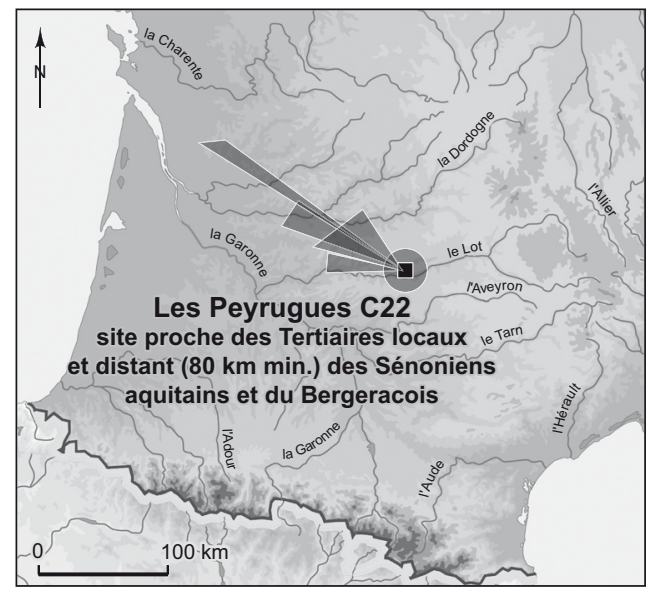

Les Peyrugues, C22
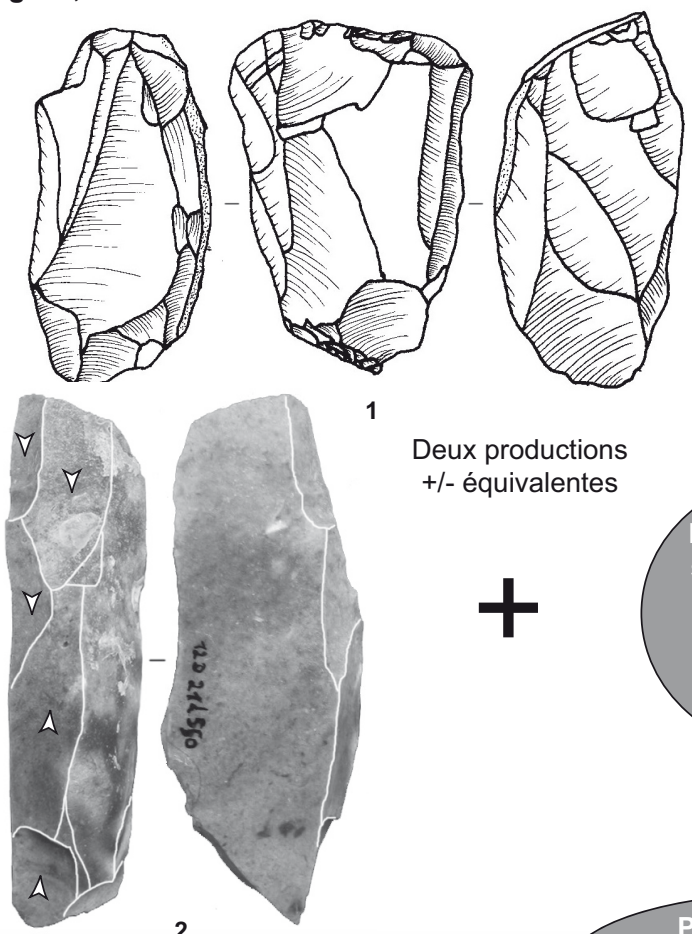

Deux productions

+/- équivalentes

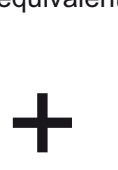

2

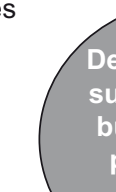

burins-nucléus

polyédriques

diversement

représentées

$\checkmark$

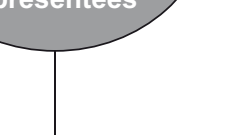

Pour des objectifs

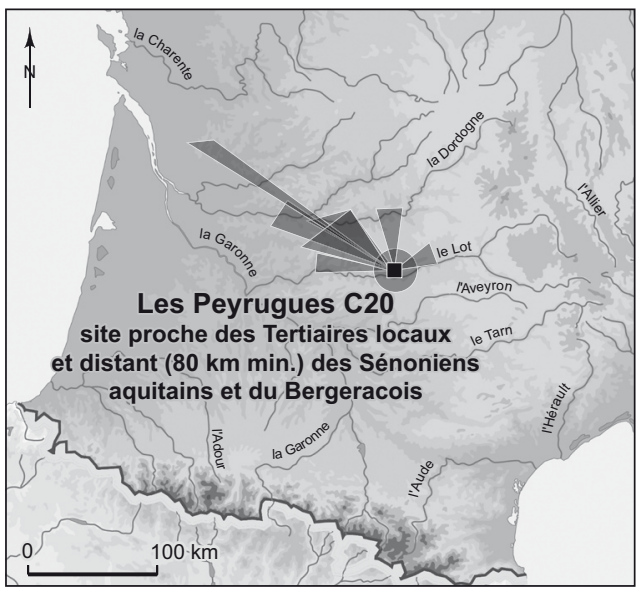

Les Peyrugues, C20

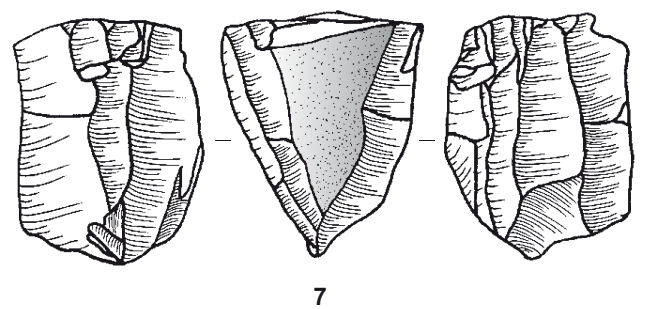

Production d'appoint

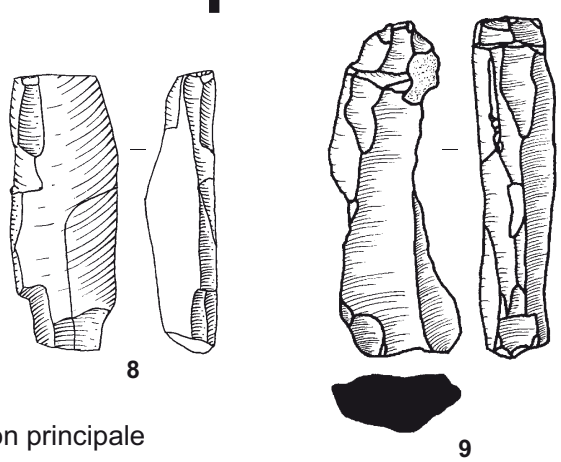

Production principale

typologiquement comparables

mais en partie différents

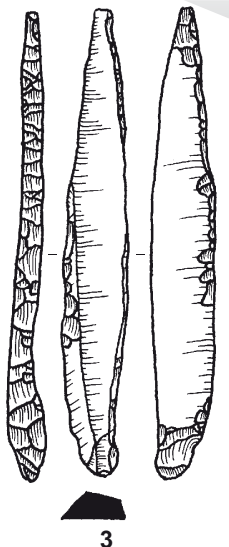

Présence de microgavettes et de pointes de la Gravette

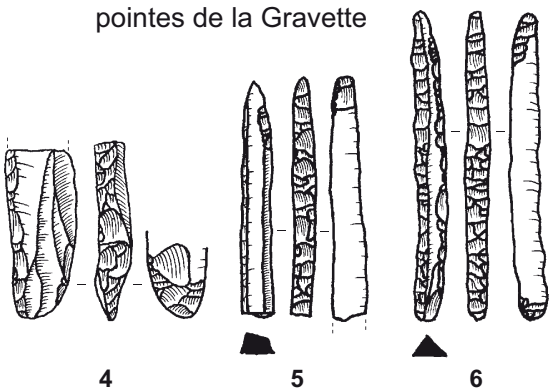

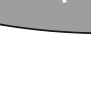

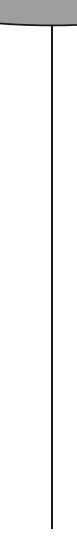

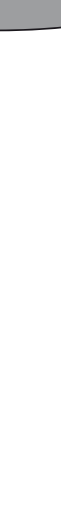

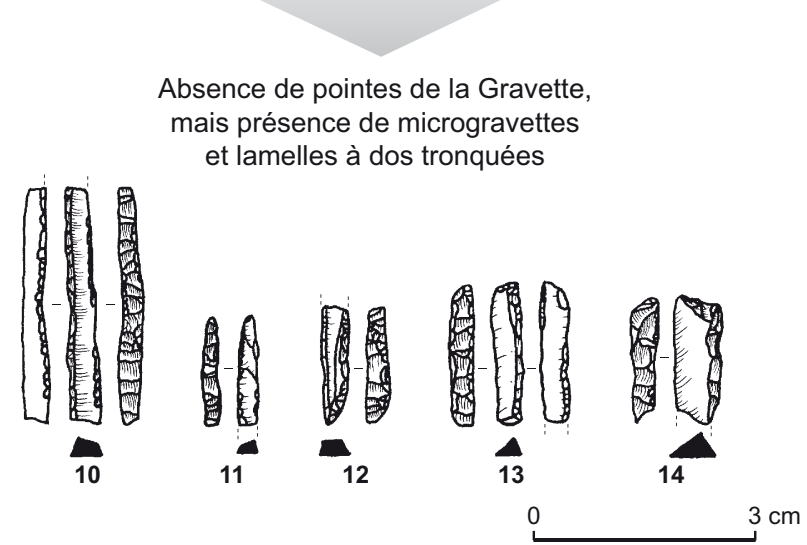

Fig. 9 - Comparaison des méthodes de débitage de lamelles sur le site du Gravettien récent des Peyrugues (C20 et C22) avec une mise en perspective des approvisionnements en matériaux à grain fin (dessins et photographie: P. Guillermin, sauf $n^{\circ} 8$ et DAO: L. Klaric, CNRS). 

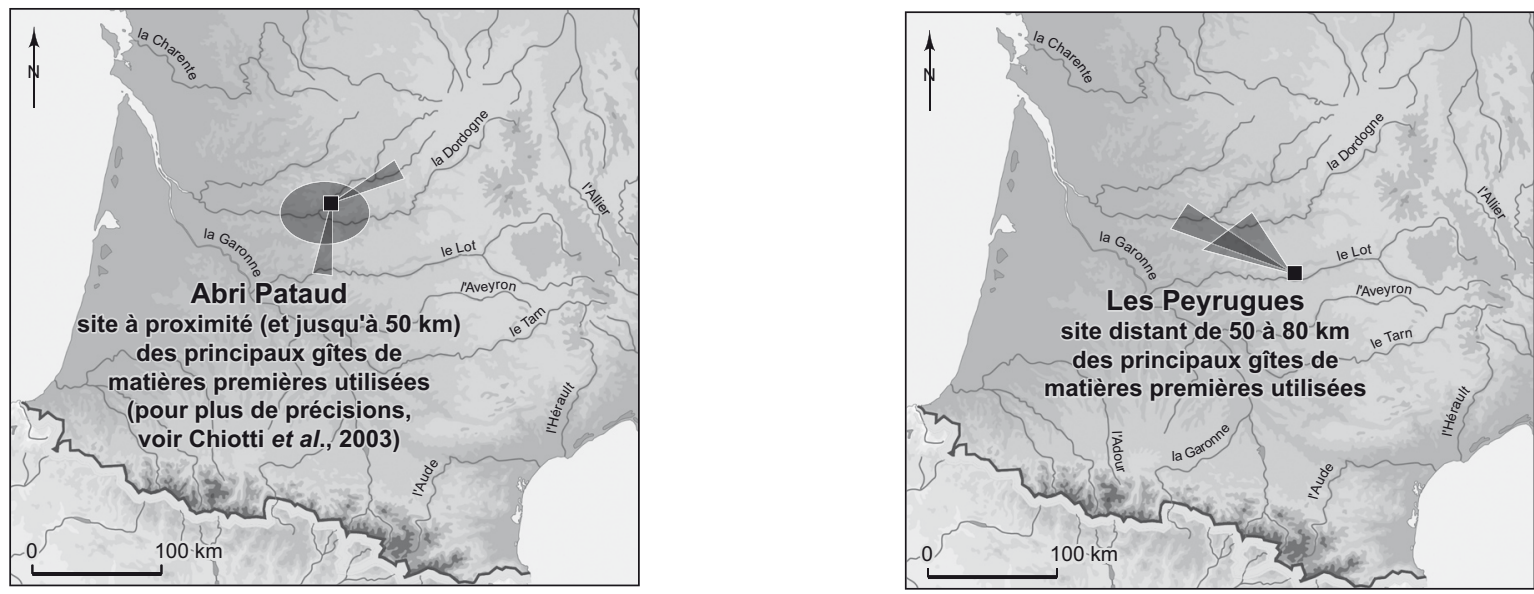

Abri Pataud, couche 2
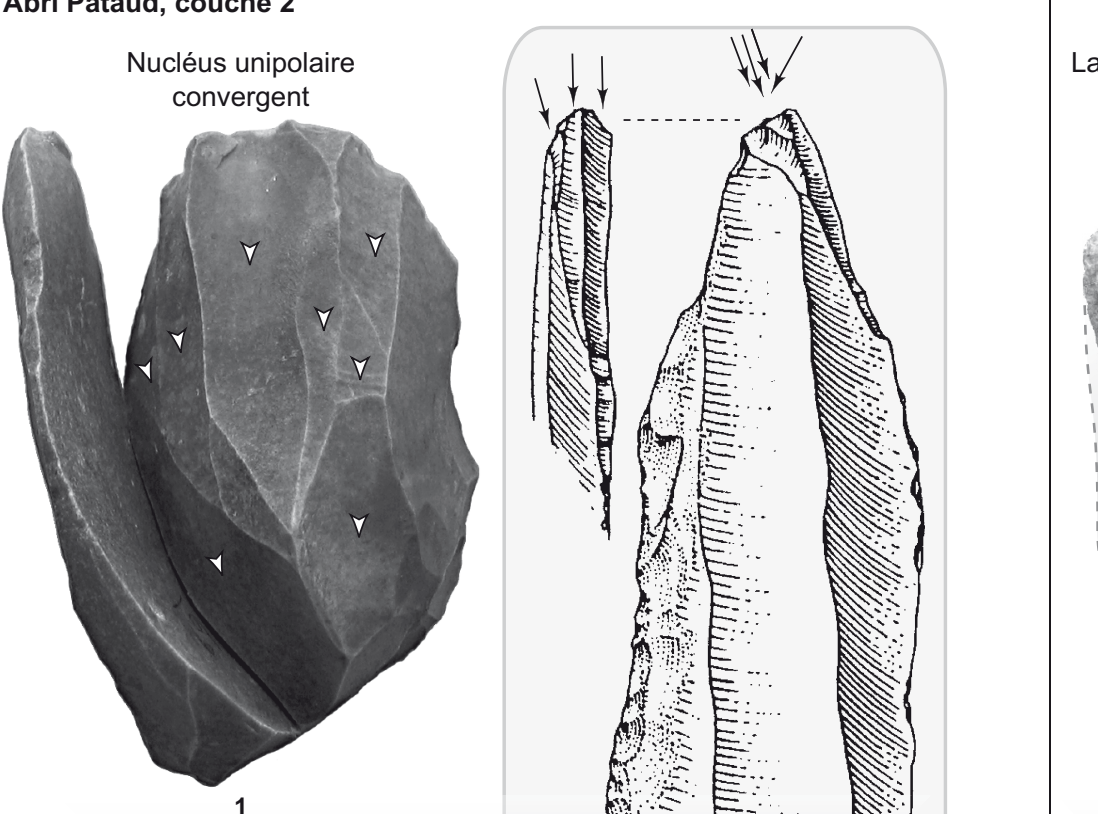

Lamellaire intercalé sur nucléus unipolaire convergent

Les Peyrugues, C18

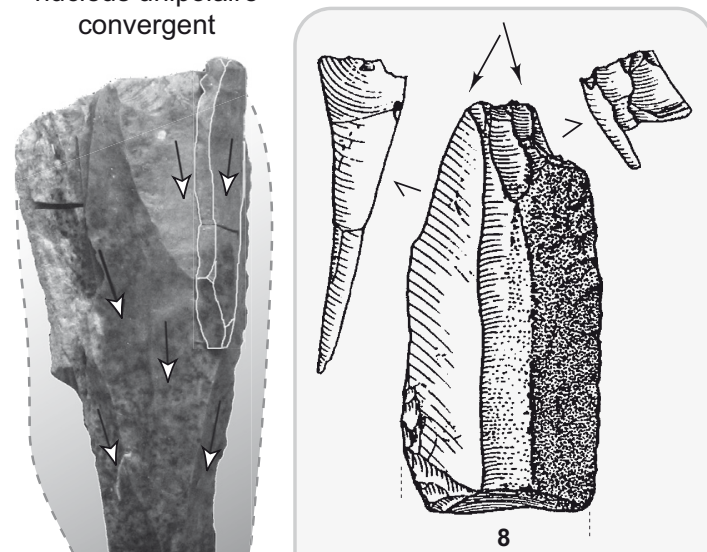

Possible rôle de nucléus à lamelles des burins dièdres ?

7

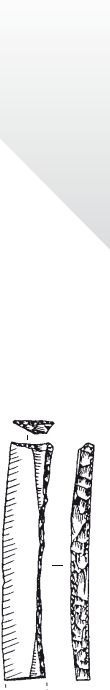

3
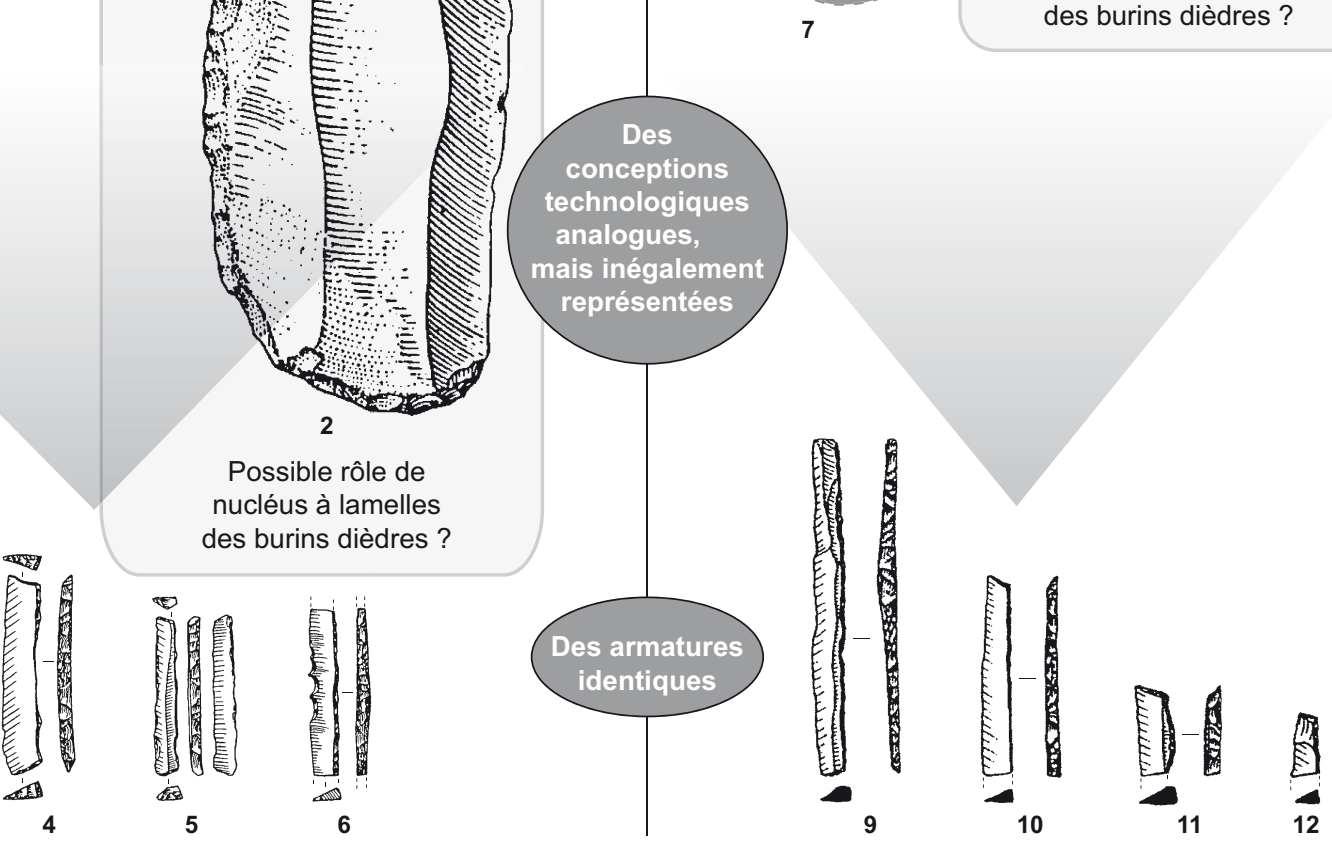
$3 \mathrm{~cm}$

Fig. 10 - Comparaison préliminaire des méthodes de débitage de lamelles sur les sites du Gravettien final de l'abri Pataud (c. 2) et des Peyrugues (C18) avec une mise en perspective des approvisionnements en matériaux à grain fin (photographie: P. Guillermin; dessins n ${ }^{o s}$ 2-6: P. Laurent in Bricker, 1995, p. 74-78; $n^{\text {os }} 8-12$ dessins: M. Jarry et DAO: L. Klaric, CNRS). 
Tabl. II - Tableau quantitatif des origines et des distances des différentes matières premières lithiques identifiées aux Peyrugues, couches C18, C20 et C22 (déterminations André Morala, pour des décomptes précis cf. Guillermin, Morala, à paraître).

\begin{tabular}{|c|c|c|c|c|c|}
\hline \multirow{2}{*}{ Matière première } & \multirow{2}{*}{ Origine } & \multirow{2}{*}{$\begin{array}{l}\text { Distance } \\
\text { site / gîtes }\end{array}$} & \multicolumn{3}{|c|}{$\%$ par couche } \\
\hline & & & C18 & $\mathrm{C2O}$ & C22 \\
\hline Jaspe (1 bloc récolté dans le Lot ou le Célé) & locale, au sud du site & entre 2 et $15 \mathrm{~km}$ & 0 & 0 & 1,7 \\
\hline Jaspéroïdes (« Prox. Brive » ou « Prox. Massif central ») & nord ou est & $60-70 \mathrm{~km}$ ou $40 \mathrm{~km}$ & 0 & 6,1 & 0 \\
\hline Tertiaires locaux & alentours proches & rayon de $15 \mathrm{~km}$ & 0,9 & 53,5 & 15,4 \\
\hline Autres Tertiaires (Figeac) & est & $30 \mathrm{~km}$ & 0 & 26 & 0 \\
\hline Sénoniens & nord-ouest & 50 à $90 \mathrm{~km}$ & 44 & 5,7 & 73,1 \\
\hline Sénoniens « blonds » & nord-ouest & $80 \mathrm{~km}$ & 0 & 0 & 5,3 \\
\hline Sénonien type « Jonzac-Saintes » & nord-ouest & $200 \mathrm{~km}$ & 0 & 0,9 & 0 \\
\hline Bergeracois & nord-ouest & $80-100 \mathrm{~km}$ & 53 & 2,7 & 0,2 \\
\hline Fumelois & ouest & $50-60 \mathrm{~km}$ & 0 & 1,7 & 0,4 \\
\hline Gavaudun & ouest & $50-60 \mathrm{~km}$ & 0 & 1,4 & 0,3 \\
\hline Silex dit « blanc porcelainé » & indéterminée & - & 0 & 0 & 1,3 \\
\hline Jurassiques & alentours proches & rayon de $15 \mathrm{~km}$ & 0 & 0,1 & 0 \\
\hline Indéterminée & - & - & 2,1 & 1,9 & 2,3 \\
\hline & & Total & 100 & 100 & 100 \\
\hline
\end{tabular}

succession stratigraphique de ces ensembles permet alors d'émettre une constatation à caractère «évolutif»: si l'on observe les différentes armatures de ces ensembles (C22, C20 et C18), il semble que la disparition "progressive» (et finalement totale en C18) des pointes sur support laminaire peut être perçue comme un phénomène «d'abandon" du concept de Gravette (Guillermin, 2006a; Guillermin et Morala, à paraître). Cet «abandon" s'opérerait alors au profit de l'émergence d'autres microlithes plus variés au sein desquels les lamelles à dos tronquées connaîtraient finalement un vif succès (surtout durant le Gravettien final, cf. infra, p. 138-139).

\section{LA QUESTION DE LA FONCTION DES OCCUPATIONS DE C20 ET C22}

Nous constatons une nette prédominance des armatures au sein de ces ensembles: elles représentent $86,4 \%$ de l'outillage de C20 (pour 147 outils) et 71,6\% de l'outillage de C22 (pour 232 outils). Par ailleurs, plusieurs fractures d'impact sont bien présentes sur ces éléments, particulièrement en C22 sur les pointes sur lames. Les fractures d'impact sur les plus petits microlithes (que l'on suppose emmanchés latéralement) sont, quant à elles, moins aisément caractérisables. L'association de ces caractères plaide donc plutôt en faveur d'occupations à vocation essentiellement cynégétique (il faut tout de même émettre quelques réserves quant à cette interprétation, étant donné que seule une petite partie de l'abri a été explorée pour ces niveaux). En outre, les résultats obtenus sur les restes de poissons permettent d'envisager une occupation saisonnière du site durant la bonne saison, aussi bien en C22 qu'en C20 (Le Gall, 2005, p. 271). Ainsi, ce genre de déplacements saisonniers en vu de la chasse et de la pêche constitue probablement une des motivations principales poussant les Gravettiens à venir s'installer aux Peyrugues au fil des siècles. Les conditions environnementales (approvisionnement en matière première locale et saison d'occupation) et la nature des activités identifiées sur le site (chasse et pêche) étant visiblement similaires entre C22 et C20, les différences de gestion technoéconomique des matériaux semblent donc plutôt revêtir pour nous une signification d'ordre chronologique. Ainsi, chaque couche correspondrait à un moment d'occupation bien distinct au sein du Gravettien récent. L'une et l'autre posséderaient donc un «fond commun» technologique fort, nuancé par plusieurs particularités relevant de la gestion des matières premières et des types de pointes de chasse lithiques.

\section{LES COMPORTEMENTS D'APPROVISIONNEMENTS}

\section{(TABL. II)}

Si nous supposons une même accessibilité/disponibilité des matériaux durant les occupations des ensembles C22 et C20, des choix très différents apparaissent en termes de stratégie technoéconomique (Guillermin, 2006a; Guillermin et Morala, à paraître). En C22, le cortège des matières premières identifiées est largement dominé par 
les silex sénoniens du nord du Bassin aquitain, dont les gîtes se trouvent au minimum entre $50 \mathrm{~km}$ et $80 \mathrm{~km}$ du site. En revanche, les ressources locales ne sont que faiblement représentées. À l'inverse, l'ensemble C20 compte pour moitié des silex tertiaires locaux sous forme de galets provenant des alluvions du Célé alors que divers matériaux (au sein desquels les silex sénoniens du nord du Bassin aquitain occupent des places intrinsèquement équivalentes) constituent, à part égale, l'autre moitié des vestiges lithiques. En dehors des matériaux communément exploités dans les deux ensembles, d'autres demeurent spécifiques à chacun. Le silex dit «blanc porcelainé», par exemple, n'est présent qu'en C22. Ce matériau, observé dans les ensembles à burins du Raysse du sud-ouest de la France (Rigaud, 1982; Lucas, 2000 ; Pottier, 2005; Morala, étude en cours), est représenté aux Peyrugues par quelques éléments. En parallèle, l'ensemble C20 témoigne de l'exploitation de quatre variétés de silex jaspéroïdes, totalement absentes de l'ensemble C22. Ces silex proviennent vraisemblablement de formations situées en marge du Quercy, soit proches du Bassin de Brive (à une distance de $50 \mathrm{~km}$ à $70 \mathrm{~km}$ environ au nord) soit des contreforts du Massif central (soit à environ $40 \mathrm{~km}$ à l'est) (Chalard et al., 2006; Guillermin, Morala, à paraître). Un dernier type de matériau, de provenance plus lointaine (200 km), est également spécifique à l'ensemble C20: il s'agit d'un silex sénonien microbréchique originaire du sud de la Charente maritime (type «Jonzac-Saintes»), plus communément appelé «grain-de-mil» (Simonnet, 1999; Bordes et al., 2005). Ainsi, les comportements d'approvisionnement des occupants des deux couches apparaissent sensiblement différents. Celui de C20 présente un caractère plus rayonnant avec une exploitation beaucoup plus marquée des ressources locales. À l'inverse, les matériaux utilisés en C22 sont nettement plus orientés qualitativement et quantitativement vers le Périgord.

\section{LA FRAGMENTATION DES CHAÎNES OPÉRATOIRES : UN RÉVÉLATEUR DES DIFFÉRENCES COMPORTEMENTALES?}

Outre les provenances et les proportions variables des matériaux siliceux, des différences au sein des stratégies technoéconomiques sont également perceptibles à travers le fractionnement des chaînes opératoires. En effet, les occupants de C22 ont transporté des blocs parfois très corticaux qui ont été mis en forme et débités sur le site. Cette exploitation a permis la récupération sur place de produits de second choix et de sous-produits de la produc- tion de supports d'armatures, pour la confection d'outils à usage domestique (grattoirs, burins, perçoirs, etc.). La matière, transportée sous cette forme, était donc susceptible de fournir une grande variété de supports en réponse aux différents besoins du groupe au cours de ses déplacements. Ainsi, malgré le caractère spécialisé (vers la chasse et la pêche) du ou des épisodes d'occupation, une anticipation «élargie» à d'autres types de besoins est perceptible en C22. Un comportement analogue, mais nettement plus marqué, a été observé pour l'ensemble de la couche $\mathrm{E}$ du gisement des Fieux (Miers, Lot) (Guillermin, 2004 et 2006b; Chalard et al., 2006) ${ }^{8}$.

Il en est tout autrement en C20. Pour cette occupation (ou ces épisodes d'occupation), l'anticipation des besoins en armatures se manifeste par l'apport de «burinsnucléus» (sur différents matériaux) en cours d'exploitation. Aux supports de microlithes obtenus sur «burinnucléus" s'ajoutent ceux provenant de l'exploitation des galets tertiaires locaux, révélant ainsi le caractère partiel de cette anticipation. Cependant, cette production sur petits blocs locaux alimente en majorité (15 pièces sur 21) l'outillage à usage domestique de l'ensemble. À l'exception d'une pièce, les supports des autres outils à usage domestique issus de matériaux allochtones ne semblent pas avoir été produits sur place. Ces outils ont donc été apportés déjà transformés ${ }^{9}$ sur le site. Ainsi, en C20, les matériaux lithiques allochtones ont été transportés sous forme d'objets répondant à des besoins plus spécifiques (des outils et des «burins-nucléus»). Le fractionnement des séquences est donc déjà beaucoup plus orienté vers des objectifs précis et une part non négligeable des besoins (reliés aux activités domestiques) est laissée à l'exploitation sur place de galets tertiaires. En comparaison avec l'ensemble C22, l'ensemble C20 montre donc une anticipation à la fois plus précise et plus partielle, illustrant vraisemblablement des choix différents dans la manière d'organiser cette expédition/ mobilité (Guillermin, 2006a et b; Guillermin et Morala, à paraître).

8. La différence entre l'ensemble CE des Fieux et l'ensemble C22 des Peyrugues est la suivante: en C22, le besoin en armatures est, en grande majorité, anticipé par l'apport de matières allochtones alors que, aux Fieux, ce sont les matériaux locaux qui sont également fortement mis à contribution dans la production d'armatures utilisées sur place.

9. Ils sont accompagnés de quelques lames légères brutes qui ont vraisemblablement été utilisées; nous manquons malheureusement d'une expertise tracéologique pour confirmer cette supposition. 


\section{DE L'EXISTENCE DE DEUX SOUS-PHASES AU SEIN DU GRAVETTIEN RÉGENT}

Nous avons vu que deux des facteurs de variabilité qui affectent habituellement les ensembles lithiques (fonction du site, disponibilité des matières premières) sont à peu près identiques d'une couche à l'autre. Pourtant, les ensembles C22 et C20, tous deux attribués au Gravettien récent, témoignent de différences plus ou moins prononcées à tous les niveaux de la stratégie d'exploitation des ressources siliceuses (objectifs des productions, fragmentation des chaînes opératoires, recours aux matériaux locaux en appoint ou recours à une importation allochtone massive). Les variations touchant aux armatures s'avèrent particulièrement marquantes, surtout avec la quasi-disparition des pointes de la Gravette en C20 alors qu'émergent, en même temps, d'autres microlithes plus variés (les lamelles à dos tronquées, cf. fig. 9, $\mathrm{n}^{\text {os }} 13-14$ ). Dans ce contexte, et vu la nette séparation stratigraphique des deux ensembles, ces différences révèlent donc, peut-être, de véritables choix, indices d'une évolution culturelle et/ou technique. Les données des Peyrugues appuieraient alors concrètement l'hypothèse de l'existence de deux phases distinctes au sein du Gravettien récent. La première phase pourrait alors être caractérisée par l'emploi de véritables Gravettes (pointes de sagaies lithiques axiales) alors que, dans la seconde, ces pièces seraient sur le déclin et remplacées par une gamme plus variée de microlithes indiquant des transformations dans l'équipement de chasse (montages composites et/ou axiaux?). Cependant, s'il paraît logique de penser que ces deux sous-phases correspondent vraisemblablement à l'évolution de groupes apparentés dans le temps, il est encore hasardeux de statuer sur les mécanismes évolutifs menant de l'une à l'autre.

\section{CONCLUSION}

En poursuivant l'exploration de l'impact des trois facteurs de variabilité évoqués (contextes d'approvisionnement, fonction du site et écart chronologique des occupations), nous avons constaté que, pour le Gravettien récent, ils n'impliquent pas nécessairement des influences du même ordre sur les systèmes techniques de production de supports d'armatures. Concernant le Gravettien moyen et le Gravettien récent, le manque de matière première à grain fin semble se répercuter très faiblement sur le système technique, tout au moins dans un contexte d'occupation de courte durée. Ainsi, la durée de l'occupation (simple halte, halte prolongée ou occupation longue) pourrait apparaître comme un autre facteur déterminant dans le recours (ou l'absence de recours) à des matériaux locaux de qualité inférieure. Ce facteur a, bien sûr, des répercussions en amont et en aval des choix technoéconomiques des groupes préhistoriques; il peut ainsi conditionner une part notable de la variabilité des systèmes techniques. En outre, le Gravettien récent, dont l'amplitude chronologique correspondrait plus ou moins à un intervalle minimal de deux à trois millénaires radiocarbone, illustre la complexité d'appréhender l'échelle des temps préhistoriques en termes d'évolution culturelle fine. Ainsi l'écart chronologique existant entre les différents sites d'une même "phase" est sans doute un élément encore sous-estimé. Le cas des Peyrugues démontre clairement l'existence d'un phénomène complexe déjà pressenti sur d'autres sites: l'existence d'une évolution diachronique qui pourrait, en partie, expliquer la variabilité des assemblages du Gravettien récent. En revanche, il semble encore très délicat de se prononcer sur la valeur à accorder aux analogies à grandes distances. En effet, des cas de convergences clairement identifiés au sein du Gravettien à l'échelle de l'Europe (Klaric et al., en préparation) ne peuvent qu'inciter à la prudence. Si parfois ces analogies semblent relever d'une véritable parenté technique ( $c f$. le Blot et Mainz-Linsenberg), dans d'autres cas (Vale dos Covões et le Blot) cette possibilité reste très incertaine, compte tenu des réserves évoquées.

\section{DES SOLUTIONS TECHNIQUES DIVERSIFIÉES POUR DES OBJECTIFS ANALOGUES: QUELLE UNITÉ POUR LE GRAVETTIEN FINAL OCCIDENTAL?}

En France, à la fin de la séquence gravettienne, on rencontre un ensemble d'industries regroupées sous le terme de «Protomagdalénien» (Peyrony, 1938; Movius, 1958; Bordes, Sonneville-Bordes, 1966; Clay, 1968; Bordes, 1978; Bosselin, 1991 et 1992; Surmely, Alix, 2005). Si, de nos jours, il est bien établi que ces industries n'annoncent, en aucun cas, les prémices du Magdalénien, le vocable de «Protomagdalénien » n'a jamais été abandonné (essentiellement pour des raisons historiographiques et de commodité). Cependant, l'expression «Gravettien final» (plus neutre) paraît plus adéquate pour qualifier ces industries contemporaines des débuts du Pléniglaciaire. 


\section{APRÈS LE SUCGÈS DE LA MICROGRAVETTE, L'ÉMERGENCE DES LAMELLES À DOS TRONQUÉES DU «PROTOMAGDALÉNIEN »: UN INDICE DES TRANSFORMATIONS DE L'ÉQUIPEMENT CYNÉGÉTIQUE GRAVETTIEN}

Si le concept de «microgravette» semble avoir «fait école» à une large échelle durant le Gravettien récent, il tend néanmoins à disparaître presque complètement dans les ensembles du Gravettien final en France. Il faut tout juste signaler quelques rares exemplaires du type dans certains ensembles comme à Pataud ou au Blot (Bosselin, 1997, p. 92; Guillermin, thèse en cours). Ces microlithes disparaissent donc quasiment et, de manière concomitante, émerge un autre type d'armature: la lamelle à dos tronquée ou bitronquée ${ }^{10}$ (fig. 10, nos $3-6$ et 9-12). Sur les quatre principaux sites connus (Pataud, les Peyrugues, Laugerie-Haute et le Blot) un seul (le Blot) fait pourtant figure d'exception puisque les indices de microgravettes et de lamelles à dos tronquées y sont relativement voisins ${ }^{11}$ (entre 1 et $10 \%$ selon les ensembles stratigraphiques considérés) (Bosselin, 1997). Néanmoins, dans les trois autres gisements, il semble que les lamelles à dos tronquées constituent le seul type dominant. Si ces microlithes ne sont pas particulièrement bien représentés dans la plupart des ensembles du Gravettien récent que nous avons examinés (Cirque de la Patrie, Blot et MainzLinsenberg), il faut cependant signaler leur abondance relative dans l'ensemble C20 des Peyrugues (environ $40 \%$ des armatures $c f$. fig. 9, $\mathrm{n}^{\text {os }} 13$-14) et également dans la série lithique de la couche $\mathrm{E}$ des Fieux attribuée à une phase évoluée du Gravettien moyen (Guillermin, 2004 et 2006b). En outre, ces microlithes sont également connus dans une phase encore plus ancienne: le Noaillien (à Brassempouy notamment, cf. fig. 3, nos 5-6). Durant le Gravettien final, le succès de ces microlithes semble tel qu'on les retrouve sur un vaste territoire à l'échelle de l'Europe du sud-ouest. Ainsi au Portugal, des microlithes tronqués et bitronqués

10. Un problème d'identification se pose entre pièces tronquées et bitronquées. En effet, dans le cas de pièces fragmentées où seule l'une des extrémités est conservée, il est impossible de savoir quelle est la nature de l'extrémité manquante. Ainsi, il se peut que, dans ces assemblages, quelques exemplaires de lamelles à dos tronquées et pointues puissent exister (comme l'attestent quelques rares exemplaires identifiés à l'abri Pataud notamment). En outre, on peut aussi se demander si certaines de ces pièces n'ont pas été intentionnellement cassées, une simple fracture remplaçant alors une troncature classique.

11. On peut néanmoins suspecter l'existence de contaminations entre les ensembles du Protomagdalénien et du Gravettien récent sousjacents, ce qui soulève un doute sur la validité de l'association des microgravettes et du reste de l'industrie (Buisson 1991; Klaric, 1999). ont été identifiés dans certains sites de la vallée du Côa (Cardina 1 et Olga Grande 4), de l'Estremadura (Cabeço do Porto Marinho II et Terra do Manual 1940-1942, entre autres, cf. fig. 11, $\mathrm{n}^{\text {os }} 3-5,8-9$ et 19,21$)$ et aussi du massif du Sicó (Aubry et al., 2001, p. 39). Comme sur les sites français, les véritables microgravettes sont pratiquement absentes de ces gisements (voir cependant les exemplaires de Cabeço do Porto Marinho, fig. 11, $\mathrm{n}^{\mathrm{o}} 10$ et de Cardina 1, fig. 11, $\left.\mathrm{n}^{\text {os }} 18-20\right)$.

La quasi-disparition des microgravettes et la généralisation de ces lamelles à dos tronquées et bitronquées suggèrent indubitablement des transformations dans la conception des armes de chasse entre Gravettien récent et Gravettien final. Si les pointes de la Gravette et les microgravettes peuvent correspondre à des emmanchements axiaux (et peut-être parfois latéraux pour les microgravettes) (Cattelain et Perpère, 1993 et 1996; Soriano, 1998; etc.), les microlithes à dos tronqués (non perforants) évoquent nécessairement des montages composites strictement latéraux sur des pointes ${ }^{12}$ en matériaux périssables (bois de cervidé ou bois végétal). Or, comme les modalités de production des supports des Gravettes, microgravettes et lamelles à dos peuvent varier d'un site à l'autre à l'intérieur même du Gravettien récent (cf. supra, p. 126-131), il faut aussi s'interroger sur d'éventuelles variations du même ordre au sein du Gravettien final. Si, pour la confection des microgravettes et des lamelles à dos, la rectitude et la régularité du support constituaient deux exigences majeures des tailleurs, qu'en est-il pour les lamelles à dos tronquées? Le succès et la diffusion du concept de ces microlithes à large échelle s'est-il aussi accompagné d'une «homogénéisation » des méthodes de production des supports? Enfin, en quoi la disponibilité des matières premières a-t-elle pu affecter les systèmes techniques de production des supports de ces armatures?

\section{EN FRANGE: PREMIERS RÉSULTATS DE L'ÉTUDE DES ENSEMBLES DE PATAUD (C2) ET DES PEYRUGUES (C18)}

En France, à partir des observations menées sur les séries du Gravettien final de l'abri Pataud (C2) et des Peyrugues (C18), plusieurs résultats préliminaires peuvent être énoncés (puisqu'il s'agit d'un travail en cours d'étude,

12. Il est cependant impossible d'exclure l'hypothèse qu'une partie de ces pièces ait, aussi, pu servir emmanchées comme couteaux. 

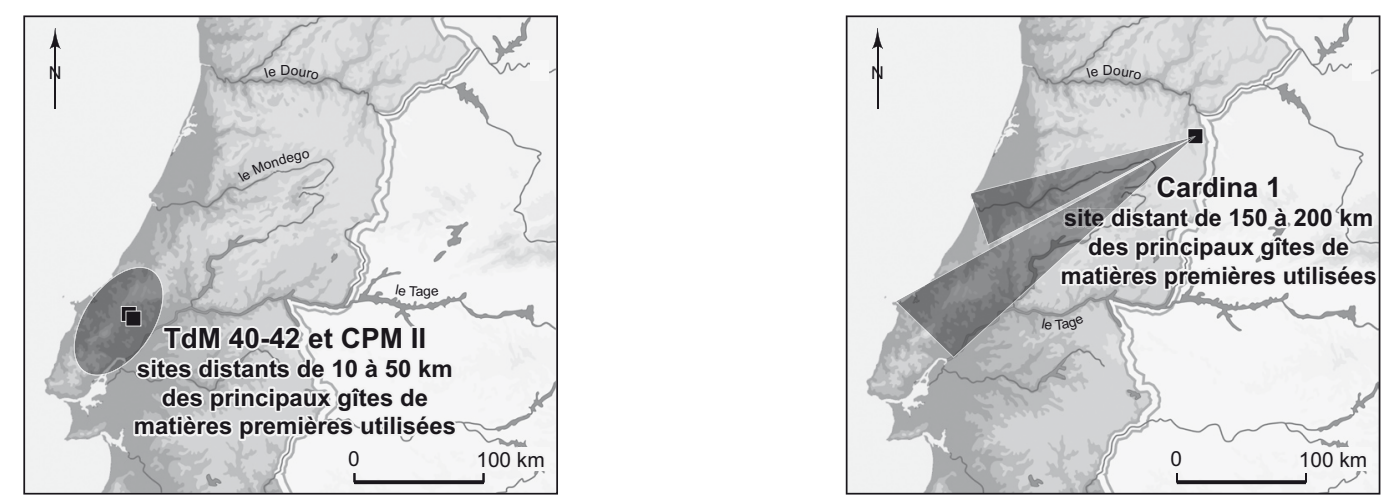

Terra do Manual 1940-1942
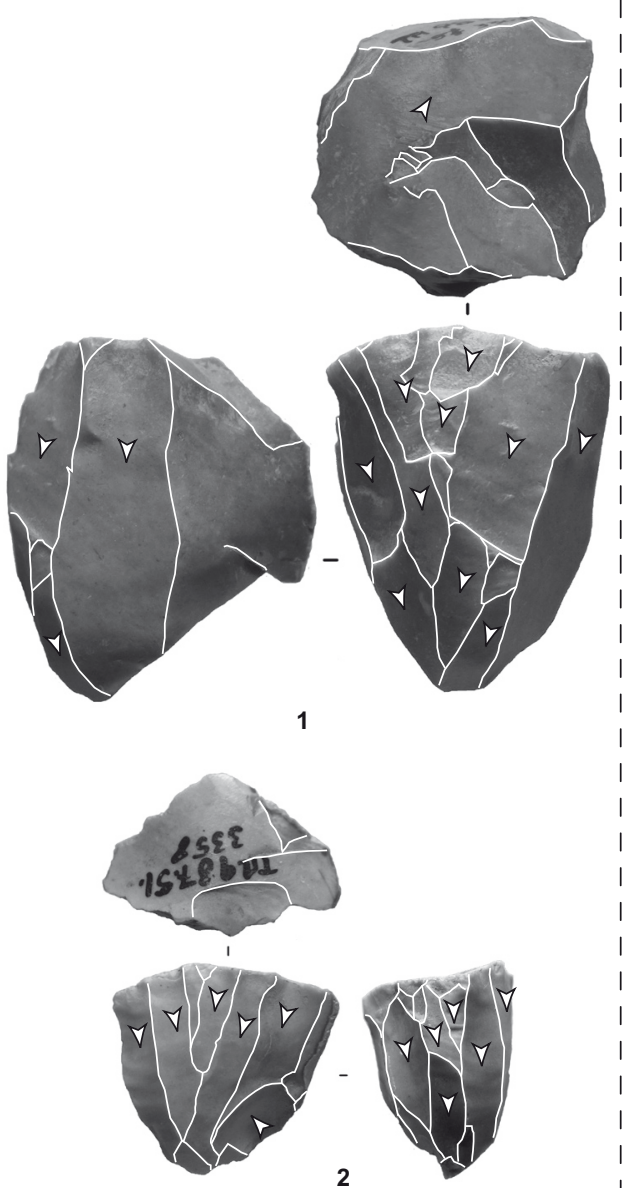

\section{Cabeço do Porto Marinho II}
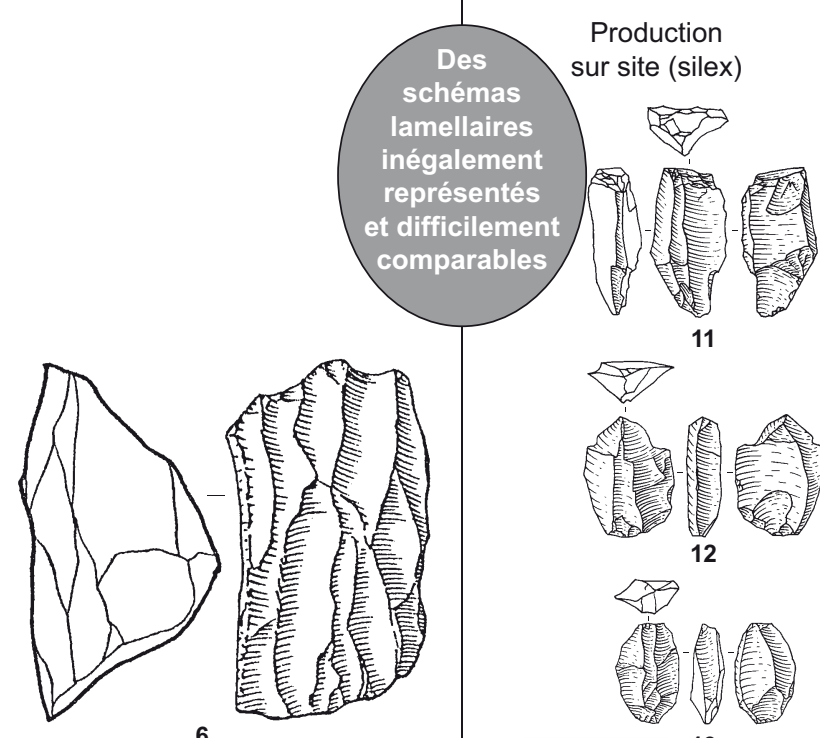

6
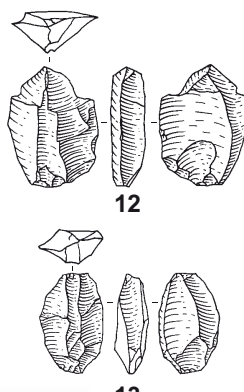

13

Cardina 1

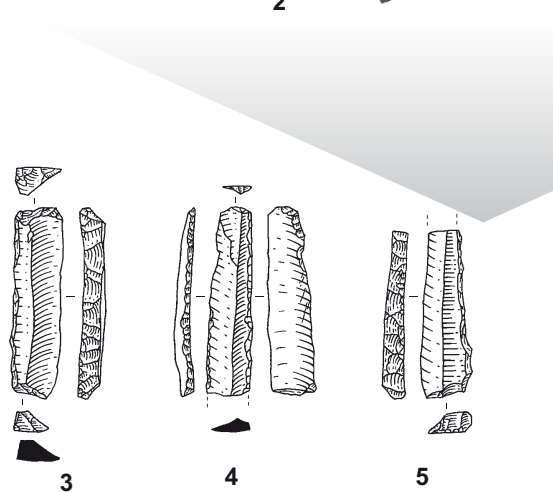

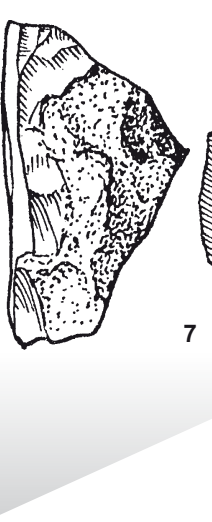

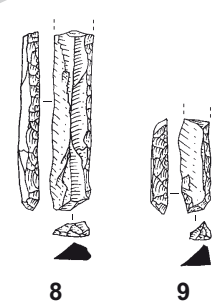

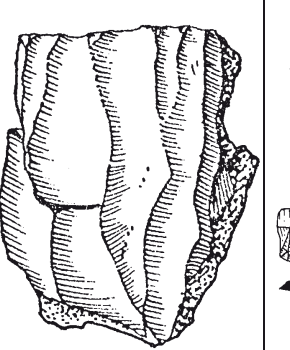

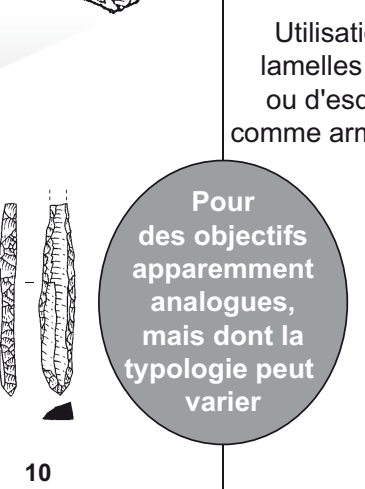

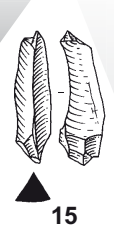

4 资

17
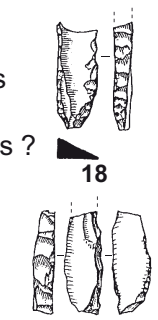

20
Production hors site (silex)

Importation de supports bruts et/ou de microlithes déjà finis?
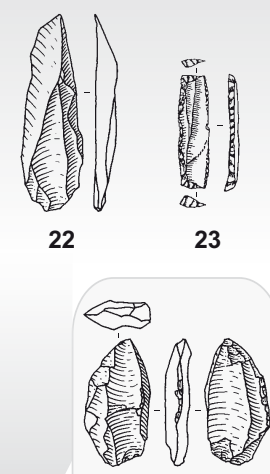

24
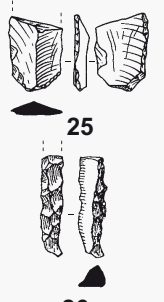

26

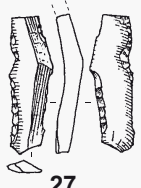

Cristal de roche (prob. local)

Fig. 11 - Comparaison préliminaire des méthodes de débitage de lamelles sur les sites du Gravettien final du Portugal, Terra do Manual 1940-1942, Cabeço do Porto Marinho II et Cardina 1, avec une mise en perspective des approvisionnements en matériaux à grain fin (dessins, photographies et DAO: L. Klaric, CNRS, sauf dessins n $n^{o s}$ 6-7, 18-21, 23, 26: T. Aubry). 
ces résultats demanderont nécessairement à être complétés et nuancés; voir Guillermin, thèse en cours).

\section{L'ABANDON DES CONCEPTS «FORTS » DU GRAVETTIEN}

Tout d'abord, il semble que sur ces deux sites, la quasiabsence, voire l'absence, de pointes et micropointes de la Gravette (aux Peyrugues) s'accompagne de l'abandon du schéma laminaire dit «classique» du Gravettien récent, caractérisé par l'exploitation de nucléus au cintre resserré à partir de deux plans de frappe hiérarchisés. Pour produire les supports des lamelles à dos tronquées, les groupes du Gravettien final ont privilégié un débitage laminaire unipolaire convergent de petit module (entre $5 \mathrm{~cm}$ et $7 \mathrm{~cm}$ de longueur) (fig. 10, n ${ }^{\circ} 1$ ). Il s'agit d'un schéma qui vise à exploiter un volume au cintre étalé et arrondi avec un recul frontal, en alternant l'extraction de lames de flanc (convergeant vers une base au cintre plus resserré) et de petites lames très régulières et rectilignes ${ }^{13}$ (en partie centrale de table laminaire). Ce type d'exploitation n'est pourtant pas propre au Gravettien final puisqu'il a déjà été observé dans d'autres ensembles gravettiens plus anciens, mais avec d'autres particularités (Guillermin, 2003, 2004 et 2006b; Pesesse 2003 et 2006, p. 471-473). Les caractères recherchés pour les supports sont la minceur et la régularité d'un bord, le plus souvent laissé brut, qui sera opposé à celui portant le dos. La rectitude est nettement favorisée, mais elle n'est ni stricte, ni systématique. De plus, contrairement aux pointes et micropointes de la Gravette, le support n'est pas produit pour être utilisé entier mais segmenté; ainsi, les critères recherchés (régularité, rectitude et minceur) ne concernent pas systématiquement l'intégralité du support. Sur ce point-là, le Gravettien final français contraste donc nettement avec le Gravettien récent tel qu'il a été caractérisé pour les sites précédemment évoqués. Il semble donc y avoir un abandon des forts concepts typo-technologiques de cette phase précédente. Certes, l'absence du concept de «pointe de la Gravette» et du schéma qui lui est associé a déjà été observée dans d'autres faciès gravettiens ( $c f$. Rayssien), mais ici, cette absence revêt une autre signification puisque l'on s'accorde à reconnaître que le «Protomagdalénien» constitue l'ultime transformation du techno-complexe gravettien. En outre, relevons également l'absence de modalités de production de supports sur des «burins-nucléus» polyédriques analogues à ceux connus dans le Gravettien récent. Nous ne saurions pour autant

13. Tout au moins dans leur partie proximo-mésiale. éluder l'évocation des grands burins dièdres sur lames (caractéristiques du «Protomagdalénien») qui témoignent d'une grande "productivité» de chutes de burin, au gabarit lamellaire (fig. 10, $\mathrm{n}^{\text {os }} 2-8$ ). Cette observation permet de poser l'hypothèse (durant le Gravettien final) d'un statut de ces artéfacts équivalent à celui des «burinsnucléus » polyédriques du Gravettien récent. Les premières études menées sur les séries des Peyrugues et de Pataud n'ont cependant pas encore permis de répondre à cette question et nous conserverons ici une certaine prudence en attendant l'approfondissement de notre étude (Guillermin, thèse en cours).

\section{L'OCGUPATION DES PEYRUGUES: UN «RAID» DEPUIS LE PÉRIGORD}

Dans le contexte particulier des Peyrugues, le schéma laminaire unipolaire convergent s'applique à des blocs d'assez grandes dimensions (15 cm environ), où, parallèlement à la production de lames de gabarit important, des petites lames et lamelles sont obtenues de manière intercalée (fig. 10, $\mathrm{n}^{\text {o }}$ 7) (Guillermin, 2006a; Guillermin, Morala, à paraître). Cette modalité s'exprime dans un contexte, où, à l'instar des niveaux précédents, il semble s'agir d'une occupation à vocation essentiellement cynégétique (70\% d'armatures). Contrairement aux cortèges plus variés de matières premières de C20 et C22, les matériaux de C18 sont, à plus de à 96\%, issus du Périgord (tabl. II), se partageant à parts quasi égales entre les silex du Maestrichtien de la région de Bergerac ( $80 \mathrm{~km}$ à $100 \mathrm{~km}$ environ) et du Sénonien du nord du Bassin aquitain (environ $50 \mathrm{~km}$ à $90 \mathrm{~km})$. Les comportements d'approvisionnement de ce groupe du Gravettien final se caractérisent donc par deux points forts: la monotonie des matériaux de bonne qualité utilisés et l'absence totale d'exploitation des ressources locales de qualité inférieure. Ce phénomène indiquerait donc une anticipation totale des besoins depuis le Périgord en vu d'une «incursion en Quercy» dont le motif reste à définir. Celle-ci n'ayant aucun lien avec l'acquisition de ressources siliceuses, nous pouvons postuler qu'elle ait (comme pour C22 et C20) un rapport avec la chasse (et/ou la pêche), activité apparemment dominante aux Peyrugues. Cependant, cette hypothèse ne peut être exclusive, car les vestiges fauniques retrouvés peuvent témoigner de simples activités de subsistance d'un groupe venu pour d'autres raisons (rencontres d'autres groupes, acquisition d'un autre type de ressources, prospections en vu d'un élargissement ou d'un changement de territoire). 
Quoi qu'il en soit, il semble que ce déplacement ait été de courte durée et l'on pourrait donc le qualifier de «raid» (ibid.; Guillermin, Morala, à paraître). Dans ce contexte, les occupants de C18 ont transporté leurs matériaux sous des formes diverses. Le Sénonien a été introduit notamment sous forme de quelques blocs très corticaux, témoignant (au même titre que ce qui a été décrit en C22) d'une anticipation élargie à l'ensemble des besoins du groupe. Ces blocs ont permis de produire sur place des lames de grand gabarit pour alimenter les besoins en outillage domestique, complétant ainsi un apport de lames brutes ou préalablement transformées. Cet apport important, témoigne d'une anticipation "globale» pour des besoins partiellement définis au départ. Cela soulève la question de la connaissance du territoire quercinois par ces Gravettiens du Périgord. La volonté d'anticipation maximale, sinon totale, des besoins, perçue à travers les importations de matières premières de bonne qualité et d'origine lointaine, pourrait être interprétée comme résultant d'une méconnaissance des ressources siliceuses de cette région ou bien comme un choix délibéré découlant d'une connaissance des ressources locales et d'une nette préférence pour d'autres matériaux.

\section{UNE STRATÉGIE TECHNOÉCONOMIQUE PARTICULIÈRE}

Un territoire englobant Périgord et Quercy se dessine alors pour cette période. À l'échelle de ce territoire, le comportement technoéconomique du Gravettien final témoigne d'un système qui repose sur un approvisionnement relativement localisé ne laissant guère de place à l'opportunisme et l'adaptabilité en termes d'exploitation des ressources locales durant les déplacements. Les quelques données résultant des séries du Gravettien final du Blot vont également dans ce sens, au vu de l'origine très éloignée de $99 \%$ des matériaux qui proviennent apparemment d'Indreet-Loire et du Loir-et-Cher, soit au minimum $250 \mathrm{~km}$ de distance (Surmely et Pasty, 2003). Dans ce contexte, où les ensembles présentent par ailleurs un taux d'armatures très élevé, les ressources locales n'ont quasiment pas été exploitées, même pour un outillage domestique. Une hypothèse peut alors être formulée à partir de la documentation disponible: il semble que les territoires de la fin du Gravettien en France ont pu être relativement étendus avec des pôles privilégiés respectifs (Périgord pour Pataud, les Peyrugues et Laugerie; Touraine pour le Blot) pour l'acquisition des ressources siliceuses. Les incursions réalisées en dehors de ce(s) pôle(s) seraient assorties d'une anticipation totale des besoins, témoignant, à première vue, de la volonté de maintenir une certaine stabilité du système technique face à des conditions environnementales susceptibles de fluctuer au gré des territoires parcourus.

\section{AU PORTUGAL: DIVERSITÉ ET ANALOGIES DES INDUSTRIES DU GRAVETTIEN FINAL, DEUX FACETTES D'UNE MÊME ENTITÉ?}

$\mathrm{Au}$ Portugal, le Gravettien final est surtout connu en Estremadura, mais aussi, de façon plus marginale, dans le massif du Sicó et, plus au Nord, dans la vallée du Côa. Dans ces régions, la meilleure conservation des niveaux d'occupation du Gravettien final est en relation directe avec une augmentation du taux de sédimentation et la position chronologique de ces niveaux postérieurement à la phase érosive majeure 26/27000 BP du Paléolithique supérieur ancien (Aubry et al., 2008; Angelucci, 2002; Zilhão, Almeida, 2002). Si ces industries sont toutes rattachées à la fin du Gravettien (Zilhão, 1997; Aubry, Fontugne, Moura, 1997; Aubry, 2001; Almeida, 2000), les rapprochements ont surtout été effectués sur la base de la présence de microlithes tronqués et bitronqués (fig. 11, $\mathrm{n}^{\text {os }}$ 3-5, 8-9 et 19-21) et des fourchettes de dates par thermoluminescence et radiocarbone (entre 22000 et 20000 BP). Seules l'Estremadura et la vallée du Côa peuvent nous renseigner de manière globale sur les systèmes techniques de production de supports d'armatures (les séries du massif du Sicó s'avèrent, pour l'instant, trop pauvres quantitativement pour permettre des reconstitutions et des comparaisons à large échelle). L'intérêt de ces deux régions est d'offrir des contextes d'approvisionnement en matériaux radicalement différents puisque la première (Estremadura) compte de nombreuses sources de matières premières à grain fin alors que la seconde (vallée du Côa) n'en présente aucune (à l'exception du cristal de roche et des silicifications thermales à grain fin, très localisées et disponibles sous forme de petits volumes ${ }^{14}$ ). On peut donc s'interroger sur les variations des systèmes techniques de production de supports de microlithes dans chacun de ces contextes. Par ailleurs, les premières études réalisées pour la vallée du Côa (Aubry, 2002; Aubry et al., 2002; Aubry, Mangado-Llach, 2003), ont montré, pour le Gravettien final (et pour d'autres phases comme le Solutréen et le Magdalénien), l'existence d'importation de silex des régions du massif du Sicó, de l'Estremadura et du centre de la Meseta. La présence systématique, mais en très faible

14. Cependant ces silicifications thermales n'ont pas été exploitées par les groupes gravettiens (à l'inverse du cristal de roche). 
quantité, de ces matériaux soulève plusieurs questions, et ouvre la voie à plusieurs interprétations, notamment celle de groupes à «forte mobilité » comme cela a pu être proposé pour le Gravettien d'Europe du nord et d'Europe centrale (Féblot-Augustins, 1997 et 1999; Floss, 2000). Mais qu'en est-il réellement lorsque l'on se penche sur les systèmes techniques de production de supports de microlithes et sur ce que nous savons des comportements d'approvisionnement dans la vallée du Côa?

\section{LE Site de CARdina 1 (VAlléE dU CôA)}

Si l'accès aux matériaux à grain fin ne pose pas de problème en Estremadura, il n'en va pas de même dans la vallée du Côa et ses environs puisque cette région ne compte pas de source de silex exploitable par les hommes préhistoriques. D'autres matériaux lithiques sont en revanche présents (essentiellement des quartz, quartzites et cristaux de roche) et ont été intensément exploités par les hommes préhistoriques (Aubry et al., 2002; Aubry, Mangado-Llach, 2003). À côté de ces matériaux locaux (plus de $97 \%$ des matériaux présents à Cardina 1), de petites quantités de silex allochtones ont aussi été retrouvées (moins de $3 \%$ ). Ainsi, les deux niveaux de Gravettien final du site de Cardina 1 présentent un lot de microlithes retouchés où les silex (provenant du massif du Sicó et d'Estremadura à respectivement $150 \mathrm{~km}$ et $250 \mathrm{~km}$ ) sont majoritairement (près de $80 \%$ du corpus) utilisés pour la confection de pièces à dos et lamelles à retouches marginales (fig. 11, $\mathrm{n}^{\text {os }} 18$-21). Le cristal de roche, plus minoritaire (20\% du corpus), est surtout dévolu à la confection de lamelles à retouches marginales (fig. 11, $n^{\text {os }}$ 25-27). Quel que soit le matériau utilisé, les armatures présentent, en général, une importante variabilité morphologique et typologique qui rend difficile le classement en types bien individualisés. On peut néanmoins observer que les armatures à dos abrupt ou semi-abrupt représentent près de $50 \%$ de l'ensemble, alors que les armatures à retouches marginales, elles, n'en constituent que $37 \%$ environ (le reste, soit $13 \%$, correspond à des pièces, certes retouchées, mais dont nous ne sommes pas certains qu'il s'agisse bien d'armatures). D'un point de vue typologique, ce sont les lamelles à dos simples/fragments de lamelles à dos sans précision (38\%) et les lamelles à dos tronquées (12\%) qui dominent. Les lamelles à retouches marginales $(37 \%)$ constituent la catégorie qui regroupe la plus grande variabilité avec des pièces présentant des retouches directes, inverses, alternes et/ou partielles. Aucun type caractéristique ne se dégage vraiment de ce groupe hétérogène.
La production de supports en silex identifiée sur le site correspond à une centaine de petits nucléus de type «pièce esquillée» (Aubry et al., 1997) (fig. 11, nos 11-13). Tous, sans exception, ont été débités selon un schéma «bipolaire sur enclume». Cette méthode permet une exploitation très poussée de petits fragments de matériaux à grain fin (ici des lames, des éclats ou d'anciens outils). Les objectifs de cette production sont franchement micro-lamellaires (fig. 11, $\mathrm{n}^{\text {os }} 14-15$ et 17 ), les nucléus abandonnés en portent d'ailleurs fréquemment les négatifs caractéristiques. De telles morphologies n'ont pu être obtenues qu'au prix d'une gestion soignée du débitage. Produire de véritables lamelles de manière récurrente avec cette méthode a nécessité une configuration particulière du volume mettant en jeu une extrémité triédrique destinée à être posée sur l'enclume (fig. 11, no 12, partie supérieure). Cette extrémité opposée à un plan de percussion robuste (une troncature ou un plan fracture) a permis de détacher des lamelles par contrecoup le long des nervures du trièdre. Pour maintenir une bonne convexité, renforcer les nervures et faciliter le détachement des lamelles, les tailleurs ont aussi fréquemment eu recours à de menus aménagements de crête latéraux (et parfois aussi à des inversions de plan de frappe). Lors d'une reconstitution expérimentale, nous nous sommes rendu compte que des percussions répétées portées de manière aléatoire sur le nucléus ne permettaient pas d'obtenir des morphologies comparables. Au contraire, travailler de cette manière conduit à produire ce que, typologiquement, nous décririons comme de véritables «pièces esquillées » ne portant qu'occasionnellement des négatifs d'enlèvements lamellaires (pour quelques exemples voir, entre autres, Chauchat et al., 1985; Le Brun-Ricalens, 2006). Seule une démarche contrôlée s'accompagnant d'une gestion réfléchie nous a permis de reproduire ces pièces expérimentalement. Si certaines des lamelles obtenues peuvent, en partie, avoir alimenté la confection des armatures, il faut aussi citer le déficit des plus petits éléments comme un argument en faveur de l'utilisation des esquilles ${ }^{15}$. Il est donc possible qu'à Cardina 1 les tailleurs aient recherché non seulement des petites lamelles, mais aussi probablement des esquilles tranchantes (fig. 11, $\mathrm{n}^{\text {os }}$ 16-17). Cependant, la démonstration de ce dernier point reste délicate, surtout si de tels artéfacts ont été utilisés bruts (comme le suggèrent certaines données ethnographiques voir Zilhão, 1997, p. 113). En outre, plusieurs dizaines

15. Ce déficit des petits éléments en silex est d'autant plus remarquable qu'il contraste fortement avec ce que l'on peut observer pour le quartz ou le quartzite pour lesquels les petits éléments sont notablement mieux représentés. 
de petites lamelles brutes en silex, rectilignes et au débitage soigné (par percussion lancée) témoignent aussi peut-être d'un apport de réserves brutes (fig. 11, no 22) en vu d'une utilisation différée ou bien de la conduite d'opérations de débitage sur de véritables nucléus lamellaires en silex dont il ne resterait presque aucune trace. Soulignons aussi que des microlithes fabriqués ailleurs ont également pu être importés sur le site (fig. 11, no 23). En ce qui concerne le cristal de roche (quartz hyalin), la difficulté à distinguer ce matériau de certaines variétés de quartz (quartz filonien), nous a conduits à n'en examiner qu'un échantillon limité. Néanmoins, ces premières observations nous ont permis de déterminer qu'il existe pour le cristal le même type de production sur nucléus bipolaires sur enclume (fig. 11, no 24).

\section{Terra do MANUAL 1940-1942 et CABEÇO do PORTO MARINHO II, ESTREMADURA (RIO MAIOR)}

En Estremadura, nous avons pu observer que certaines armatures des sites de Terra do Manual 1940-1942 et Cabeço Porto do Marinho II (Zilhão, 1997; Almeida, 2000) étaient effectivement très proches typologiquement d'une partie des microlithes de Cardina 1 (lamelles à dos tronquées et bitronquées, $c f$. fig. $11, \mathrm{n}^{\text {os }}$ 3-9). Cependant, sur ces deux gisements, nous n'avons pas retrouvé la très grande diversité typologique évoquée à Cardina 1 (si un problème de collecte peut être invoqué pour Terra do Manual, ce n'est pas le cas pour Cabeço do Porto Marinho II). Nous avons d'ailleurs pu observer que les armatures sont beaucoup plus normées d'un point de vue tant dimensionnel que typologique sur ces deux gisements. Quant aux systèmes techniques, nous avons pu constater l'existence de différences radicales entre les deux régions. En effet, les sites du Rio Maior sont voisins des zones d'affleurement de silex de bonne qualité (en général de quelques centaines de mètres à $5 \mathrm{~km}$ ) et ces matériaux ont donc été exploités dispendieusement pour la production des supports d'outils et d'armatures (Zilhão, 1997). Ainsi, sur chacun de ces sites, les chaînes opératoires laminaires et lamellaires semblent globalement présentes. Les supports utilisés pour la confection des armatures microlithiques sont essentiellement des petites lames ou des lamelles, en majorité obtenues par une méthode préférentiellement unipolaire sur petits blocs (fig. 11, $\mathrm{n}^{\text {os }} 1-2$ et 7 ) et parfois aussi sur gros éclats. Enfin, sur ces deux gisements, nous n'avons identifié aucune modalité de production de supports lamellaires faisant appel à une méthode de débitage bipolaire sur enclume, analogue à celle décrite à Cardina 1. Cette différence radicale entre les sites du
Côa et ceux du Rio Maior peut en partie s'expliquer par la proximité/l'éloignement des sources de matériaux à grain fin. Cardina 1 montrerait donc un système technique adapté à une utilisation optimale des silex, ce qui témoignerait d'une véritable adaptation au contexte de la vallée du Côa pauvre en ressources siliceuses à grain fin autres que le cristal de roche.

\section{L'HYPOTHÈSE D'UN GROUPE À «FORTE MOBILITÉ» CONTREDITE?}

Plusieurs hypothèses existent quant au mode de fréquentation du territoire de la région du Côa pour le Paléolithique supérieur et plus spécialement pour le Gravettien (Aubry et al., 2002; Aubry, Mangado-Llach, 2003 et 2006). La première considère que le bassin du Côa a été un lieu privilégié pour des incursions saisonnières de groupes provenant des différentes régions d'où sont originaires les silex (Rio Maior, massif du Sicó et centre de la péninsule Ibérique). Le second modèle pose l'hypothèse d'un groupe local, basé sur le cours du Côa, qui aurait pu être rejoint temporairement par d'autres groupes sur des sites d'agrégations saisonniers ou bien encore lors de contacts ponctuels aux marges de leur territoire (ibid.). Ces rencontres périodiques auraient alors été l'occasion pour le groupe occupant la vallée du Côa d'acquérir de petites quantités de matériaux à grain fin. Dans un environnement dépourvu de silex et où le cristal de roche et les silicifications filoniennes (quartz) à grain fin se présentent en petits volumes, les hommes du Gravettien final de Cardina 1 ont, apparemment, déployé des stratégies de gestion des matériaux alliant des modalités de débitage très économiques et, probablement, l'utilisation de réserves ponctuelles de silex importés. Cette stratégie s'accompagna sans doute d'un plus grand degré de variabilité morphodimensionnelle des produits utilisés qui a vraisemblablement pu conduire à l'acceptation d'une norme moins stricte pour les types d'armatures lithiques employées. La question est donc de savoir s'il s'agissait d'une adaptation ponctuelle dans le temps (les tailleurs ne recourant à de telles solutions que dans le contexte de la vallée) ou de pratiques pérennes consécutives à l'exploitation préférentielle d'un territoire restreint à la vallée et ses environs. Une approche superficielle du problème pourrait nous conduire à interpréter nos données technologiques dans le sens de la première hypothèse. C'est-à-dire qu'un groupe unique fréquenterait un seul et même territoire (incluant des zones riches en silex et d'autres complètement dépourvues) de manière 
cyclique, ce qui conduirait à l'adoption alternée de systèmes techniques radicalement différents (débitage unipolaire sur bloc versus débitage sur nucléus type «pièce esquillée») en fonction des zones visitées.

Nous avons vu avec les exemples précédents que si cette explication simpliste pouvait être valable elle n'est pas toujours la plus crédible. En l'occurrence, en ce qui concerne le Gravettien final, plusieurs arguments convergent pour la contredire. Tout d'abord, à Cardina 1, l'utilisation massive de l'ensemble des ressources lithiques de la vallée pour différentes tâches domestiques reflète une très bonne connaissance de l'environnement local. En outre, l'utilisation de variétés de silicifications filoniennes provenant d'une distance d'environ $50 \mathrm{~km}$ (dans les environs de la vallée) montre également des déplacements ponctuels vers des zones plus lointaines. Ensuite, les structures d'habitat identifiées sur le site plaident plutôt en faveur d'une occupation relativement pérenne. Enfin, ces arguments sont aussi renforcés par le fait que ces systèmes techniques et ces comportements se retrouvent sur les autres sites gravettiens du Côa (Olga Grande 4, voir Aubry, 1998 et 2001), ce qui indique au moins une continuité comportementale sur une assez longue plage de temps (d'après les datations par thermoluminescence). Ces données, ainsi que l'association systématique de silex provenant de sources de l'intérieur de la Meseta espagnole et du littoral portugais au sein d'autres occupations de la vallée, contrediraient donc plutôt l'idée qu'elle n'ait été fréquentée que de manière brève et épisodique durant le Gravettien.

Ces contradictions s'avèrent encore plus flagrantes si l'on confronte les données des systèmes de production de microlithes. En effet, entre l'Estremadura et la vallée du Côa, les systèmes techniques développés diffèrent radicalement sur un plan technique. On peut tout juste penser que certaines des petites lamelles brutes les plus régulières retrouvées à Cardina 1 (fig. 11, $\mathrm{n}^{\mathrm{o}}$ 22) ont pu être produites selon des modalités comparables à celles identifiées en Estremadura. Mais ce dernier point ne prouve en aucun cas qu'elles aient été produites par un seul et même groupe. Rappelons, par ailleurs, que, en Estremadura, aucun débitage de type «pièce esquillée» n'a été identifié pour l'instant. Or, on peut supposer que, si la vallée du Côa ne représentait qu'une halte dans un vaste territoire englobant des zones riches en matériaux siliceux, les hommes auraient pu développer des stratégies et des systèmes techniques permettant de conserver, peu ou prou, le même degré d'exigence dans la réalisation des armatures lithiques (à l'instar de la méthode du Raysse ou des «burins-nucléus» polyédriques qui ont permis l'obtention de supports relativement normés quelles que soient les conditions d'approvisionnements). Même dans l'hypothèse de séjours temporaires mais de longue durée dans la vallée du Côa, on peut supposer que le besoin d'armatures aurait largement pu être anticipé, notamment par l'emport massif de réserves de petits blocs ou de supports bruts ou de microlithes déjà prêts à l'emploi (à l'instar de ce qui a été pratiqué par les occupants du Gravettien final des Peyrugues). En outre, le recours au débitage sur cristal de roche aurait pu fournir une solution satisfaisante pour l'obtention de supports aisément transformables en lamelles à dos tronquées ou bitronquées, or cette ressource n'a été que peu utilisée à cette fin. Au contraire des sites du Massif central français où les silex allochtones dominent, l'hypothèse d'un groupe à forte mobilité nous paraît donc peu vraisemblable et nous pencherions plutôt pour la seconde hypothèse: celle d'un groupe régional (exploitant l'ensemble des ressources du territoire de la vallée) qui ne récupérerait du silex que par le biais d'échanges lors de contacts périodiques avec d'autres groupes aux marges du territoire ou lors de grands rassemblements (Aubry et al., 2003). Ainsi, si les armatures lithiques peuvent être des marqueurs identitaires forts dans certains contextes gravettiens, l'exemple de la vallée du Côa permet d'avancer l'idée que, face à certaines contraintes environnementales et dans une logique d'occupation pérenne d'un territoire, ces artéfacts seraient parfois moins investis, ou tout au moins plus variables. Ainsi, la survivance de certains traits techniques communs à d'autres régions où la confection des armatures lithiques ne souffrirait pas de contraintes économiques majeures pourrait s'expliquer par des échanges et des contacts entre groupes voisins.

\section{CONGLUSION}

Ce bref panorama du Gravettien final en France et au Portugal ouvre des pistes de réflexion relativement prometteuses (quoique variables d'une région à l'autre) en ce qui concerne les stratégies technoéconomiques des groupes humains de cette période. À propos des «lamelles à dos tronquées", il est encore délicat d'expliquer leur succès au détriment des gravettes et microgravettes. Tout au plus peut-on postuler un engouement lié à une transformation de l'équipement de chasse qui repose désormais sur des pointes composites (bon compromis entre résistance et capacité vulnérante) et peut-être aussi sur des pointes exclusivement en matériaux organiques (ce qui reste délicat à déterminer étant donné le peu de sites avec industrie 
osseuse conservée). De telles transformations pourraientelles être concomitantes de changements de tactiques/ stratégies de chasse consécutifs aux altérations environnementales liées aux prémices du Pléniglaciaire? Il est délicat de se prononcer sur cette question puisque l'on ne peut pas encore corréler convenablement les épisodes d'occupation et les courbes de variations climatiques. Certes le nombre restreint de sites bien conservés et étudiés limite pour l'instant, quelque peu, nos possibilités d'interprétation, mais nous espérons toutefois des progrès spectaculaires dans les années à venir. En effet, le Gravettien final français compte une majorité de sites qui peuvent bénéficier d'études technologiques approfondies tout en offrant l'opportunité de documenter d'autres champs (faunes chassées et saisonnalité notamment) encore méconnus pour les phases plus anciennes du Gravettien. En France, un problème majeur subsiste pourtant pour parfaire nos modèles sur le Gravettien final: l'absence de gisement de plein air. Quelques analogies frappantes se manifestent surtout à travers les armatures et certaines convergences esquissées du point de vue des systèmes techniques de production de supports d'armatures ( $c f$. Pataud, Peyrugues et Terra do Manual, Cabeço do Porto Marinho II). Cependant, il faut surtout relever la divergence des hypothèses que nous avons pu avancer pour les comportements technoéconomiques des groupes du Gravettien final du sud-ouest de la France (très mobiles mais centrés sur des ressources siliceuses de qualité) et de la moitié nord du Portugal (moins mobiles mais probablement intégrés dans un réseau de contacts permettant l'acquisition de ressources siliceuses de bonne qualité). Dans le cas de la vallée du Côa, il semble possible de percevoir une occupation pérenne d'un territoire limité impliquant une véritable transformation/adaptation du système technique mais avec un maintien relatif de certains traits liés à l'équipement de chasse (barbelures lithiques). En revanche, dans le cas du Périgord/Quercy, nous serions confrontés à des groupes occupant majoritairement une région plus vaste et riche en matériaux à grain fin (Périgord), mais devant fréquenter (pour des raisons encore indéterminées sans doute liées à l'activité cynégétique) épisodiquement une zone qui en est moins bien pourvue (Quercy). Ces groupes auraient alors eu recours à une anticipation globale des besoins ne reposant pas sur l'adoption d'un système de production de supports de microlithes sur nucléus légers de type «burinnucléus ». Les comportements des types de gibiers chassés et le facteur des «matières premières » sont probablement déterminants lorsque l'on se trouve confronté à des occu- pations de longue durée ou à caractère véritablement pérenne dans des régions où les matériaux à grain fin font défaut. Dans des régions où la fréquentation est plus épisodique, on peut envisager trois possibilités: le recours à des systèmes techniques adaptés à tout type d'environnement (Rayssien), le recours à des adaptations ponctuelles du système technique de type «burin-nucléus» (peut-être le cas d'une phase du Gravettien récent) ou le «refus d'adaptation " avec une anticipation globale des besoins par un emport plus «massif» de réserve (Gravettien final du Périgord/Quercy). Là encore, la question de la fonction des occupations semble primordiale, même si elle reste pour l'instant difficile d'accès.

\section{$*$ \\ * *}

Malgré des résultats encore inégaux, différentes hypothèses d'explication de la variabilité des modalités de production de supports d'armatures commencent à s'esquisser pour les trois phases considérées et pour la bande géographique traitée (Rhénanie, France, Portugal). Grâce à une observation fondée sur différentes échelles, plusieurs facteurs de variabilité ont pu être explorés, permettant ainsi de dépasser les simples constats analogies/différences afférents aux analyses technologiques traditionnelles. Si, dans un premier temps, certaines analogies entre modalités de production de microlithes (et microlithes eux-mêmes) suggèrent des relations phylétiques, d'autres, à la lueur d'éléments contextuels, paraissent de plus faible valeur et s'apparentent davantage à de possibles convergences. La prise en considération de ces éléments contextuels est donc venue enrichir et compliquer la problématique en nous entraînant dans la dimension fonctionnelle et économique. $\mathrm{Au}$ final, nous proposons trois catégories de facteurs de variabilité qui, une fois questionnés, permettent d'apporter de nouveaux éclairages sur les modalités de production de supports d'armatures lithiques.

Par ordre croissant, il faut d'abord noter une variabilité intra-site qui s'exprime à l'intérieur même du système technique caractérisé. À ce niveau, plusieurs facteurs non exclusifs peuvent expliquer la variabilité: niveaux de savoir-faire, existence de productions distinctes, phénomènes de palimpsestes d'occupations, disponibilité, tailles des rognons et variétés des silex homogènes à grain fin, nature de l'occupation, etc. Si certains sont assez aisément perceptibles de manière générale (productions distinctes, problèmes de palimpsestes, disponibilité en ressources lithiques), d'autres requièrent des études plus approfondies 
qu'il est hélas parfois difficile ou impossible de mettre en œuvre en raison des conditions de conservation ou de la relative rareté du matériel (niveaux de savoir-faire, saisonnalité, etc.). Néanmoins, il s'avère essentiel de s'efforcer d'expliquer les variabilités constatées à l'intérieur d'un site, surtout lorsque l'on envisage des comparaisons élargies.

Le deuxième degré correspond à la variabilité observée entre les sites d'une même phase (par ex.: Gravettien moyen, récent ou final). L'échelle d'observation augmentant, la pertinence des interprétations s'en trouve amenuisée et l'on se retrouve fréquemment amené à raisonner sur des comparaisons ne s'appuyant que sur un ou deux facteurs pour lesquels il est possible de développer des approches qualitatives et quantitatives précises: conception du système de production des supports d'armatures et options de gestion des matières premières lithiques. Actuellement, des problèmes insolubles de résolution chronologique et de diachronie relative des gisements limitent grandement les possibilités d'interprétations plus poussées. Néanmoins, la prise en compte conjointe d'une dimension territoriale (approvisionnement en matières premières lithiques) et de la chronologie relative des stratigraphies, peut permettre des avancées pertinentes dans les réflexions sur l'identité et sur la succession des différents groupes du Gravettien moyen et récent en particulier (par ex.: phasage interne probable du Gravettien récent). À ce titre, il faut donc insister sur l'importance des sites stratifiés (avec plusieurs niveaux d'un même épisode culturel - aux Peyrugues par exemple -) qui sont les seuls, pour l'instant, à offrir un point de vue diachronique de ce problème.

Le troisième degré de variabilité correspond finalement aux fluctuations observables entre sous-phases (Noaillien/ Rayssien) à l'intérieur d'une grande «phase» chronoculturelle (par ex.: Gravettien moyen). À l'inverse du deuxième degré, les comparaisons s'avèrent ici plus aisées, car elles reposent sur des grands traits techniques conceptuels qui permettent d'opérer des rapprochements ou de mettre en évidence des différences. Le problème majeur, alors, réside dans la signification que nous accordons à ce troisième niveau. En effet, si la distinction d'entité chronologique est possible grâce à ce type d'étude, il reste extrêmement délicat d'expliquer le passage de l'une à l'autre de ces phases. Si des divergences sont aisément caractérisables, nous ne parvenons que rarement à expliquer les phénomènes de «transition" entre différentes phases. En ce qui concerne le Gravettien, nous en sommes, pour l'instant, surtout à une révision des grandes phases définies au cours du $\mathrm{XX}^{\mathrm{e}}$ siècle.
Pour finir, ce rapide bilan des systèmes techniques de production de microlithes permet également de lancer de nouvelles pistes de réflexion sur les comportements technoéconomiques et sur les «identités» des groupes du Gravettien moyen, récent et final d'une partie de l'Europe du sud-ouest. Cependant, ces approches comparatives ne doivent pas nous faire oublier que nous attribuons peut-être parfois trop systématiquement et trop rapidement une forte charge identitaire aux opérations de taille et à la confection des armatures de chasse. Dans certains cas, les hommes préhistoriques ont certainement pu investir de manière un peu moins forte ce pan de la culture matérielle au profit d'autres éléments à caractère symbolique et sans doute plus identitaires. Cela pourrait peut-être d'ailleurs être le cas dans la vallée du Côa, notamment si l'on considère l'ampleur des dispositifs d'art rupestre qui peuvent en partie être gravettiens (voir Aubry, Baptista, 2000; Aubry et al., 2002).

\section{PERSPECTIVES GRAVETTIENNES: DE LA PRÉSUMÉE «CULTURE UNITAIRE » À LA «MOSAÏQUE CULTURELLE», UN NÉCESSAIRE CHANGEMENT DE PARADIGME?}

Si certains traits techniques (comme l'emploi des pointes et micropointes de la Gravette) peuvent avoir été partagés par différents groupes humains issus de certaines régions d'Europe du sud-ouest, nos résultats démontrent incontestablement qu'une véritable unité culturelle gravettienne sur plusieurs millénaires paraît hautement improbable. Tout juste est-on aujourd'hui en mesure de plaider pour l'existence de quelques moments plus unitaires qui semblent marquer épisodiquement l'Europe paléolithique entre - 28000 et - 21000 BP. L'étude des systèmes techniques lithiques nous a permis de montrer l'existence de spécificités régionales (locale comme à Côa ou supra-régionale pour le Rayssien) qui contredisent l'idée même d'une homogénéité culturelle globale. Même si le paradigme d'une culture gravettienne monolithique et homogène est encore particulièrement vivace à l'heure actuelle, les nouveaux arguments présentés ici nous permettent d'envisager l'Europe gravettienne de façon plus nuancée. Pourquoi, désormais, ne pas la considérer comme une vaste mosaïque ${ }^{16}$ de groupes humains ne partageant

16. Sur le concept de «mosaïque culturelle» des groupes humains préhistoriques, voir l'article de Jean-Georges Rozoy qui en détaille et explicite les bases et mécanisme (Rozoy, 1997). 
pas nécessairement la même culture matérielle, les mêmes idées ou croyances ou encore les mêmes modes de vie sur près de huit millénaires? Quelques parties de cette grande mosaique pourraient alors, à certains moments et durant certains laps de temps (malgré la diversité des ressources biotiques exploitées), s'homogénéiser/s'harmoniser sous la forme d'entités géographiquement plus vastes présentant plusieurs traits communs remarquables du point de vue de la culture matérielle. En de telles occasions, les réseaux d'échanges seraient alors plus actifs, en raison de faibles changements démographiques et/ou d'une crise environnementale qui obligeraient à des contacts plus fréquents (comme au Gravettien récent peut-être?). De tels moments «unitaires» pourraient alors correspondre à des phénomènes de «diffusion, colonisation ou amalgame» de groupes initialement distincts. Si cette vision renouvelée du Gravettien nous semble aujourd'hui convaincante, beaucoup reste à faire avant d'espérer reconstituer plus précisément les dynamiques chrono-ethno-culturelles des populations de l'Europe préhistorique entre le XXVIII et le $\mathrm{XX}^{\mathrm{e}}$ millénaire av. J.-C. L'enjeu à venir sera de percevoir le fonctionnement social de cette mosaiqque plus ou moins serrée, c'est-à-dire de démêler la taille des mailles et des fils qui constituent les différentes parties de l'écheveau.

\section{Remerciements}

Nous souhaitons ici remercier les rapporteurs de cet article pour leurs conseils et leurs suggestions d'améliorations du texte de l'article. Merci également à Jacques Pelegrin pour les discussions fructueuses que nous avons partagées durant la phase finale de rédaction de cet article et pour ses remarques judicieuses qui nous ont permis de clarifier notre propos. Merci aussi aux organisateurs de la session C86 «Productions lamellaires du Paléolithique supérieur» (N. Teyssandier, P. Bodu, M.-I. Cattin, L. Klaric et L. Slimak) du Congrès UISPP de Lisbonne de 2006 qui fut à l'origine de cet article. Il nous faut également remercier les institutions qui nous ont permis l'accès aux collections des gisements présentés dans l'article (le musée
d'Archéologie nationale de Saint-Germain-en-Laye, le musée national de Préhistoire des Eyzies-de-Tayac, l'annexe du Muséum national d'histoire naturelle de l'abri Pataud, le museu nacional de Arqueologia de Lisbonne et le musée de l'Institut Monrepos du Römisch-Germanisches Zentralmuseum à Neuwied). Patricia Guillermin remercie particulièrement Michel Allard pour sa confiance et son autorisation pour l'étude des Peyrugues, ainsi que Marc Jarry qui l'a accueillie au sein de l'équipe de l'ACR Quercy. Laurent Klaric souhaite enfin exprimer sa gratitude à la Fondation Fyssen qui lui a attribué un financement post-doctoral (en 2005) pour travailler en collaboration avec T. Aubry sur le Gravettien final du Portugal. 


\section{BIBLIOGRAPHIE}

\section{Abréviations}

$\begin{array}{ll}\text { BAR } & \text { British Archaeological Report. } \\ \text { BSPF } & \text { Bulletin de la Société préhistorique française. } \\ \text { CEDARC } & \text { Centre d'études et de documentation archéologiques. } \\ \text { CTHS } & \text { Comité des travaux historiques et scientifiques. } \\ \text { DAF } & \text { Documents d'archéologie française. } \\ \text { ERAUL } & \text { Études et recherches archéologiques de l'université de Liège. } \\ \text { INRAP } & \text { Institut national de la recherche archéologique préventive. } \\ \text { MSH } & \text { Maison des sciences de l'homme. } \\ \text { SRA } & \text { Service régional de l'archéologie. } \\ \text { UISPP } & \text { Union internationale des sciences préhistoriques et protohistoriques. }\end{array}$

\section{ALLARD M.}

1996: Les Peyrugues, Orniac (Lot), Rapport de synthèse, Fouille programmée 1994-1996, SRA Midi-Pyrénées, 73 p.

Allard M., Chalard P., MaRTin H.

2005: "Témoins de mobilité humaine aux Peyrugues (Orniac, Lot) durant le Paléolithique supérieur: signification spatio-temporelle», in JAUBERT J., BARBAZA M. (DIR.), Territoires, déplacements, mobilité, échanges durant la Préhistoire: terres et hommes du Sud, Actes du $126^{e}$ congrès national des sociétés historiques et scientifiques, Toulouse, 9-14 avril 2001, Paris, éd. du CTHS, p. 219-231.

Allard M., DRIEUX M., JARRY M., POMIÈS M.-P., RODIÈRE J.

1997: «Perles en bois de renne du niveau 18 des Peyrugues, à Orniac (Lot) : hypothèse sur l'origine du Protomagdalénien», Paléo, 9, p. 355-369

\section{ALMEIDA F.}

2000: The Terminal Gravettian of Portuguese Estremadura: Technological Variability of the Lithic Industry, Thèse de doctorat, Philosophie, spécialité Anthropologie, Dallas, Southern Methodist University, $472 \mathrm{p}$.

\section{Almeida M.}

2005: Première approche à l'interprétation palethnologique $d u$ groupe solutréen des Maîtreaux: perspectives sur la technologie et répartition spatiale des vestiges lithiques et ses implications pour l'interprétation $d u$ registre archéologique, mémoire de DEA, Univ. Paris-I, 82 p.

ANGELUCGI D

2002: «The Geoarchaeological Context», in
Zilhão J., Trinkaus E. (DIR.), Portrait of the Artist as a Child: the Gravettian Human Skeleton from the Abrigo do Lagar Velho and its Archeological Context, Lisbonne, Instituto português de arqueologia (coll. Trabalhos de arqueologia, 22), p. 58-92.

\section{ARAUjo IGReja M. DE}

2006: "Étude tracéologique des industries lithiques du gisement gravettien de la Picardie: premiers résultats", in KLARIC L. (DIR.), Rapport de fouilles 2006, Annexe 6, SRA Centre, $7 \mathrm{p}$.

AUbry T.

1998: «Olga Grande 4: uma sequência do Paleolítico superior no planalto entre Rio Côa e a Ribeira de Aguiar ", Revista portuguesa de arqueologia, 1, 1, p. 5-26.

2001: «L'occupation de la basse vallée du Côa pendant le Paléolithique supérieur», in Zilhão J., AUbRY T., CARVAlHO A. F. (DIR.), Les Premiers Hommes modernes de la péninsule Ibérique, Actes du colloque de la commission VIII de l'UISPP, Vila Nova de Foz Côa, 1998, Lisbonne, Instituto português de arqueologia (coll. Trabalhos de arqueologia, 17), p. 253-273.

2002: «Le contexte archéologique de l'art paléolithique à l'air libre de la vallée du Côa”, in SACCHI D. (DIR.), L'Art paléolithique à l'air libre: le paysage modifié par limage, Actes du colloque GAEP-GEOPRÉ, Tautavel-Campône, 1999, Carcassonne, Groupe Audois d'études préhistoriques, p. 25-38.

Aubry T., Almeida M., Dimugcio L., Gameiro C., Neves M. J., Klaric L.

2008: "Caractérisation et discontinuités des registres pédo-sédimentaires de l'Occident péninsulaire, entre 30000 et 10000 BP: implication sur l'interprétation archéologique », in AUBRY T., ALMEIDA F., ARAUjO A. C. (DIR.), Space and Time: which Diachronies, which Synchronies, which Scales?, Actes de la session C64 du $X V^{e}$ congrès de l'UISPP, Lisbonne, 4-9 sept. 2006, Oxford, Archaeopress (coll. BAR, International Series, 1831), p. 9-21.

AUbry T., Almeida M., MangadoLlach J., NeVes M. J., Peyrousse J.-B., WALTER B.

2007: «Mythes et réalités préhistoriques: apport du site des Maîtreaux à la définition de la variabilité des productions lithiques au Solutréen", in EVIN J. (DIR.), Un siècle de discours scientifique en Préhistoire: aux conceptions d'aujourd'hui, Actes du XXVI congrès du centenaire de la SPF, Avignon-Bonnieux, 21-25 sept. 2004, Paris, SPF, 3 vol., p. 105-124.

\section{AUbry T., ARAUjo IGReja M. DE}

À paraitre: "Inferring on the Economy of Siliceous Raw Materials of Two Distinct Regions: The Côa Valley and the Massif of Sicó (Portugal): a Multidisciplinary Perspective », in ARAUJO IGREJA M. DE, Clemente COnTE I. (DIR.), Recent Functional Studies on Non-Flint Stone Tools: Methodological Improvements and Archaeological Inferences, Actes du "Workshop», Lisbonne, 23-25 mai 2008

AUbry T., BAPTista A. M.

2000: "Une datation objective de l'art du Côa», La Recherche, hors-série, 4, nov. 2000, p. 54-55.

Aubry T., Brugal J.-P., Chauvière F.X., FIGUEIRAL I., MOURA M. H. PLISSON H.

2001: «Modalités d'occupations au Paléolithique supérieur dans la grotte de 
Buraca Escura (Redinha, Pombal, Portugal) ", Revista portuguesa de arqueologia, 4, 2, p. 19-46.

Aubry T., Fontugne M., Moura M. H. 1997: «Les occupations de la grotte de Buraca Grande depuis le Paléolithique supérieur et les apports de la séquence holocène à l'étude de la transition Mésolithique/ Néolithique au Portugal", BSPF, 94, 2, p. 182-190.

\section{AUBRY T., MANGADO-LlaCH X.}

2003: «Interprétation de l'approvisionnement en matières premières siliceuses sur les sites du Paléolithique supérieur de la vallée du Côa (Portugal) », in SURMELY F. et C., Demars P.-Y., SÉronie-Vivien A. (DIR.), Les Matières premières lithiques en Préhistoire, Actes de la table ronde internationale d'Aurillac, 20-22 juin 2002, Cressensac, Association de préhistoire du Sud-Ouest (coll. Suppl. à Préhistoire du Sud-Ouest, 5), p. 27-40.

2006: «The Côa Valley (Portugal): from Lithic Raw Materials Characterization to the Reconstruction of Settlement Patterns during the Upper Palaeolithic », in BRessy C., BuRke A., Chalard P., MARTIN H. (DIR.), Notions de territoire et de mobilité: exemples de l'Europe et des premières nations en Amérique du Nord avant le contact européen, Actes de session du $X^{e}$ congrès annuel de l'European Association of Archeologists, Lyon, 8-11 sept. 2004, Liège, éd. ERAUL (coll. ERAUL, 116), p. 41-49.

AUbry T., MANGAdo-Llach X., SAMPaio J. D., SEllami F.

2002: "Open-Air Rock-Art, Territories and Modes of Exploitation during the Upper Palaeolithic in the Côa Valley (Portugal)», Antiquity, 76, p. 62-76.

AUbry T, Zilhão J., AlMEIDA F.

2007: «Â propos de la variabilité technique et culturelle de l'entité gravettienne au Portugal: bilan des dernières découvertes et perspectives de recherche", in RIGAUD J.-P. (DIR.), «Le Gravettien: entités régionales d'une paléoculture européenne, Actes de la table ronde internationale $\left(1^{\text {re }}\right.$ partie), Les Eyziesde-Tayac, 7-9 juillet 2004 », Paléo, 19, p. 53-72.

Aubry T., Zilhão J., Almeida F., FonTUGNe M.

1997: «Production d'armatures microlithiques pendant le Paléolithique supérieur et le Mésolithique au Portugal», in BALBIN R., BUENO P. (DIR.), II Congreso de Arqueologia peninsular: Paleolitico y Epipaleolitico, Zamora, 24-27 sept. 1996, Zamora, éd. Fundacion Rei Afonso Henriques, p. 259-272.

\section{AUDOUZE F.}

2006: «Essai de modélisation du cycle annuel de nomadisation des Magdaléniens du Bassin parisien», BSPF, 103, 4, p. 683-694.

Bodu P., Debout G., Bignon O.

2006: «Variabilité des habitudes tardiglaciaires dans le Bassin parisien: l'organisation spatiale et sociale de l'Azilien ancien du Closeau ", BSPF, 103, 4, p. 711-728.

Bodu P., Julien M., Valentin B., DEBOUT G. (DIR.)

2006: «Un dernier hiver à Pincevent: les Magdaléniens du niveau IV0 (Pincevent, La Grande Paroisse, Seine-et-Marne)», Gallia Préhistoire, 48, p. 1-180.

\section{BORDES F}

1968a: «La question périgordienne», in Autin J., Piveteau J. (DIR.), La Préhistoire: problèmes et tendances, Paris, éd. du CNRS, p. 59-70.

1968b: «Emplacement des tentes du Périgordien supérieur évolué à Corbiac (près de Bergerac) Dordogne", Quärtar, 19, p. 251-262.

1978: «Le Protomagdalénien de LaugerieHaute Est (fouilles F. Bordes) ", BSPF, 75, 11-12, p. 501-521.

BORDES F., SONNEVILLE-BORDES D. DE 1966: «Protomagdalénien ou Périgordien VII ?", L’Anthropologie, 70, 1-2, p. 113-122.

\section{BORDES J.-G.}

2000: «La séquence aurignacienne de Caminade revisitée : l'apport des raccords d'intérêt stratigraphique», Paléo, 12, p. $387-407$.

2002: Les Interstratifications Châtelperronien/ Aurignacien du Roc-de-Combe et du Piage (Lot): analyse taphonomique des industries lithiques, implications archéologiques, Thèse de doctorat de Préhistoire et Géologie du Quaternaire, Univ. Bordeaux-I, 365 p.

BORDES J.-G., BON F., LE BRUNRICALENS F.

2005: «Le transport des matières premières lithiques à l'Aurignacien entre le nord et le sud de l'Aquitaine: faits attendus, faits nouveaux ", in JAUBERT J., BARBAZA M. (DIR.), Territoires, déplacements, mobilité, échanges durant la Préhistoire: terres et hommes du Sud, Actes du $126^{e}$ congrès national des sociétés historiques et scientifiques, Toulouse, 9-14 avril 2001, Paris, éd. du CTHS, p. 185-198.

\section{BOSSELIN B.}

1991 : Les Industries lithiques du Protomagdalénien à partir des données nouvelles du site du Blot à Cerzat (Haute-Loire), Thèse de doctorat, Univ. de Franche-Comté, 2 vol., 473 p.

1992: «Le Protomagdalénien du Blot: étude typologique comparée", BSPF, 89, 3, p. 82-96.

1997: Le Protomagdalénien du Blot: les industries lithiques dans le contexte du Gravettien français, Liège, éd. ERAUL (coll. ERAUL, 64), 329 p.

\section{BRACCO J.P}

1997: «L'utilisation du quartzau Paléolithique supérieur: quelques réflexions technoéconomiques", Préhistoire Anthropologie méditerranéenne, 6, p. 285-288

BRICKER H. M. (DIR.)

1995: Le Paléolithique supérieur de l'abri Pataud (Dordogne): les fouilles de H. L. Movius Jr, Paris, éd. de la MSH (coll. DAF, 50), 328 p., 82 fig.

BUISSON D.

1991: «Le Périgordien du Blot», BSPF, 88, 4, p. $104-108$

\section{Cattelain P., Perpère M.}

1993: "Tir expérimental de sagaies et de flèches emmanchées de pointes de la Gravette», Bulletin du CEDARC, ArcheoSitula, 17-20, p. 5-28.

1996: «Tir expérimental de répliques de pointes de la Gravette: bilan et perspectives», Notae Praehistoricae, 16, p. 55-61.

Chalard P., Guillermin P., JARRY M.

2006: "Acquisition et exploitation des silex allochtones au Gravettien: l'exemple de la couche $\mathrm{E}$ du gisement des Fieux (Lot, France) ", in BRESSY C., BURKE A., CHALARD P., MARTIN H. (DIR.), Notions de territoire et de mobilité: exemples de l'Europe et des premières nations en Amérique du Nord avant le contact européen, Actes de session du $X^{e}$ congrès annuel de l'European Association of Archaeologists, Lyon, 8-11 sept. 2004, Liège, éd. ERAUL (coll. ERAUL, 116), p. 29-40.

Chauchat C., NORMand G., RAYNAL J.-P., SANTAMARIA R.

1985: «Le retour de la pièce esquillée ", $B S P F$, 82,2 , p. $35-41$

Chevassut S.

2007: Un type d'armature à retouche marginale du 
Gravettien moyen: les lamelles de La Picardie (La Picardie, Indre-et-Loire), Analyse morphodimensionnelle, conceptuelle et fonctionnelle, mémoire de Master 1, Univ. Paris-I, 72 p.

2008: Les Lamelles de La Picardie: analyse morpho-dimensionnelle et fonctionnelle (La Picardie, Indre-et-Loire), mémoire de Master 2, Univ. Paris-I, 73 p.

\section{CHEYNIER A.}

1962: Le Cirque de la Patrie à Nemours (Seine-etMarne), Paris, SPF (coll. Mémoires de la SPF, VI), $195 \mathrm{p}$.

Chiotti L., Leoz L. E., Nespoulet R., PotTier C.

2003: «Quelques exemples de stratégies d'approvisionnement dans l'Aurignacien et le Gravettien de l'abri Pataud (Dordogne) », in Surmely F. ET C., Demars P.-Y., SÉRONIE-VIVIEN A. (DIR.), Les Matières premières lithiques en Préhistoire, Actes de la table ronde internationale d'Aurillac, 20-22 juin 2002, Cressensac, Association de préhistoire du Sud-Ouest (coll. Suppl. à Préhistoire du Sud-Ouest, 5), p. 115-122.

Clay R. B.

1968: The Protomagdalenian Culture, Thèse de doctorat, Anthropologie, Carbondale, Southern Illinois University, 2 vol., 660 p.

Combier J., Montet-White A. (DIR.)

2002: Solutré 1968-1998, Paris, SPF (coll. Mémoire de la SPF, XXX), 281 p.

\section{CONARD N. J., MOREAU L.}

2006: "Current Research on the Gravettian of the Swabian Jura", Mitteilungen der Gesellschaft für Urgeschichte, 13, p. 29-59.

\section{DAVID N. C.}

1985: Excavation of the Abri Pataud, Les Eyzies (Dordogne): The Noaillian (Level 4) Assemblage and the Noaillian Culture in Western Europe, Cambridge, Harvard University, Peabody Museum, 355 p.

\section{DE BIE M., VAN GILS M.}

2006: «Les habitats des groupes à Federmesser (aziliens) dans le nord de la Belgique», BSPF, 103, 4, p. 781-790.

\section{DELPORTE H.}

1961: «Note préliminaire sur la station de la Rochette: le Périgordien supérieur», Bulletin de la Société d'études et de recherches préhistoriques, 11, p. 39-49.

1982: «L'organisation du Périgordien supérieur en France et ses rapports avec le Périgordien d'Europe occidentale », in
Klima B. (DIR.), Aurignacien, Périgordien, Gravettien, Actes des colloques XV et XVI du IX congrès de l'UISPP, Nice, 1976, Liège, éd. ERAUL (coll. ERAUL, 13, 1), p. 83-106.

\section{DIGAN M.}

2001: Le Gisement gravettien de La VigneBrun (Loire): première étude de l'industrie lithique de l'unité KL19, Thèse de doctorat, Univ. Lille-I, 2 vol., 665 p.

2006: Le Gravettien de La Vigne-Brun (Loire, France): étude de l'industrie lithique de l'unité KL19, Oxford, Archaeopress (coll. BAR, International Series, 1473), 228 p.

2008: «New Technological and Economic Data from La Vigne-Brun (unit KL19), Loire: a Contribution to the Identification of Early Gravettian Lithic Technological Expertise», Quartär, 55, p. 115-125.

\section{DJINDJIAN F., BOSSELIN B.}

1994: «Périgordien et Gravettien, l'épilogue d'une contradiction?", Préhistoire européenne, 6, p. 117-131.

\section{FÉBLOT-AUGUSTINS J.}

1997: La Circulation des matières premières au Paléolithique, Liège, éd. ERAUL (coll. ERAUL, 75), 2 vol., 275 p.

1999: «La mobilité des groupes paléolithiques", Bulletin et Mémoire de la Société d'Anthropologie de Paris, n. s. t., 11, 3-4, p. $219-260$.

\section{FEHLINGS S.}

1993: Die Steinartefakte der jungpaläolithischen Fundplätze Mainz-Linsenberg und Sprendlinge: ein Vergleich, Magisterarbeit, Univ. Köln, 86 p.

\section{FISCHER A.}

1990: «A Late Palaeolithic "School" of FlintKnapping at Trollesgave Denmark: Results from Refitting ", Acta Archaeologica, 60, p. 33-49.

\section{FLOSS H.}

1994: Rohmaterialversorgung im Paläolithikum des Mittelrheingebietes, Bonn, R. Habelt (coll. Monographie römisch germanisches Zentralmuseum, 21), 404 p.

2000: «La fin du Paléolithique en Rhénanie (Magdalénien, groupes à Federmesser, Ahrensbourgien): l'évolution du choix de matières premières lithiques, reflet d'un profond changement du climat et du comportement humain ", in BODU P., VAlentin B., Christensen M. (DIR.), L'Europe centrale et septentrionale au Tardiglaciaire, Actes de la table ronde de Nemours, 1997, Nemours, éd. APRAIF (coll. Mémoires du musée de Préhistoire d'Île-de-France, 7), p. 87-96.

\section{FOUCHER P.}

2004: Les Industries lithiques du complexe gravettien-solutréen dans les Pyrénées: techno-typologie et circulations des matières siliceuses de part et d'autre de l'axe Pyrénées-Cantabres, Thèse de doctorat, Univ. Toulouse-Le Mirail, 3 vol., 334 p.

\section{GUILLERMiN P.}

2004: Réflexions sur l'interprétation des industries gravettiennes à partir de l'étude typo-technologique d'une occupation spécialisée : la couche E du gisement des Fieux (Miers, Lot), mémoire de DEA d'Anthropologie-Ethnologie-Préhistoire, Univ. Toulouse-Le Mirail, 99 p.

2006a: «Fenêtre quercinoise sur le polymorphisme gravettien", in JARRY M. (DIR.), Cultures et environnements paléolithiques mobilités et gestions des territoires des chasseurs-cueilleurs en Quercy, Rapport d'activités 2006 d'action collective de recherche, Inrap.

2006b: «Les Fieux: une occupation gravettienne du Causse quercinois ", Paléo, 18, p. $69-94$.

\section{Guillermin P., Morala A.}

À paraître: "Les "Périgordiens" étaient-ils Quercinois? ", in JARRY M., BRUGAL J.-P., FERRIER C. (DIR.), Modalités d'occupations et exploitation des milieux au Paléolithique dans le sud-ouest de la France: l'exemple du Quercy, Actes de la session C67, XV congrès de l'UISPP, Lisbonne, sept. 2006 (coll. Suppl. à Paléo, 4).

\section{Goutas N.}

2003: «Identification de deux procédés de débitage inédits du bois de cervidés dans les niveaux gravettiens de Laugerie-Haute Est et Ouest», Paléo, 15, p. 255-262.

2004: Caractérisation et évolution du Gravettien en France par l'approche techno-économique des industries en matières dures animales (étude de six gisements du Sud-Ouest), Thèse de doctorat de Préhistoire, Univ. Paris-I, 2 vol., 675 p.

\section{HAHN J.}

1969: «Gravettien-Freilanstationen im Rheinland: Mainz-Linsenber, KoblenzMetternich und Rhens ", BonnerJahrbücher, 169, p. 44-87.

INIZAN M.-L., REDURON M., ROCHE H., TIXIER J.

1995: Technologie de la pierre taillée: Préhistoire de la pierre taillée, Meudon, CNRS, Cercle 
de recherches et d'études préhistoriques, $199 \mathrm{p}$.

Karlin C., Ploux S., Bodu P., Pigeot N. 1993: «Some Socio-Economic Aspects of the Knapping Process among Groups of Hunter-Gatherers in the Paris Basin Area", in Berthelet A., CHAVAILlON J. (DIR.), L'Usage de l'outil chez les primates humains et non-humains, Actes du colloque international de Versailles, 25-29 nov. 1988, Versailles, Fondation Fyssen Symposium, Oxford, Clarendon Press, p. 318-337.

KILDEA F. (DIR.)

2008: «La Croix de Bagneux» à Mareuil-surCher (Loir-et-Cher): un site paléolithique à occupations multiples dans la vallée du Cher, Document final de synthèse d'opération de fouille archéologique, Inrap, SRA Centre, Orléans, 2 vol., 643 p.

\section{KLARIC L.}

1999: Un schéma de production lamellaire original dans l'industrie gravettienne de l'ensemble moyen du gisement du Blot à Cerzat (HauteLoire), mémoire de DEA, Univ. Paris-I, 2 vol., 64 p.

2000: «Note sur la présence de lames aménagées par technique de Kostienki dans les couches gravettiennes du Blot (Cerzat, Haute-Loire) », BSPF, 97, 4, p. 625-636.

2003: L'Unité technique des industries à burins $d u$ Raysse dans leur contexte diachronique: réflexions sur la diversité culturelle au Gravettien à partir des données de La Picardie, d'Arcy-sur-Cure, de Brassempouy et du Cirque de la Patrie, Thèse de doctorat, Univ. Paris-I, 426 p.

2006: «Comment interpréter la variabilité technique et qualitative des débitages lamellaires: les nucléus débités par méthode du Raysse à La Picardie (Indreet-Loire, France), un "cas d'école" du Gravettien moyen d'Europe occidentale ", in Aubry T., Almeida F., Araujo A. C., TIFFAGOM M. (DIR.), Typologie vs Technologie, Résumés de la session C65, $X V^{e}$ congrès de l'UISPP, Lisbonne, 4-9 sept. 2006, p. 391

2007a: «Regional Groups in the European Middle Gravettian : a Reconsideration of the Rayssian Technology», Antiquity, 81, 311, p. 176-190.

2007b: «Des armatures aux burins: critères de distinction techniques et culturels des productions lamellaires de quelques sites du Gravettien moyen et récent", in ARAUjo IGREJA M. DE, BRACCO J.-P., LE BRUN-RICALENS F. (DIR.), Burins, formes, fonctionnements et fonctions, Actes de la table ronde internationale d'Aix-enProvence, 3-5 mars 2003, Luxembourg, Musée national d'histoire et d'art (coll. Archéologiques, 2), p. 199-223.

En préparation: "New Evidence of Flint Knapping Apprenticeship for the Middle Stage of European Western Upper Palaeolithic: the Case of Bladelets Production at la Picardie (France)».

KLARIC L. (DIR.)

2006: La Picardie (Preuilly-sur-Claise, Indreet-Loire), Rapport de fouilles 2006, SRA Centre, Orléans, $70 \mathrm{p}$

\section{KLARIC L., AUbRY T., WALTER B.}

2002: «Un nouveau type d'armature en contexte gravettien et son mode de production sur les burins du Raysse (la Picardie, commune de Preuilly-surClaise) », $B S P F, 99,4$, p. 751-764.

KLARIC L., LEV S., GYRIA Y.

En préparation: "Couteaux de Kostienki et lames aménagées par technique de Kostienki: phénomène de convergence à grandes distances ou véritable indice de parenté technique?».

\section{KOSLOWSKI J. K.}

1984: «Les lames aménagées par la "technique Kostienki” dans le Périgordien supérieur de Corbiac", in Koslowski J. K., KOSLOWSKI S. K. (DIR.), Advances in Paleolithic and Mesolithic Archaeology, Varsovie, Wydawnictwa Uniwersytetu Warszawskiego (coll. Archaeologia interregionalis), p. 31-78.

\section{LAVILle H., RigaUd J.-P.}

1973: «The Perigordian V Industries in Périgord: Typological Variation, Stratigraphy, Relative Chronology", World Archaeology, 4, p. 330-338.

\section{LE BRUN-RICALENS F.}

2006: «Les pièces esquillées: état des connaissances après un siècle de reconnaissance», Paléo, 18, p. 95-114.

\section{Le Gall $O$.}

2005: «Un contrefort du Massif central du Gravettien à l'Azilien: indices d'occupations humaines et de migrations animales fondées sur les saisonnalités ", in JAUBERT J., BARBAZA M. (DIR.), Territoires, déplacements, mobilité, échanges durant la Préhistoire: terres et hommes du Sud, Actes du $126^{e}$ congrès national des sociétés historiques et scientifiques, Toulouse, 9-14 avril 2001, Paris, éd. du CTHS, p. 265-278.

\section{LEROI-GOURHAN A., BRÉZILLON M.}

1972: Fouilles de Pincevent: essai d'analyse ethnographique d'un habitat magdalénien (la section 36), Paris, CNRS Éditions (Suppl. à Gallia Préhistoire, VII), vol. 1, 345 p. et vol. 2, $10 \mathrm{pl}$.

LEV S.Y., KLARIC L., GYRIA E.Y.

2009 : «O prichinah raznoobraziya nozhey kostenkovskogo tipa», Rossiyskaya Archeologiya, 4, p. 83-92.

\section{LORIN Y.}

2000: L'Hypothèse de l'obtention de lamelles à partir de "pièces burinantes» sur le gisement de plein air Périgordien de Rabier à Lanquais (Dordogne): caractérisation des objectifs de la production et des modalités de sa mise en cuvve, mémoire de DEA, Univ. Paris-I, 2 vol., $44 \mathrm{p}$.

\section{LUCAS G.}

2000: Les Industries lithiques du Flageolet (Dordogne): approche économique, technologique, fonctionnelle et analyse spatiale, Thèse de doctorat, Univ. Bordeaux-I, 2 vol., $600 \mathrm{p}$.

2002: «À propos des burins du Raysse du Flageolet I (Dordogne, France) », Paléo, 14, p. 63-76.

\section{MASSON A.}

1981: Pétroarchéologie des roches siliceuses: intérêt en Préhistoire, Thèse de doctorat, Univ. Lyon-I, 82 p.

\section{MAUGER M.}

1994: «L'approvisionnement en matériaux siliceux au Paléolithique supérieur", in TABORIN Y. (DIR.), Environnement et habitats magdaléniens dans le centre du Bassin parisien, Paris, éd. de la MSH (coll. DAF, 43), p. 78-93.

\section{MORALA A.}

1990: «L'atelier périgordien supérieur de Rabier (Lanquais, Dordogne): recherches sur l'origine des occupants du site sur les bases de la lithologie", in SÉRONIE-VIVIEN M.-R., LENOIR M. (DIR.), Le Silex de sa genèse à l'outil, Actes $d u V^{e}$ colloque international sur le silex, Bordeaux, 17 sept.-2 oct. 1987, Paris, éd. du CNRS (coll. Cahiers du Quaternaire, 17), p. 391-404.

\section{MOREAU L.}

À paraître: «Le Gravettien ancien de la grotte de Geißenklösterle (Jura souabe, Allemagne) : la place de la production lamellaire », in TEYSSANDIER N., BODU P., CATtin M.-I., Klaric L., Slimak L. 
(DIR.), Les Productions lamellaires au Paléolithique moyen et supérieur: une perspective diachronique, Actes de la session C86, $X V^{e}$ congrès de l'UISPP, Lisbonne, 4-9 sept. 2006

\section{MOVIUS H. L. JR}

1958: "The Proto-Magdalenian of the Abri Pataud, les Eyzies (Dordogne)", in Bericht über den $V$ internationalen Kongress für vor- und frühgeschichte Berlin, Hambourg, p. 561-565.

MÜller W., LEesCH D., BUllinger J., Cattin M.-I., Plumettaz N.

2006: «Chasse, habitats et rythme de déplacements: réflexions à partir des campements magdaléniens de Champréveyres et Monruz (Neuchâtel, Suisse) ", BSPF, 103, 4, p. 741-752.

\section{NESPOULET R.}

1996: Le Périgordien VI de l'abri Pataud, les Eyzies-de-Tayac, Dordogne: étude technologique et typologique de l'industrie lithique de la couche 3, Thèse de doctorat, Muséum national d'histoire naturelle, Paris, $260 \mathrm{p}$.

2000: «Le Gravettien final de l'abri Pataud, Les Eyzies-de-Tayac (Dordogne, France) : nouvelles données technologiques et typologiques sur l'industrie lithique provenant du niveau 3", L'Anthropologie, 104, 1, p. 63-120.

\section{PELEGRIN J.}

1995: Technologie lithique: le Châtelperronien de Roc-de-Combe (Lot) et de La Côte (Dordogne), Paris, éd. du CNRS (coll. Cahiers du Quaternaire, 20), 297 p.

\section{PERLÈS C}

1991: «Économies des matières premières et économie du débitage: deux conceptions opposées?", in 25 ans d'études technologiques en Préhistoire, Actes des XIe rencontres internationales d'archéologie et d'histoire d'Antibes, Juan-les-Pins, éd. APCDA, p. $35-45$.

\section{PESESSE D.}

2003: Approche du comportement technique au Gravettien: l'industrie lithique de l'unité OP10 de La Vigne-Brun, mémoire de DEA, Univ. de Provence, $189 \mathrm{p}$.

2006: «La "pointe à dos alternes", un nouveau fossile directeur du Gravettien?", BSPF, 103,3 , p. $456-478$.

\section{PEYRONY D.}

1938: Laugerie-Haute, près des Eyzies (Dordogne), Paris, Masson (coll. Archives de l'Institut de paléontologie humaine, mémoire 19), 84 p., 56 fig., 7 pl.

\section{PigeOT N.}

1988: «Apprendre à débiter des lames: un cas d'éducation technique chez les Magdaléniens d'Étiolles", in TEXIER J. (DIR.), Technologie préhistorique, Paris, éd. du CNRS (coll. Notes et monographies techniques, 25), p. 63-70.

1990: «Technical and Social Actors in Prehistory: Flintknapping Specialists and Apprentices at Magdalenian Etiolles", Archaeological Review from Cambridge, 9, 1 (Technology in the Humanities, $\mathrm{n}^{\circ}$ spécial), p. 126-141.

\section{PIGEOT N. (DIR.)}

2004: Les Derniers Magdaléniens d'Étiolles: perspectives culturelles et paléohistoriques (l'unité d'habitation Q31), Paris, CNRS Éditions (Suppl. à Gallia Préhistoire, XXXVII), $351 \mathrm{p}$.

\section{POTTIER C.}

2005: Le Gravettien moyen de l'abri Pataud (Dordogne, France): le niveau 4 et l'éboulis 3/4. Étude typologique et technologique de l'industrie lithique, Thèse de doctorat, Muséum national d'histoire naturelle, Paris, $396 \mathrm{p}$.

2007: «Productions lamellaires et burins du Raysse du Gravettien moyen de l'abri Pataud (Dordogne, France)", in ARAUJO IGREJA M. DE, BRACCO J.-P., LE BRUN-RICALENS F. (DIR.), Burins, formes, fonctionnements et fonctions, Actes de la table ronde d'Aix-en-Provence, 3-5 mars 2003, Luxembourg, Musée national d'histoire et d'art (coll. Archéologiques, 2), p. 121-140.

\section{RIGAUD J.-P}

1982: «Données nouvelles sur le Périgordien supérieur en Périgord", in KLIMA B. (DIR.), Aurignacien, Périgordien, Gravettien, Actes des colloques XV et XVI du IX congrès de l'UISPP, Nice, 1976, Liège, éd. ERAUL (coll. ERAUL, 13, 1-2), p. 107-118 et p. 289-324.

1988: «The Gravettian Peopoling of Southwestern France, Taxonomic Problems », in DibBle H. L., MONTET-White A. (DIR.), UpperPleistocenePrehistory of WesternEurasia, Symposium of University Museum, Univ. de Pennsylvanie, Philadelphie, janvier 1987, Philadelphie (coll. University Museum Monograph, 54), p. 387-396.

\section{RozOY J.-G.}

1997: «La fin et les moyens: quelques mécanismes, causes et significations des chan- gements des variantes dans les industries des chasseurs préhistoriques ", BSPF, 94, 4, p. $483-502$.

SCHMider B., DAVID F., ROBLIN-JOUVE A. 2004: «Nouvelles données sur le Gravettien de la grotte du Renne à Arcy-sur-Cure (Yonne)", in DEWEZ M., NOIRET P., TEHEUX E. (DIR.), Le Paléolithique supérieur, Actes du XIV congrès de l'UISPP, session 6, université de Liège, 2-8 sept. 2001, Oxford, Archaeopress, (coll. BAR, International Series, 1240), p. 13-21.

\section{Simonet A.}

2005: Les Armatures lithiques: méthodes d'études et enjeux des armatures gravet tiennes d'Isturitz, mémoire de DEA, Univ. Toulouse-Le Mirail, 94 p.

2008: «L'atelier de taille gravettien de Tercis (Landes), un cas probable d'apprentissage de la confection d'armatures lithiques", in Recherches sur les armatures de projectiles du Paléolithique supérieur au Néolithique, Actes du colloque C83, XV $\mathrm{XV}^{\mathrm{e}}$ congrès de l'UISPP, Lisbonne, 4-9 sept. 2006, P@lethnologie, 1, p. 192-219. (revue en ligne à l'adresse : http://www.palethnologie.org).

2009: Les Gravettiens des Pyrénées, des armes aux sociétés, Thèse de doctorat, univ. Toulouse-II, 391 p.

\section{SIMONNET R.}

1999: «De la géologie à la Préhistoire : le silex des pré-Pyrénées. Résultats et réflexions sur les perspectives et les limites de l'étude des matières premières lithiques ", Paléo, 11 , p. 71-88.

\section{SORIANO S.}

1998: «Les microgravettes du Périgordien de Rabier à Lanquais (Dordogne) ", Gallia Préhistoire, 40, p. 75-94.

\section{SONNEVILLE-BORDES D. DE}

1985: «Variabilités typologiques dans les outillages lithiques: remarques sur leurs significations au Paléolithique supérieur", in OTTE M. (DIR.), La Signification culturelle des industries lithiques, Actes du colloque de Liège, 3-7 oct. 1984, Studia Praehistorica Belgica 4, Oxford, Archaeopress (coll. BAR, International Series, 239), p. 391-409.

\section{STAPERT D.}

2007: "Youngsters Knapping Flint near the Campfire an Alternative View of Site K at Masstricht-Belvédère (the Netherlands) ", Archäologisches Korrespondenzblatt, 37, p. 19-35. 
Street M., Gelhausen F., Grimm S., Moseler F., Niven L., Sensburg M., TURNER E., WENZEL S., JÖRIS O.

2006: «L'occupation du bassin de Neuwied (Rhénanie centrale, Allemagne par les Magdaléniens et les groupes à Federmesser (aziliens) ", BSPF, 103, 4, p. 753780 .

\section{SURMElY F., AliX P.}

2005: «Les talons en éperon du Protomagdalénien », Paléo, 17, p. 157-176.

\section{SURMely F., PASTy J.-F.}

2003: "L'importation de silex en Auvergne durant la Préhistoire», in SURMELY F. ET C., Demars P.-Y., SÉRONIE-VIVIEN A. (DIR.), Les Matières premières lithiques en préhistoire, Actes de la table ronde internationale d'Aurillac, 20-22 juin 2002, Cressensac, Association de préhistoire du Sud-Ouest (coll. Suppl. à Préhistoire du Sud-Ouest, 5), p. $327-335$.

Terberger T., Woerz P., Serangeli J.

2009: «Au lendemain du dernier maximum glaciaire entre Rhin et Danube ", in Bodu P., Chehmana L., Klaric L., MEVEL L., SORIANO S. et TEYSSANDIER N. (DIR.), Le Paléolithique supérieur ancien de l'Europe du Nord-Ouest, réflexions et synthèses à partir d'un projet collectif de recherche sur la Paléolithique supérieur ancien du Bassin parisien, Séance de la SPF, Sens, 15-18 avril 2009 (communication).

\section{TIXIER J., REDURON M.}

1991: «Et passez aux pays des silex: rapportez-nous des lames!», in 25 ans d'études technologiques en Préhistoire, Actes des $\mathrm{XI}{ }^{e}$ rencontres internationales d'archéologie et d'histoire d'Antibes, Juan-les-Pins, éd. APCDA, p. 235-243

\section{ZILHÃO J.}

1997: O Paleolítico superior da Estremadura portuguesa, Lisbonne, éd. Colibri, 2 vol., 309 p. et 850 p.

2000: «Nature and Culture in Portugal from 30,000 to 20,000 bp ", in ROEBROEKS W., MUSSI M., SVOBODA J. ET AL. (DIR.), Hunters of the Golden Age, the Mid Upper Palaeolithic of Eurasia 30,000-20,000 BP, Leiden, Univ. of Leiden, p. 337-354.

\section{Zilhão J., Almeida F.}

2002: "The Archaeological Framework», in Zilhão J., TRINKaus E. (DIR.), Portrait of the Artist as a Child: the Gravettian Human Skeleton from the Abrigo do Lagar Velho and its Archeological Context, Lisbonne, Instituto português de arqueologia (coll. Trabalhos de arqueologia, 22), p. 29-57. 